\title{
فلسفة الأخلاق عند " هارولد آرثر بريتشارد"
}

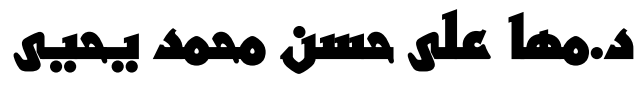 \\ مدرس فلسفة الأخلاق بكلية آداب \\ الوادى الجديلـجامعة أسيوط
}


r.r.

PDF created with pdfFactory Pro trial version www.pdffactory.com 


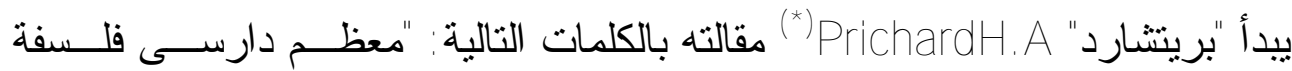

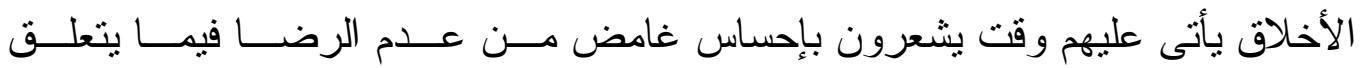

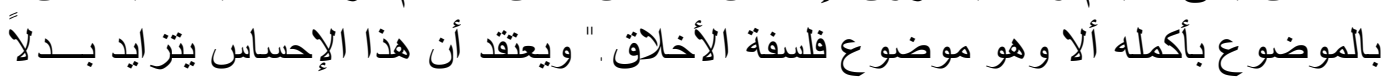

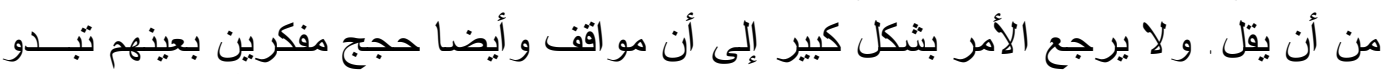

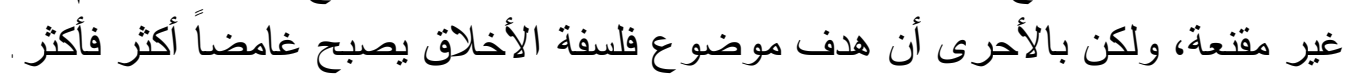

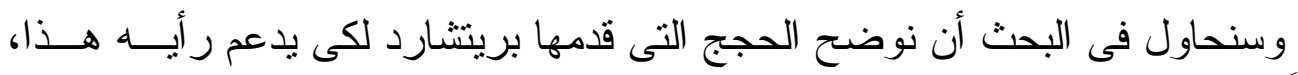

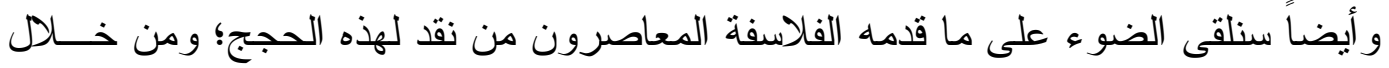

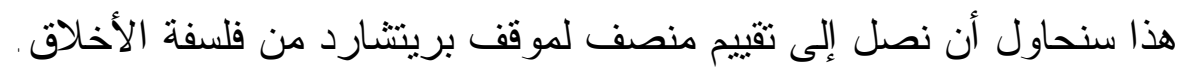

\section{هل تقوم فلسفة الأخلاق على خطأ؟}

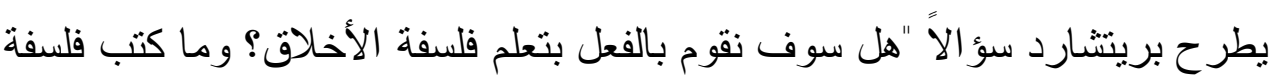

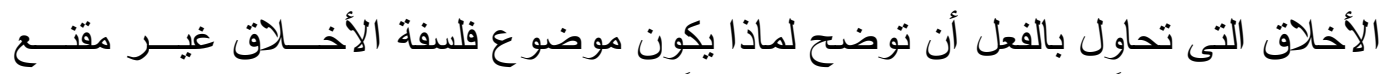

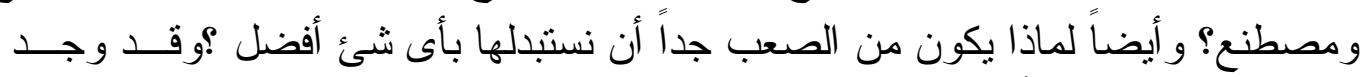

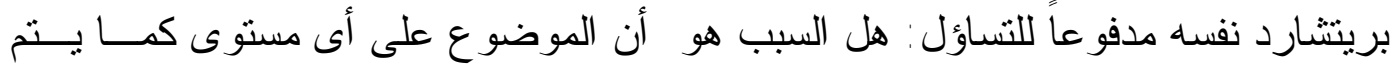

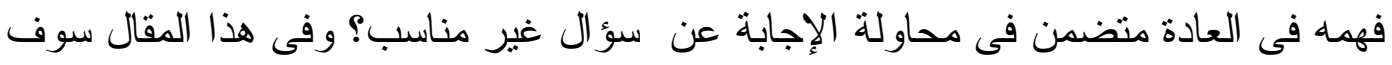

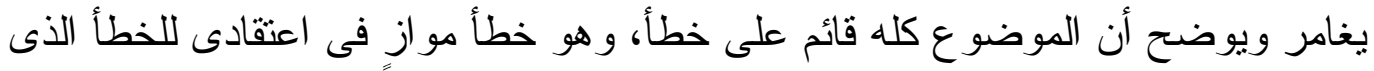
يقوم عليه الموضو ع الذى يطلق عليه فى العادة نظرية المعرفة.

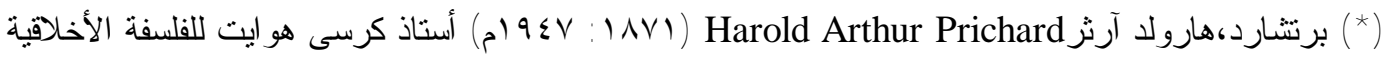

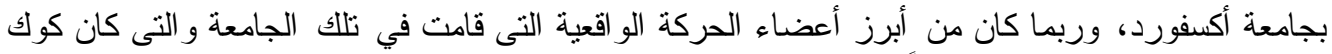

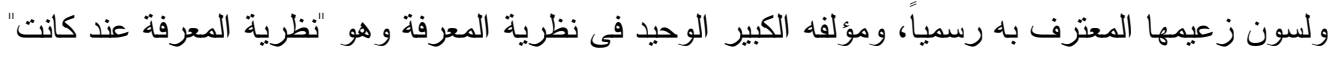

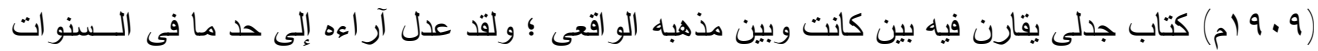

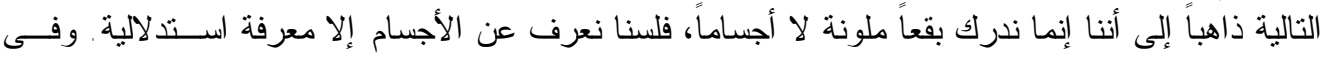

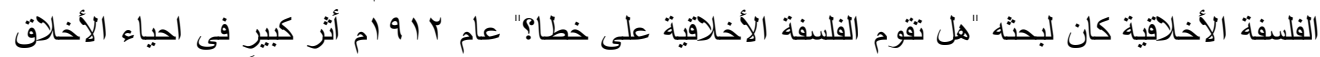

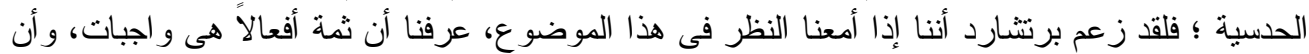

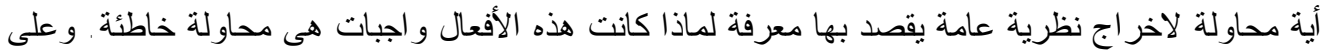

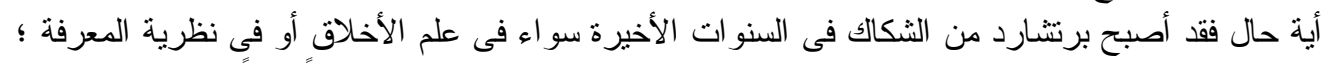

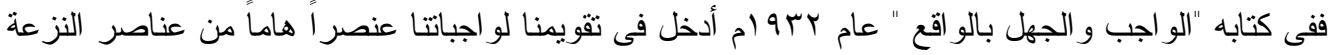

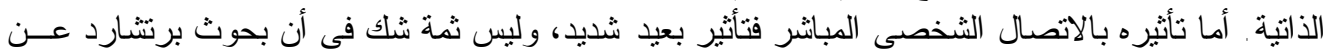

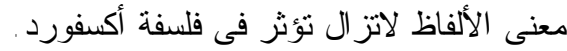

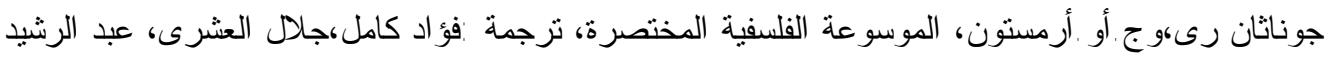

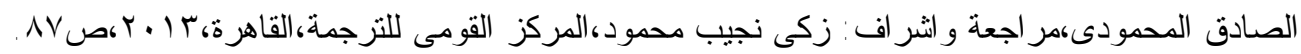
Mautner,Thomas, The Penguin Dictionary of philosophy, Penguin Books,1997,p.447 


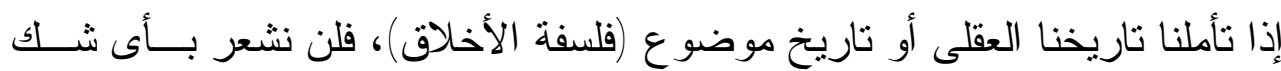

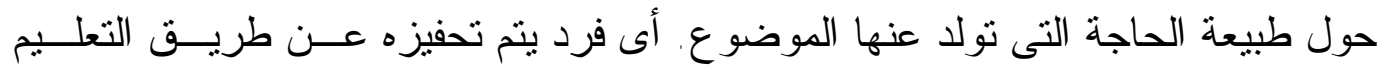

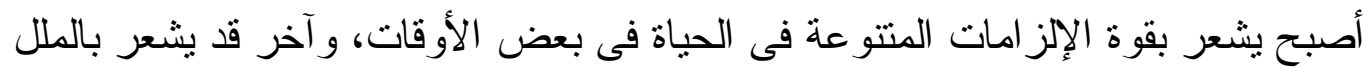

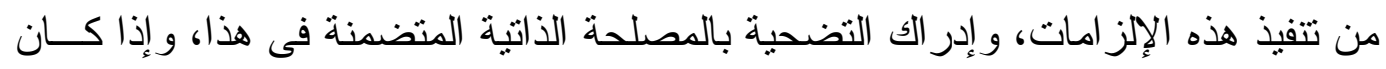

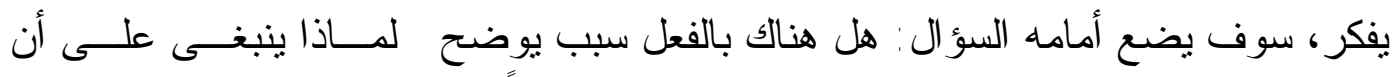

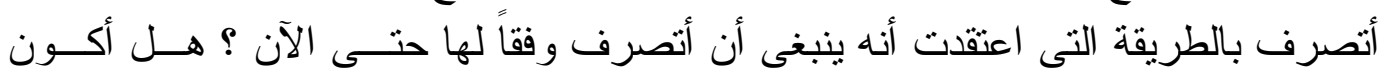

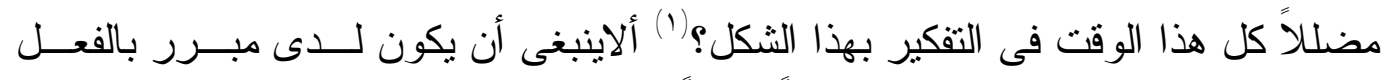

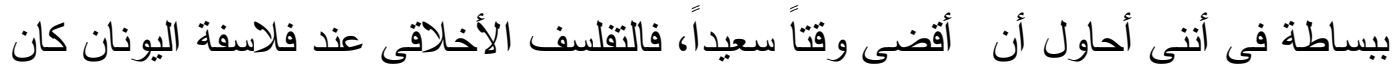

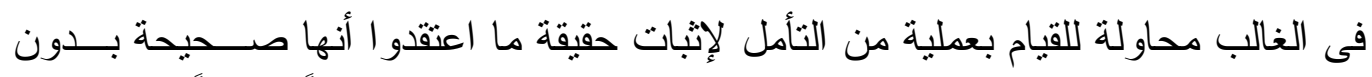

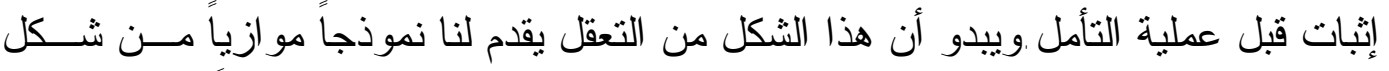

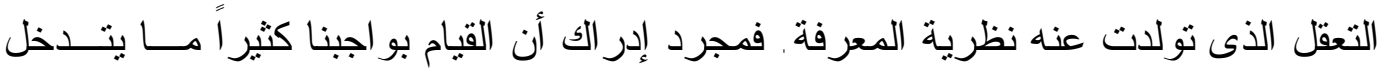

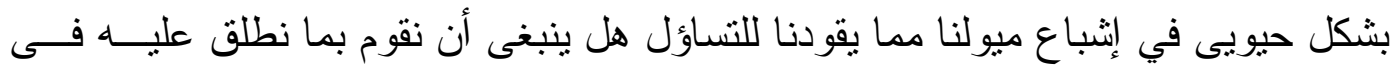

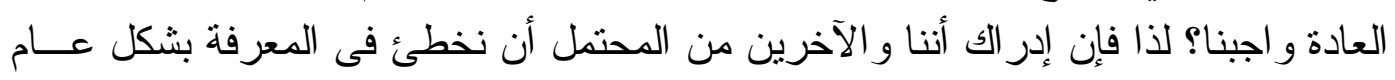

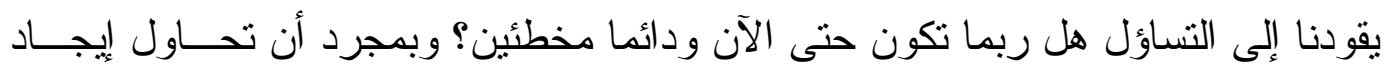

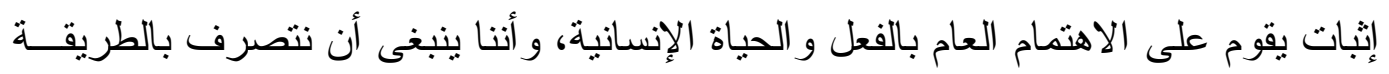

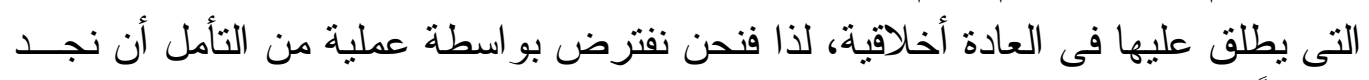

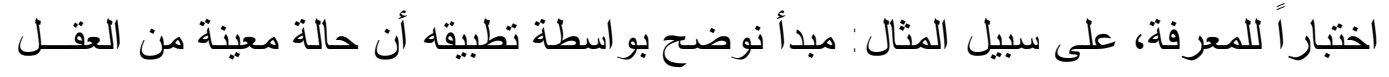
كانت بالفعل معرفة، وهى حالة توجد بشكل مستقل عن عملية التأمل.

الآن كيف تم الإجابة عن السؤ ال الأخلاقى؟ من وجهة نظر بريتشارد كل الإجابــات

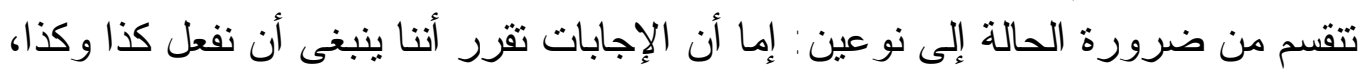

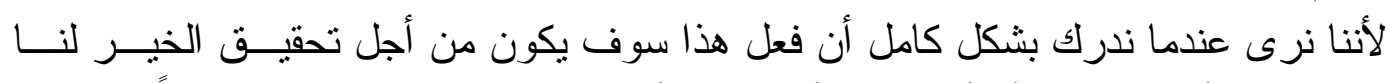

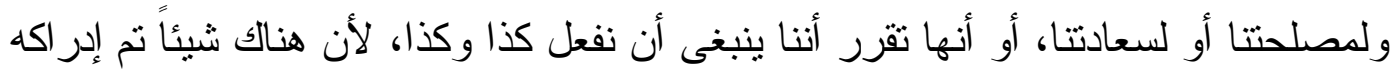

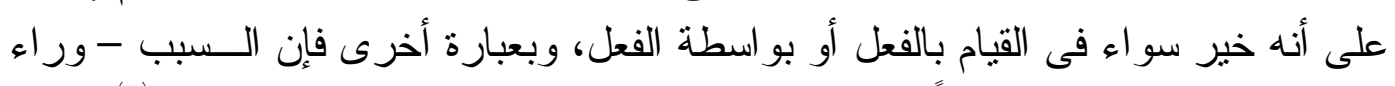

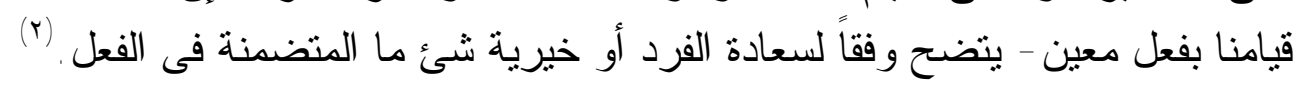

إن الميل لتبرير التصرف وفقاً للقو اعد الأخلاقية بهذه الطريقة أمر طبيعي، لأنه إذا

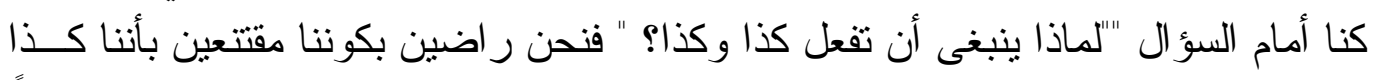

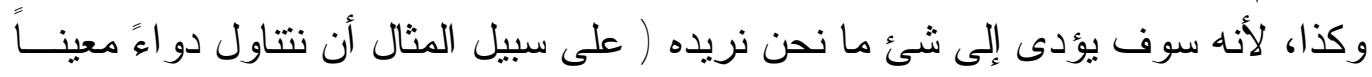

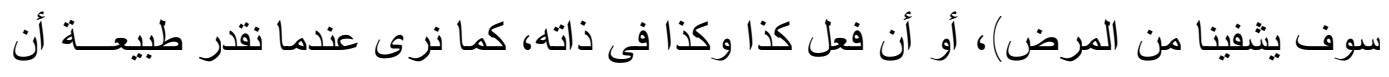




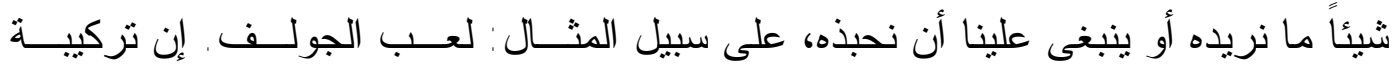

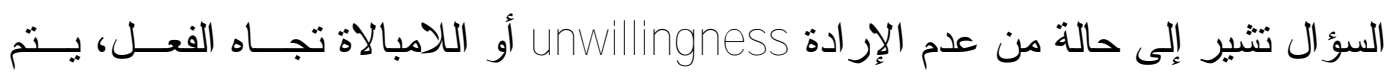

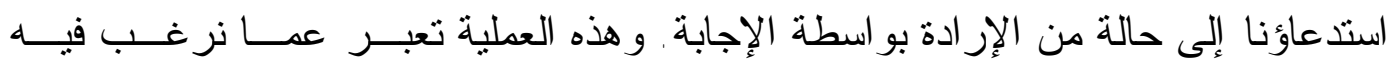

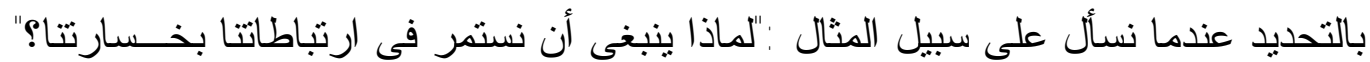

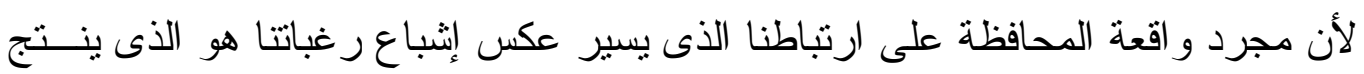

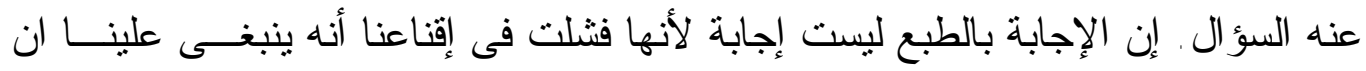

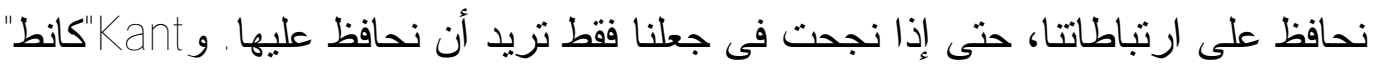

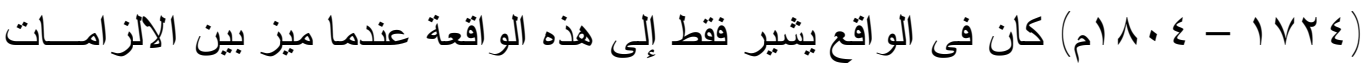

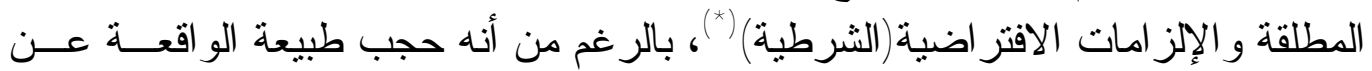

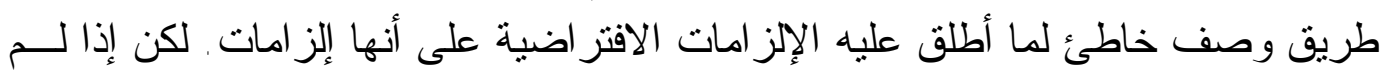

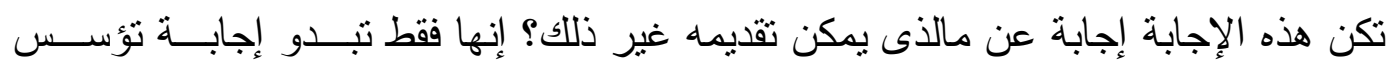

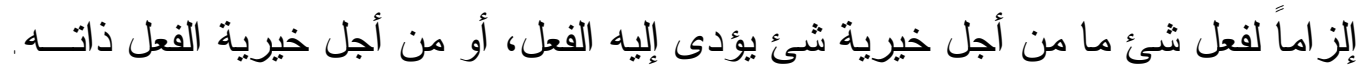

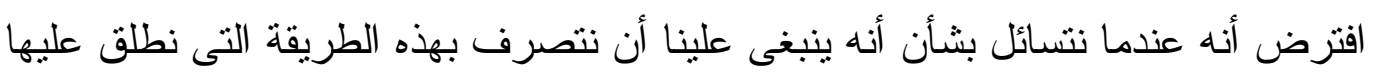

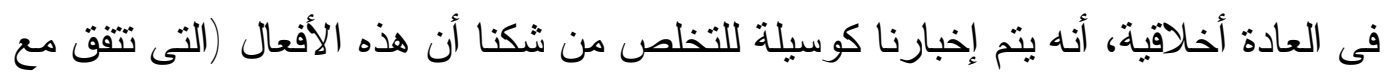

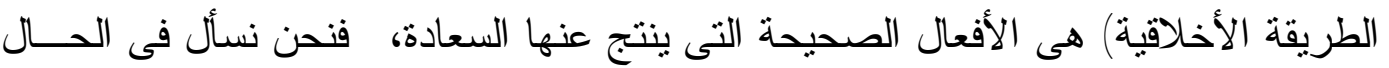

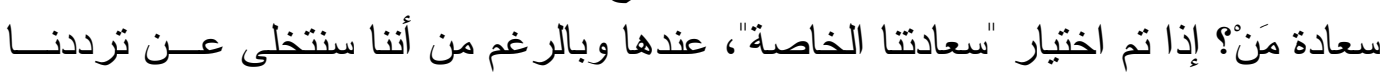

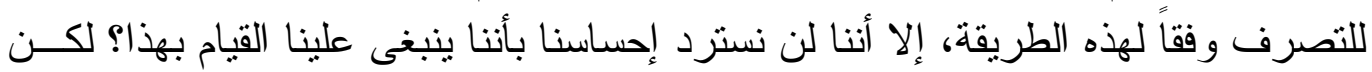

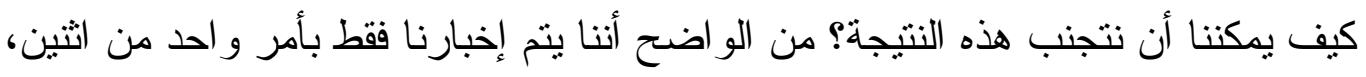

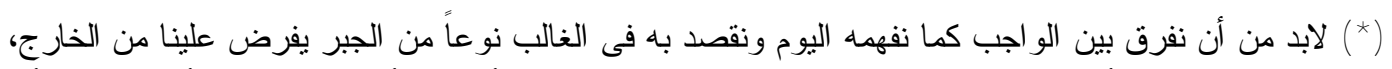

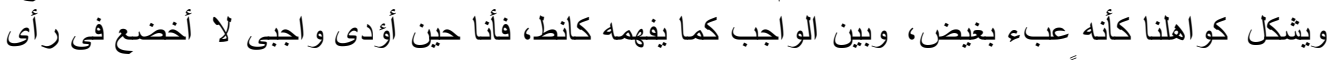

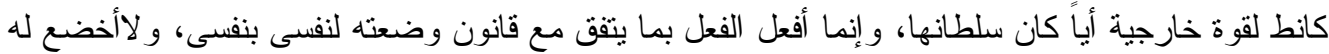

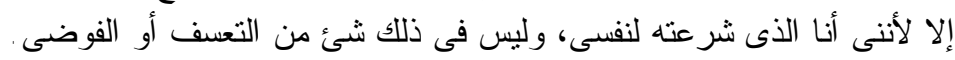

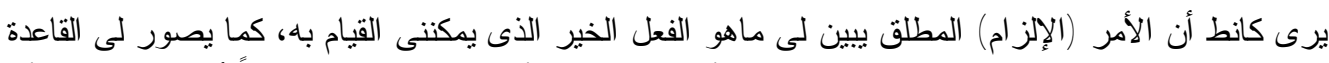

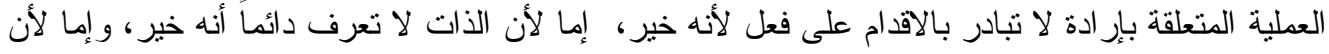

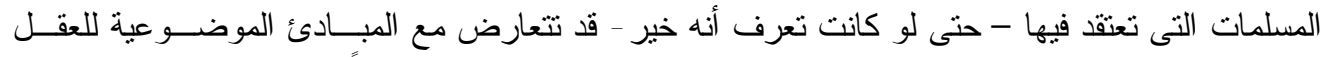

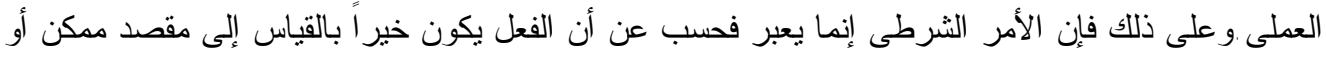

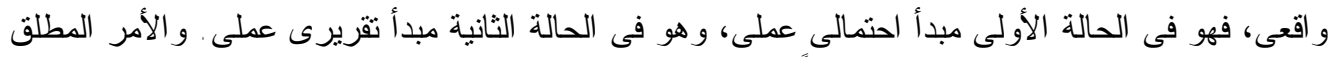

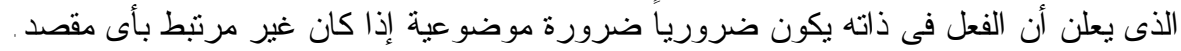

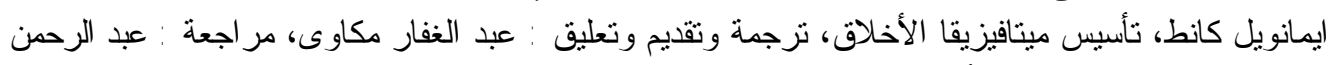

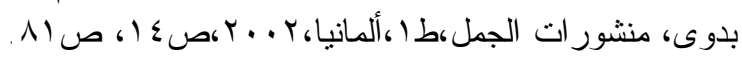
Kant, Immanuel, The Metaphysics of Morals, Translated \& Edited by Mary gregor, with an Introduction by Roger J. Sullivan, university press, U.K, 1996, p.x:xxxvi 


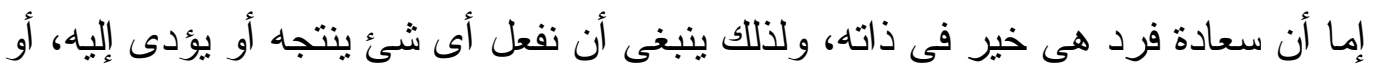

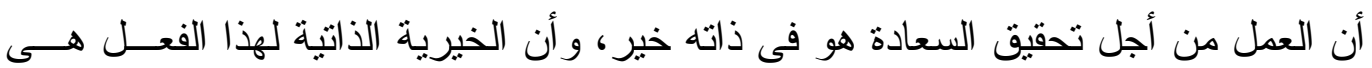

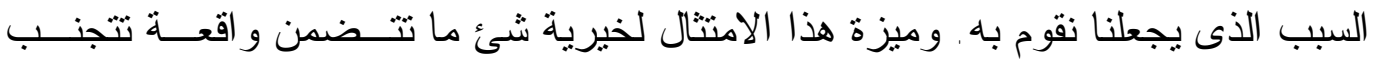

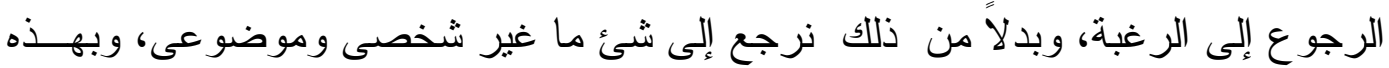

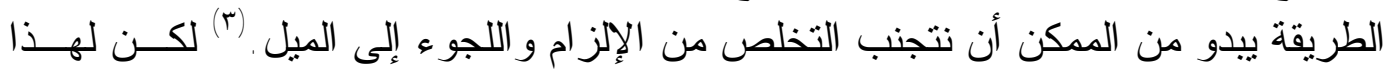

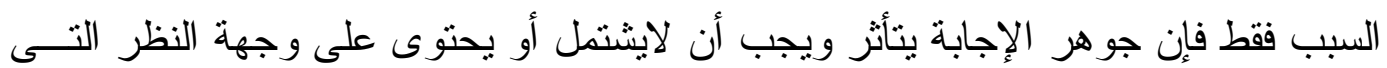

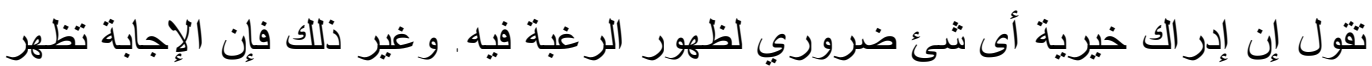

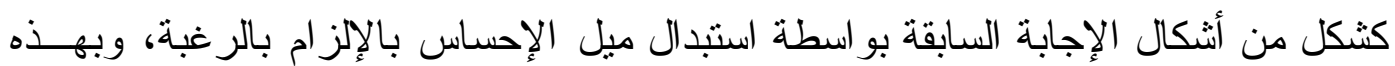

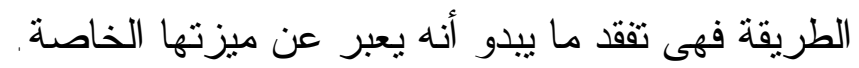

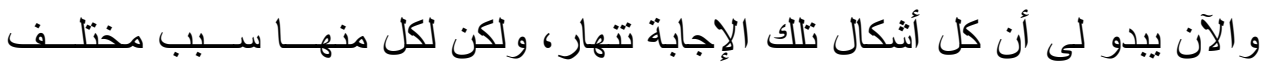

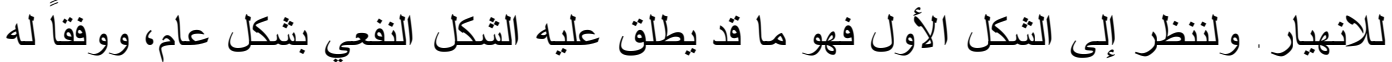

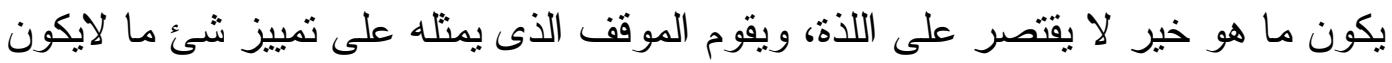

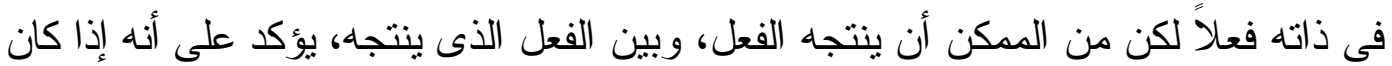

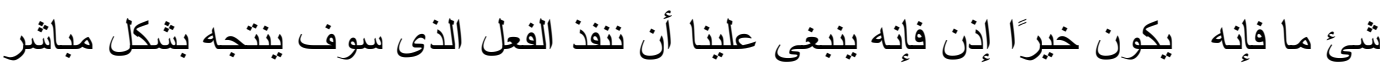

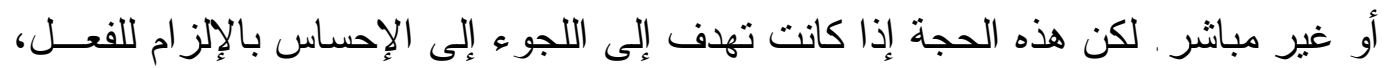

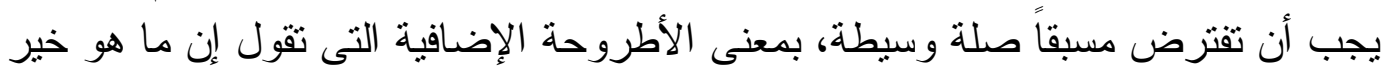

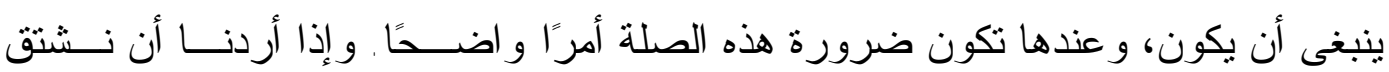

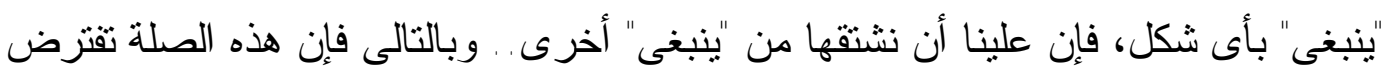

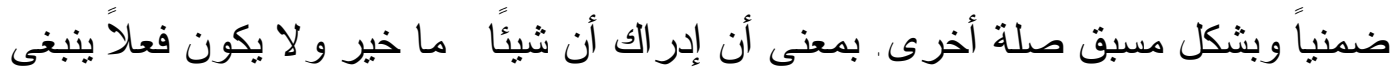

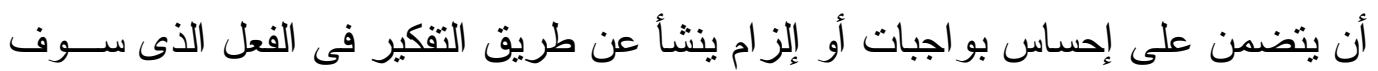

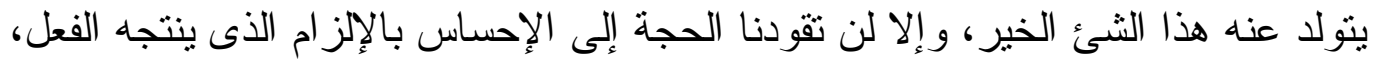

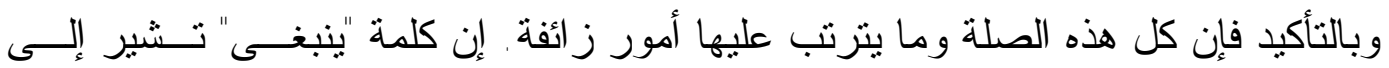

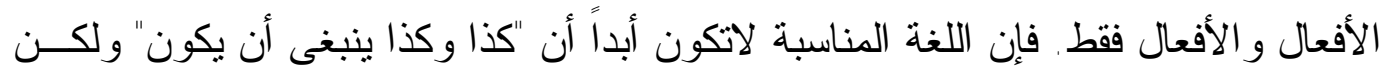

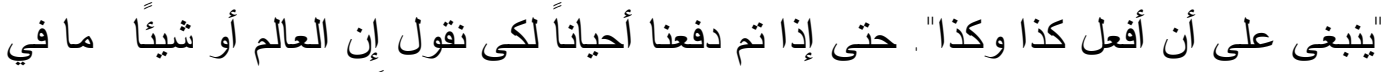

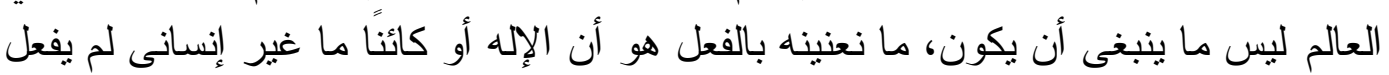

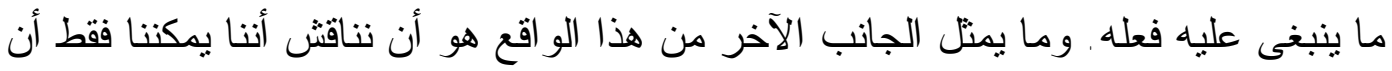

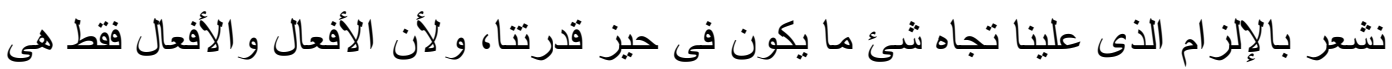

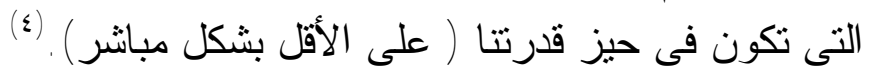




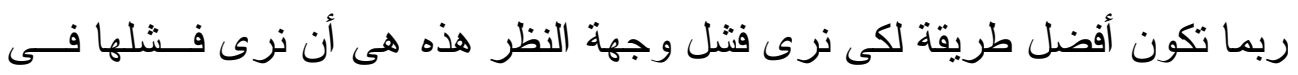

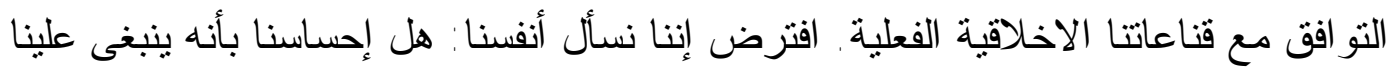

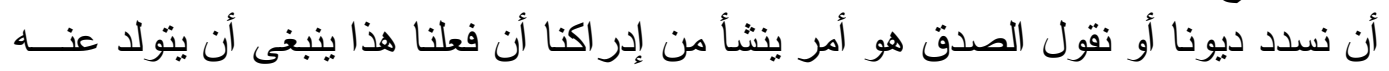

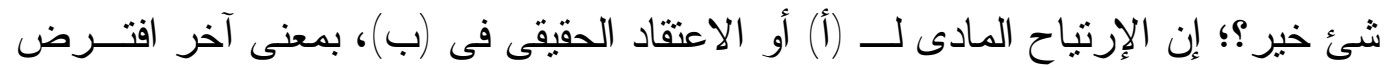

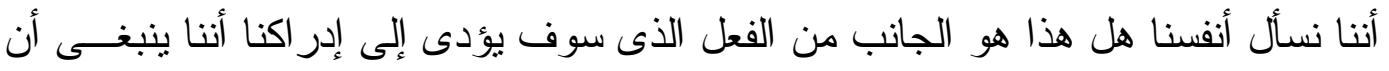

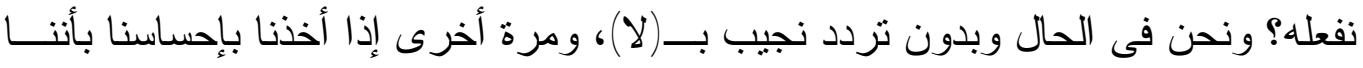

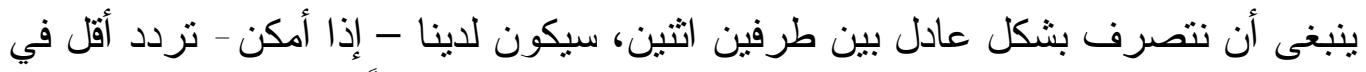

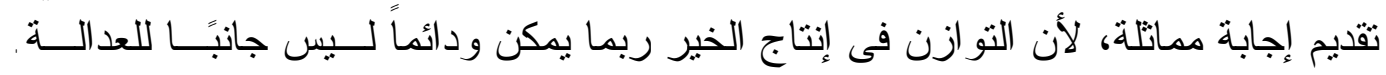

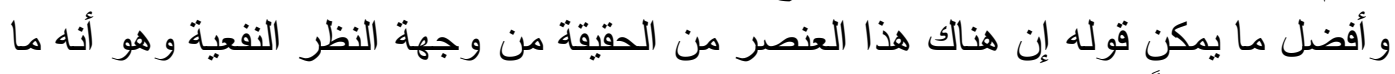

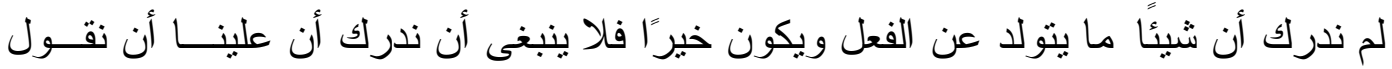

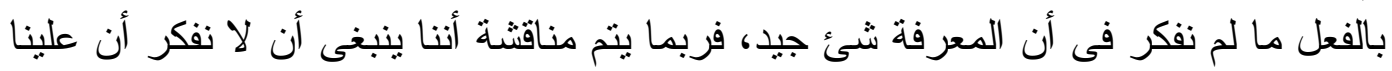

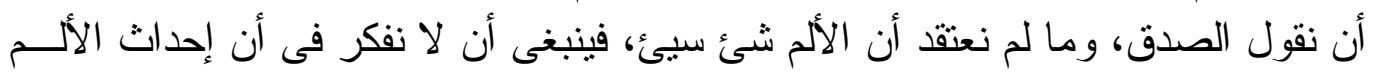

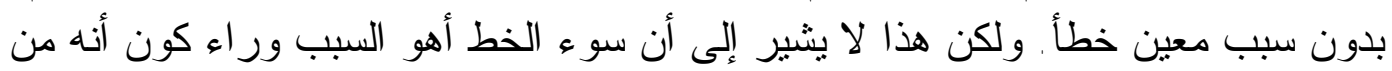

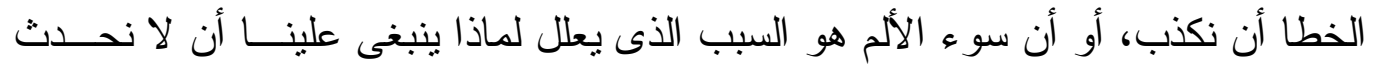

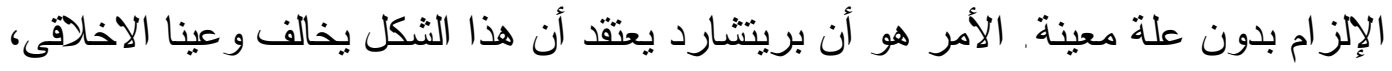

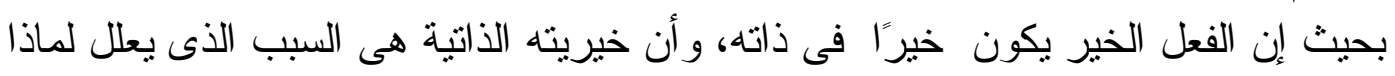

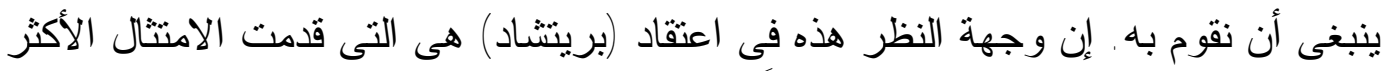

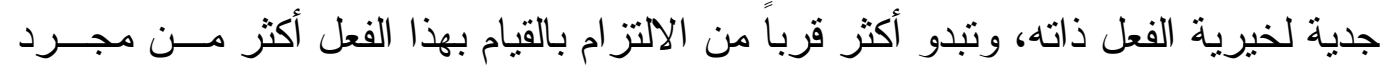

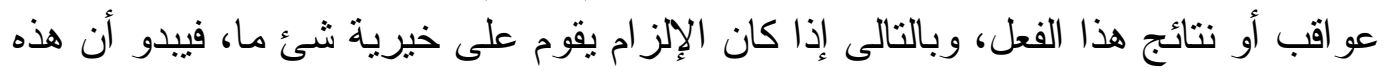

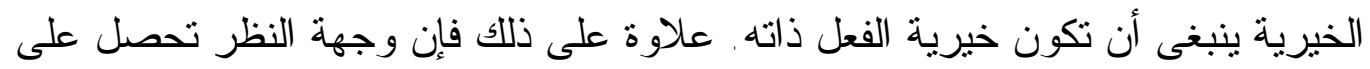

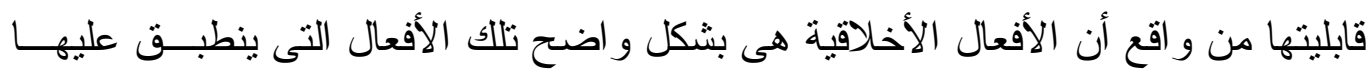

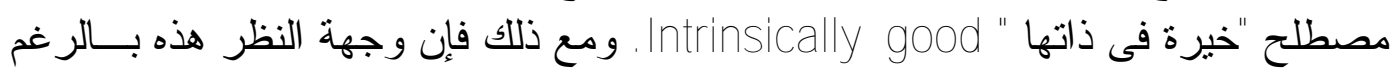

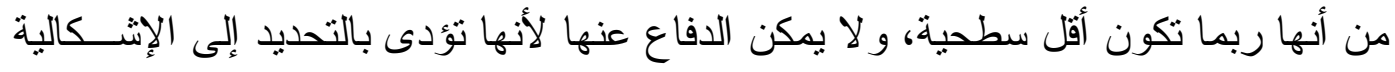

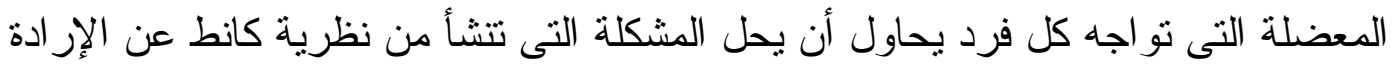

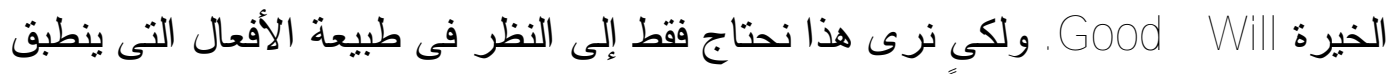

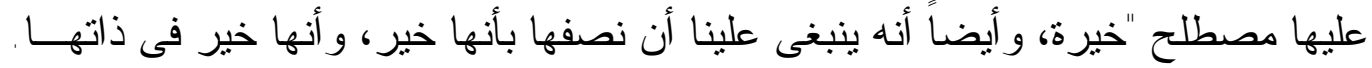

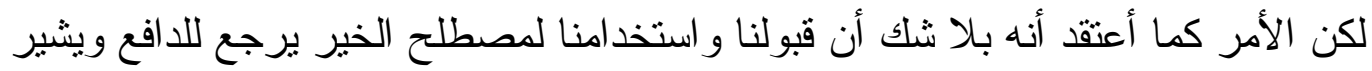

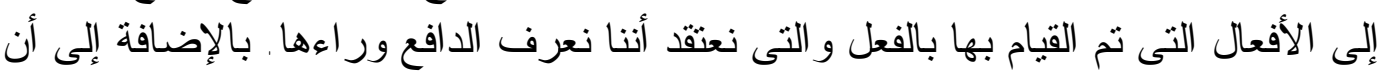

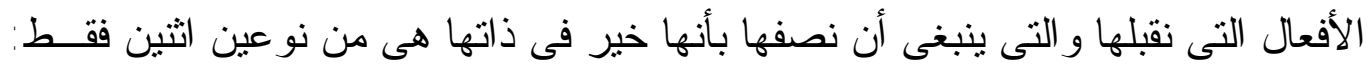




الدافع رغبة حفز ها انفعال ما خير منل الثعور بالامتتان أو شعور عائلى أو روح عامـــة.

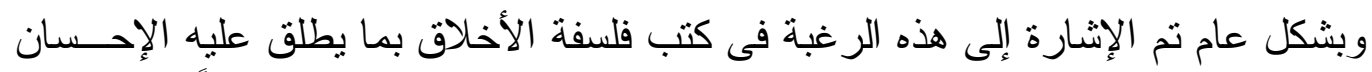
Benevolence

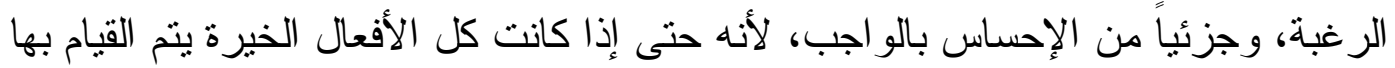

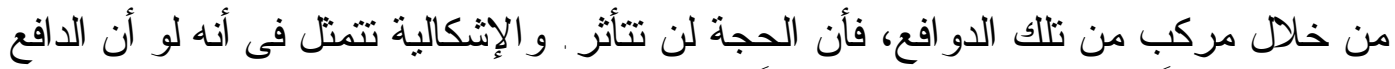

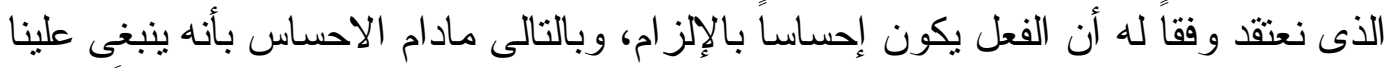

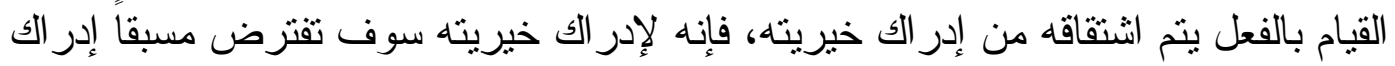

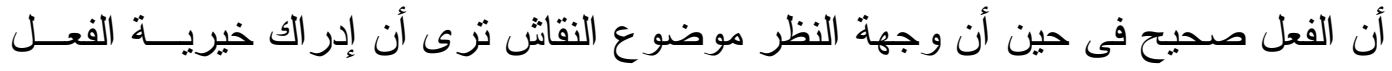

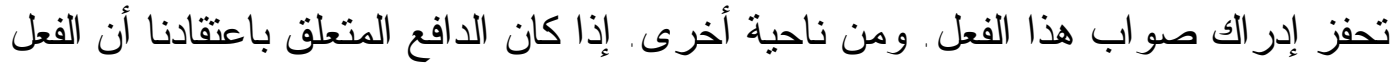

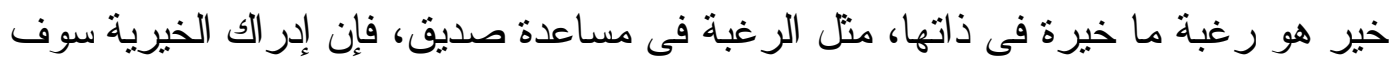

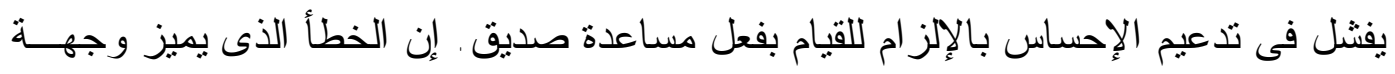

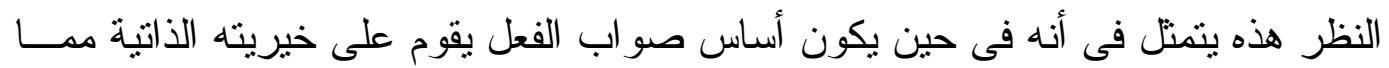

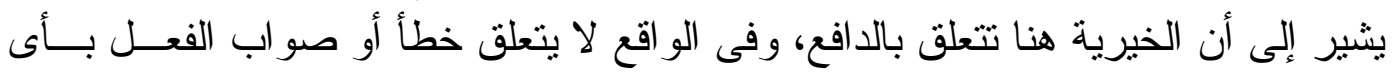

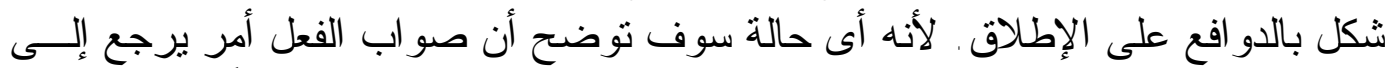

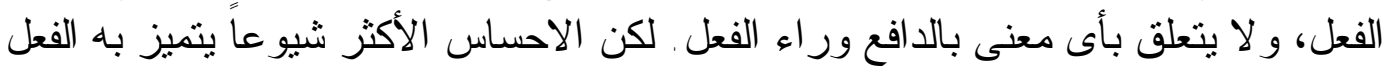

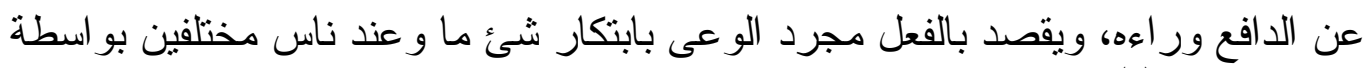
دو افع مختلفة . (0)

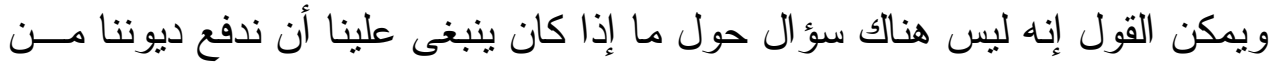

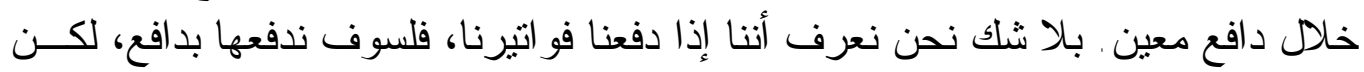

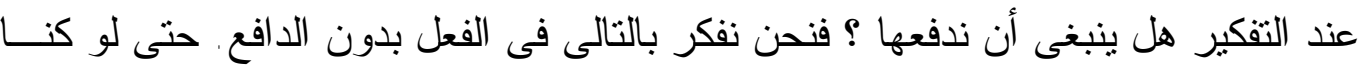

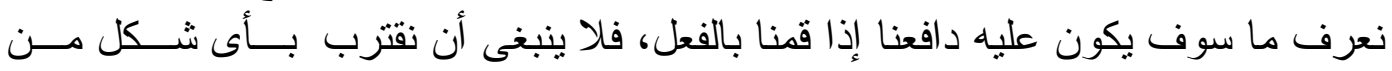

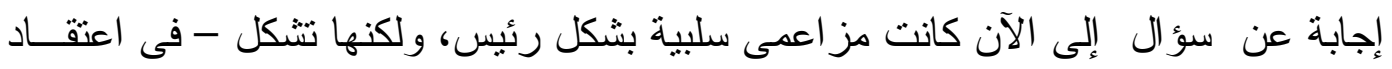

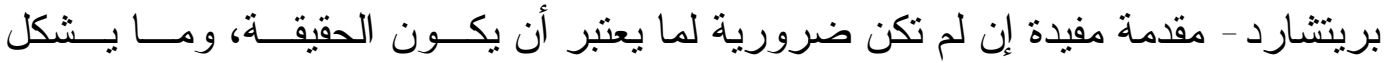

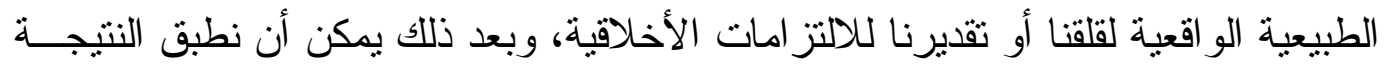
على السؤ ال حول وجود الفلسفة الأخلاقية.

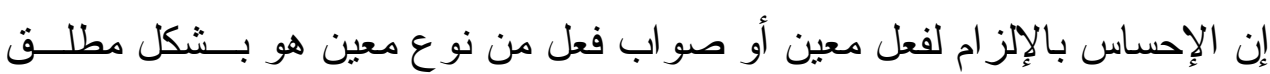

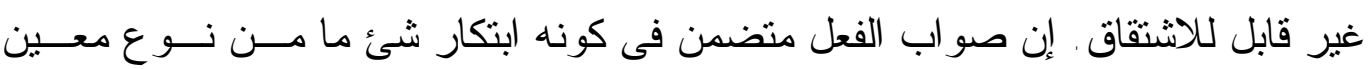

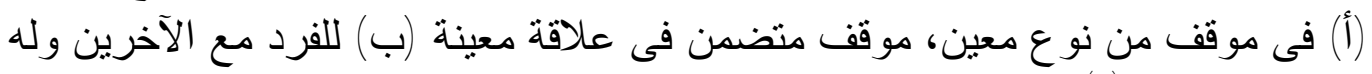




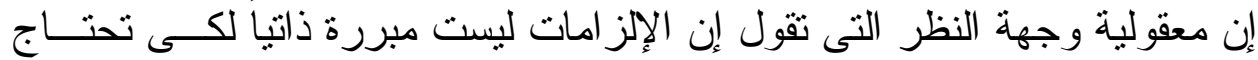
إلى دليل يتزكز فى و اقع أن الفعل الذى نشير إليه على أنه إلز ام ربما يكون فى حالة غير الإلزي

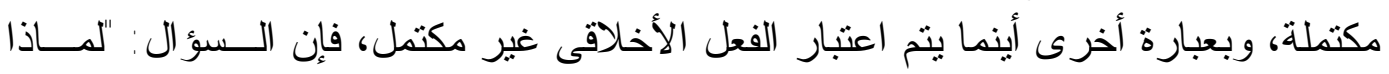

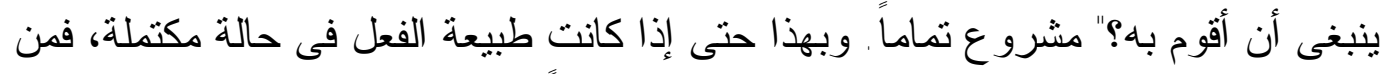
الضرورى أن نقدم سببًا أو بعبارة أخرى عَ أن توفر دليلاً.

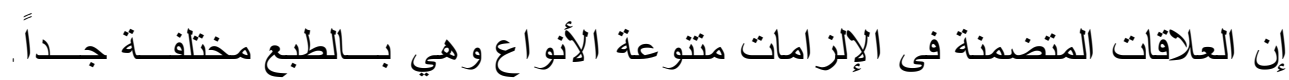

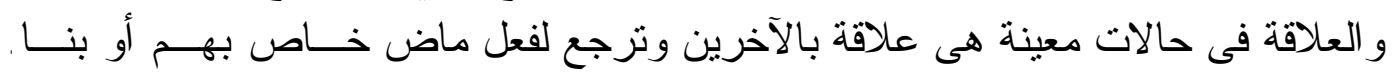

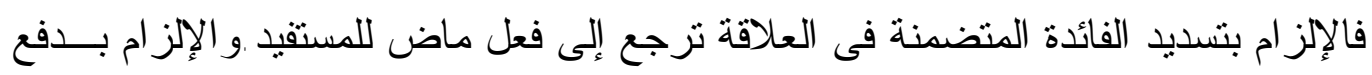

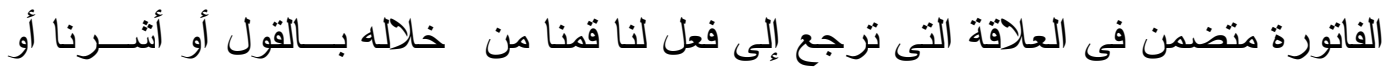

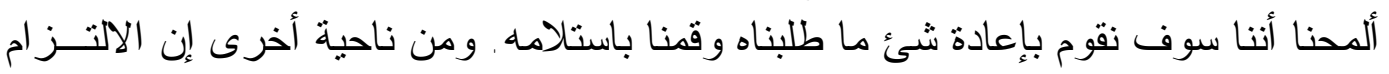

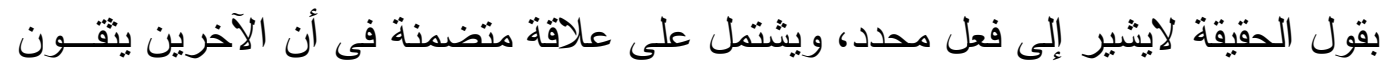

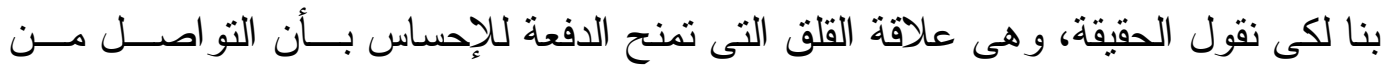

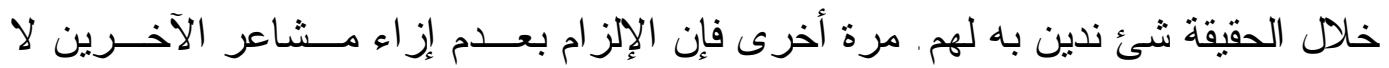

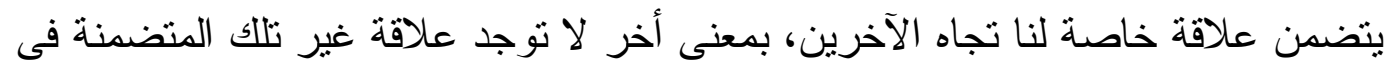

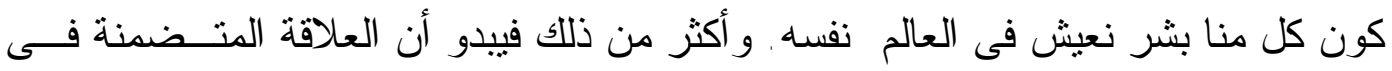

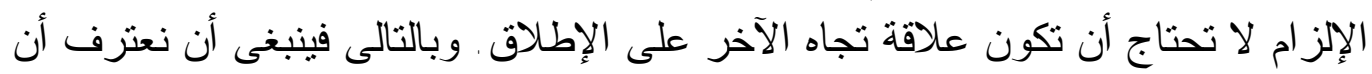

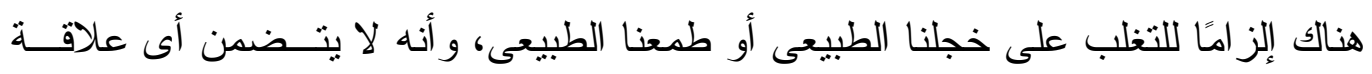

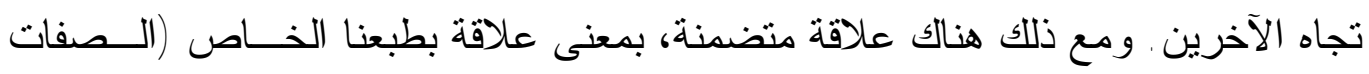

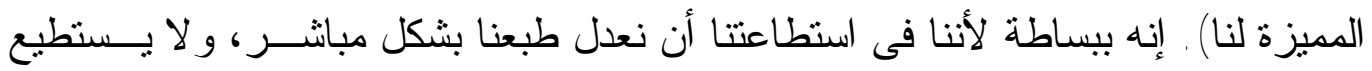

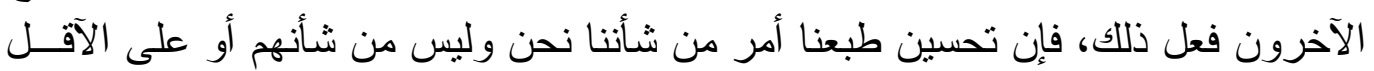

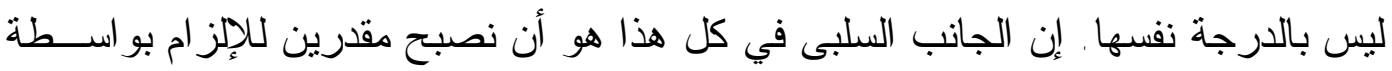

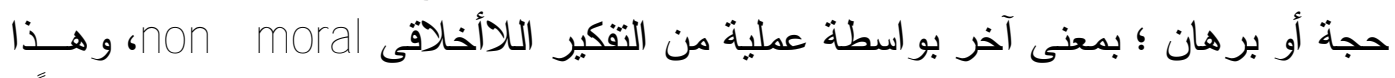

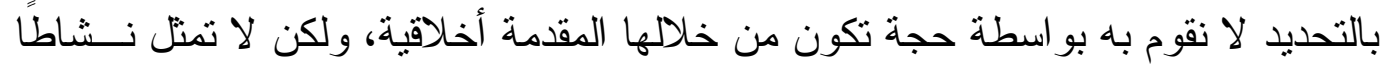

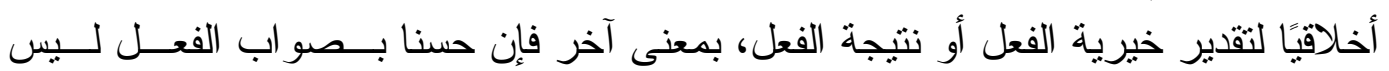

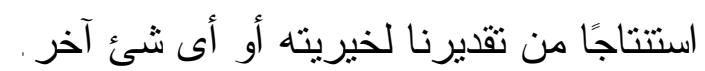

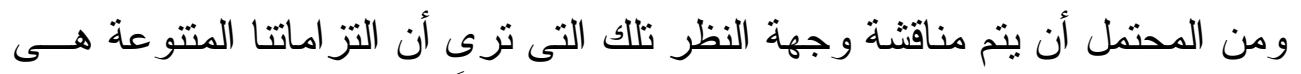

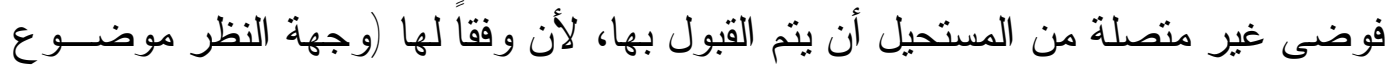

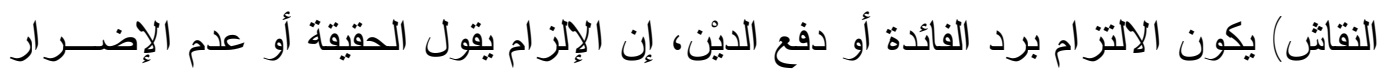




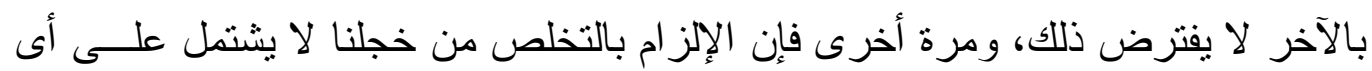

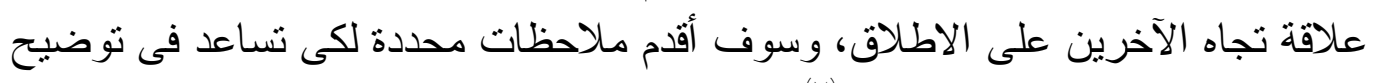

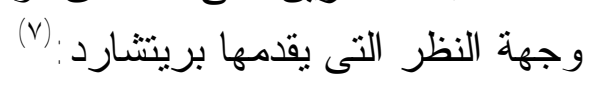

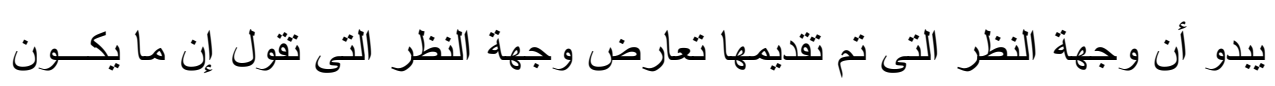
أولاً:

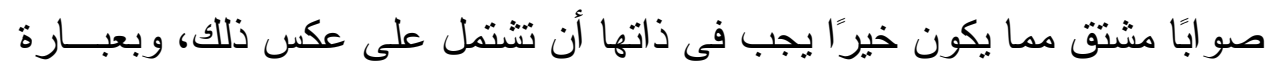

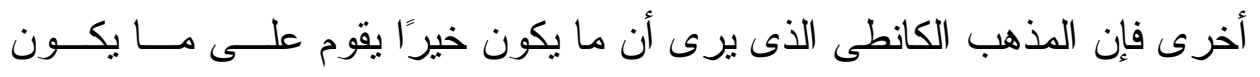

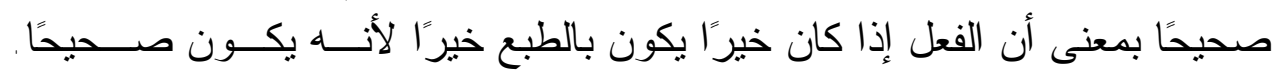

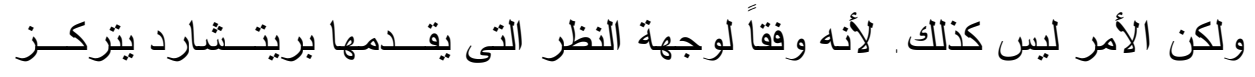

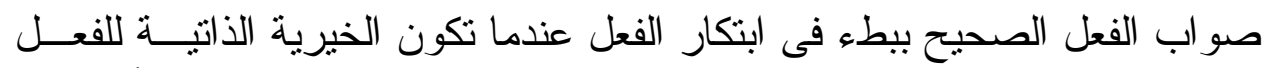

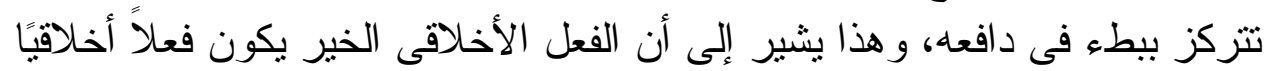

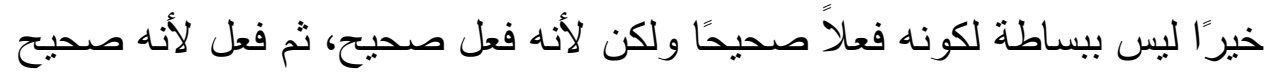

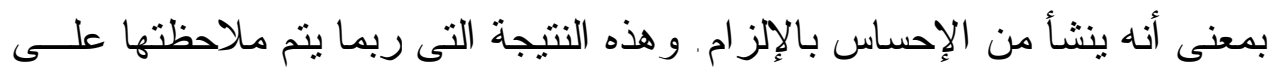

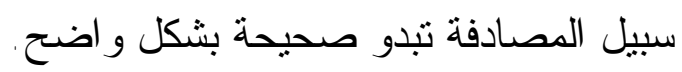

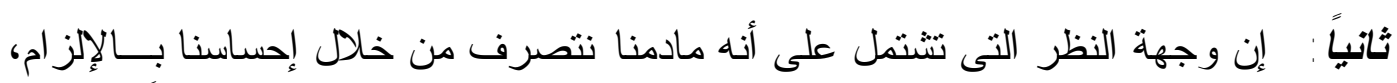

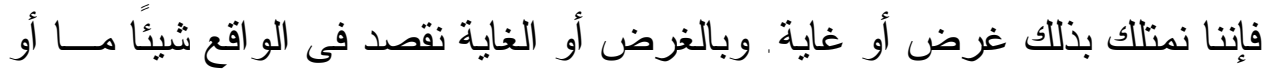

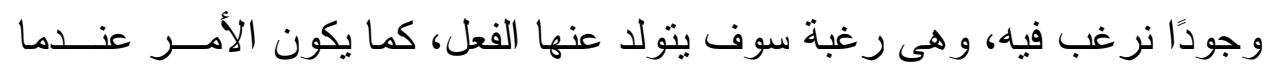

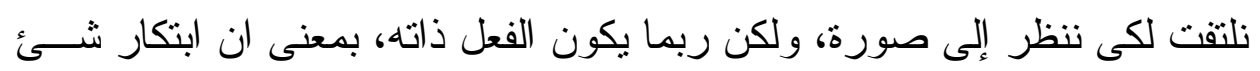

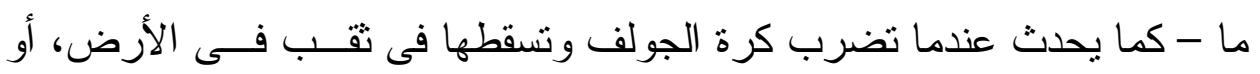

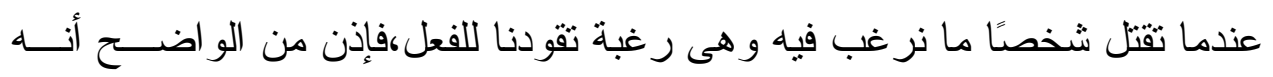

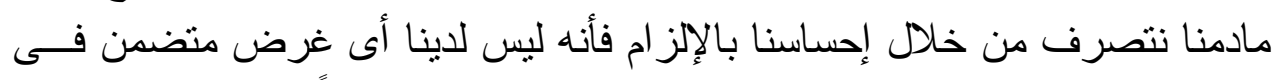

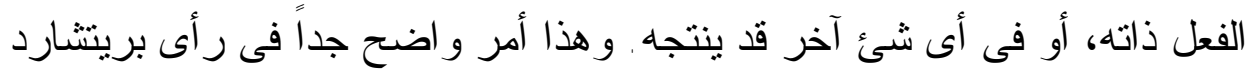

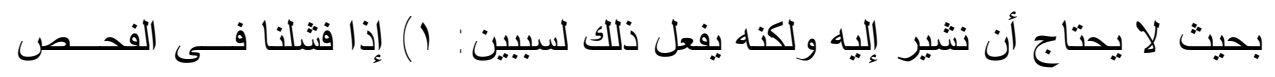

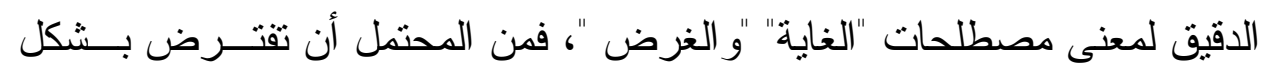

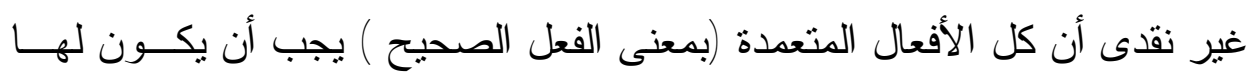

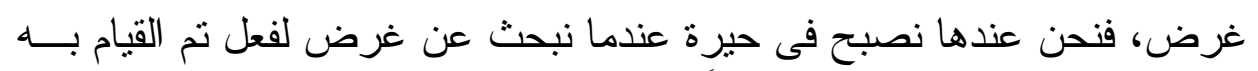

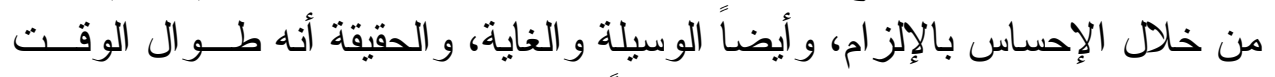

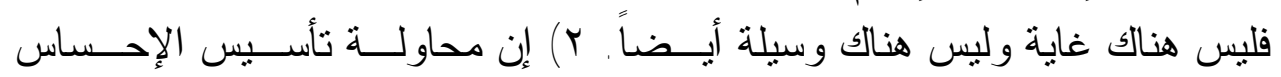

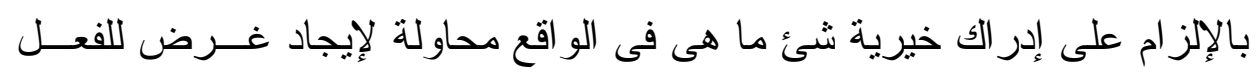




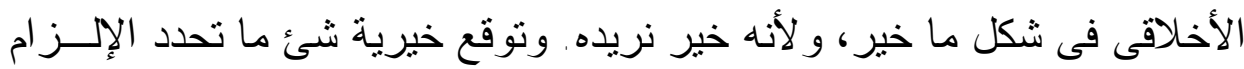

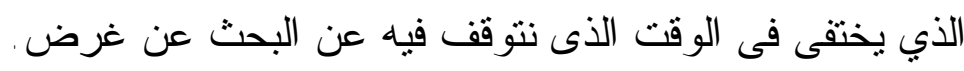

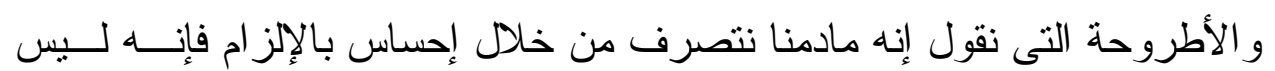

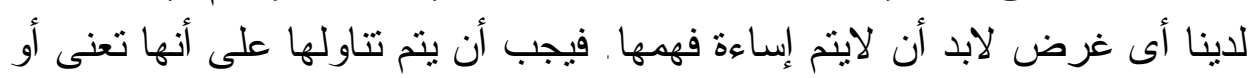

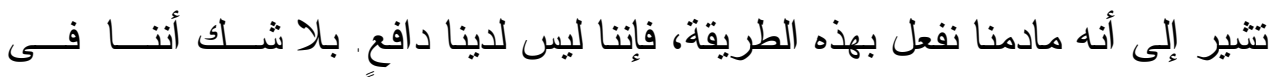

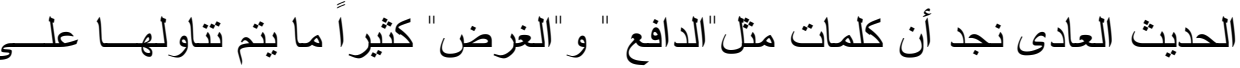

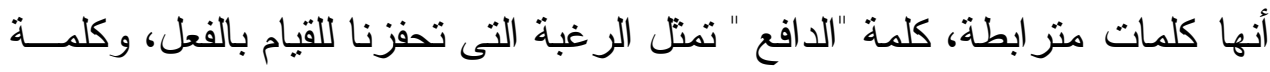

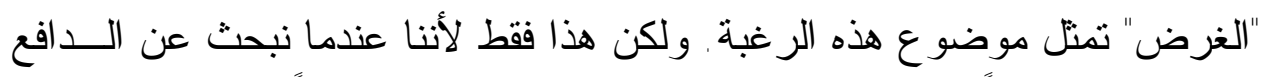

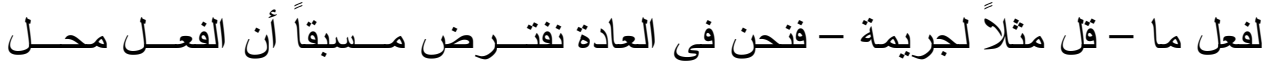

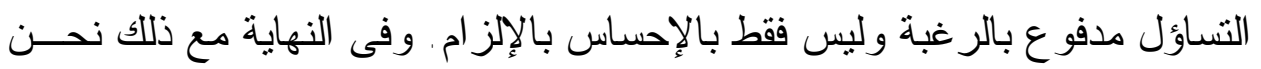

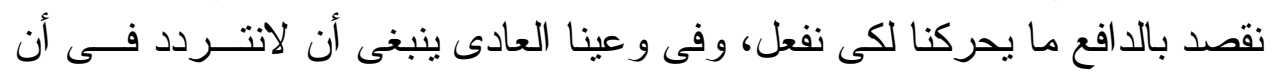

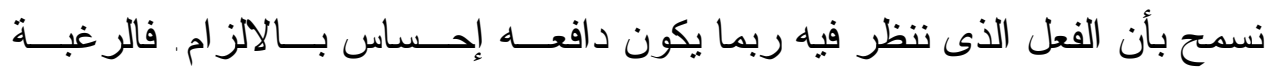

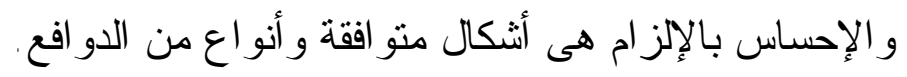

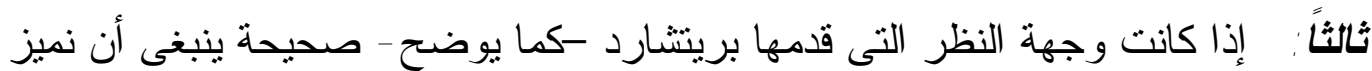

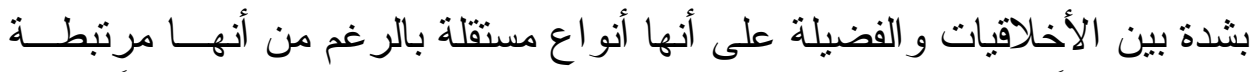

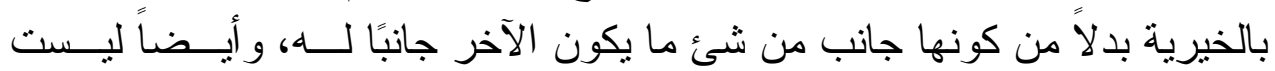

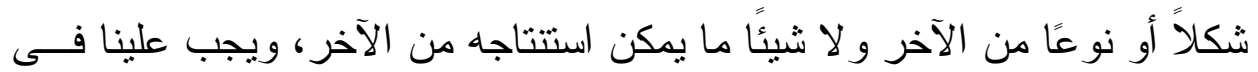

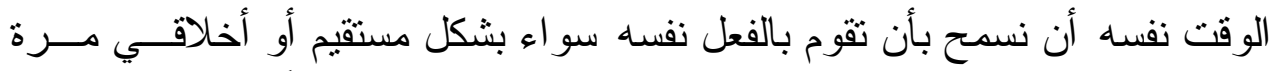

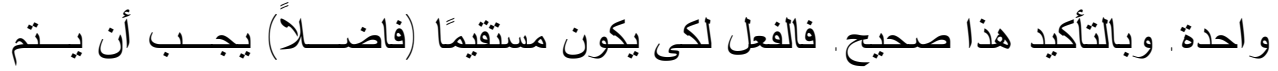

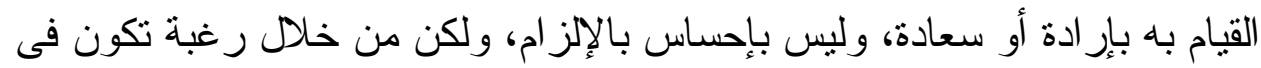

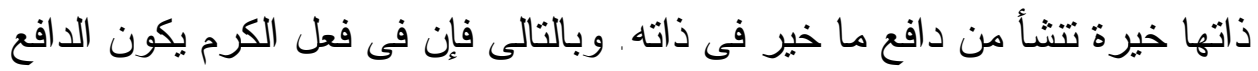

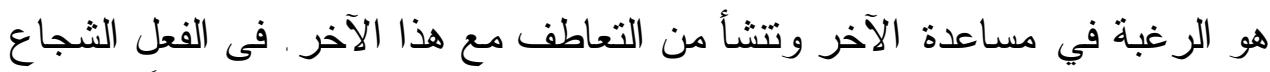

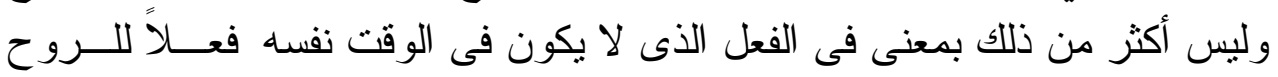

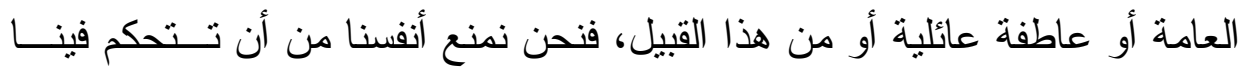

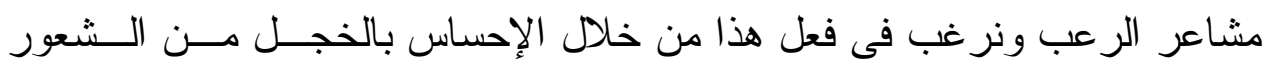

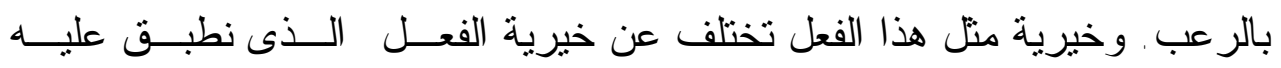

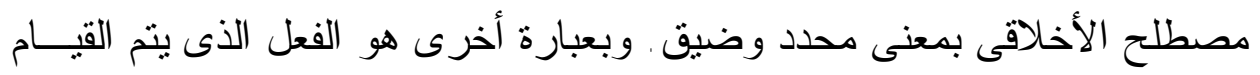

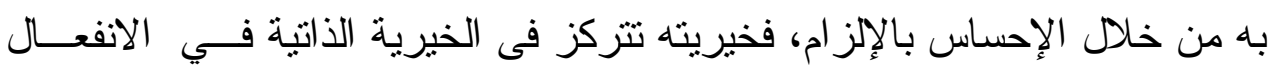




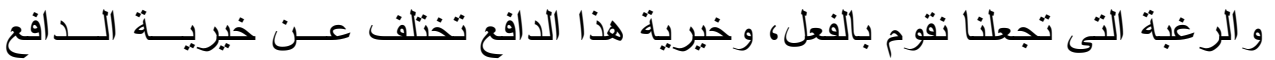

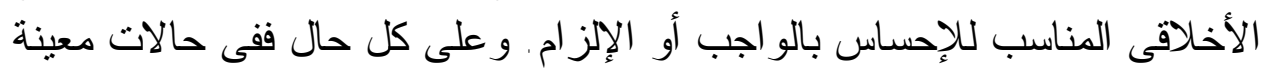

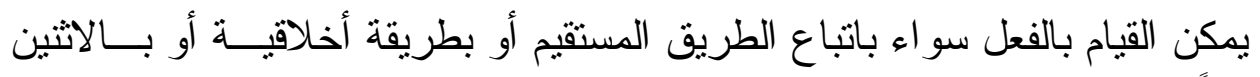

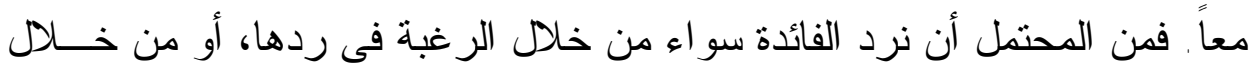

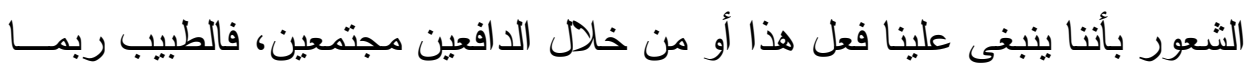

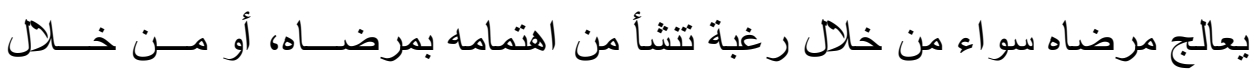

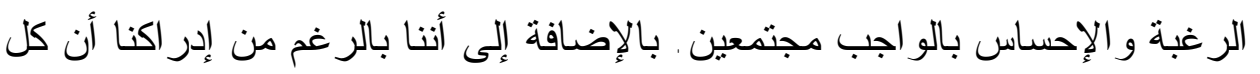

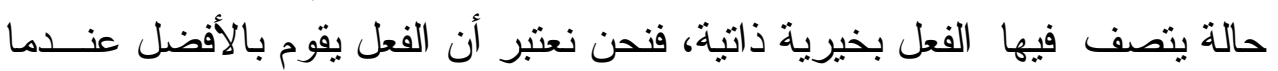

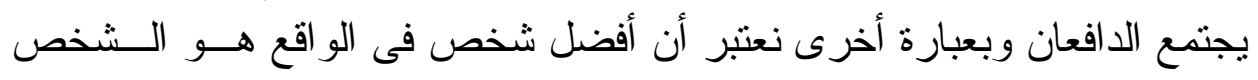
الذى تتحد فيه الاستقامة (الفضيلة) و الأخلاق .

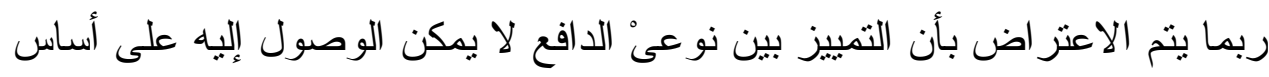

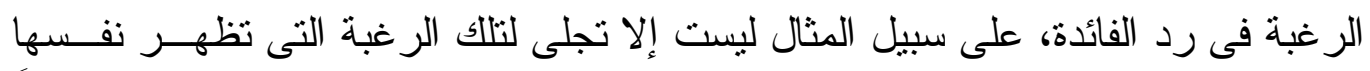

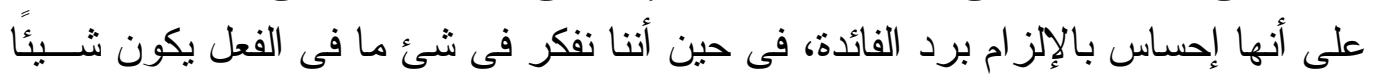

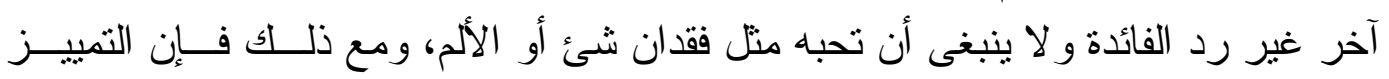

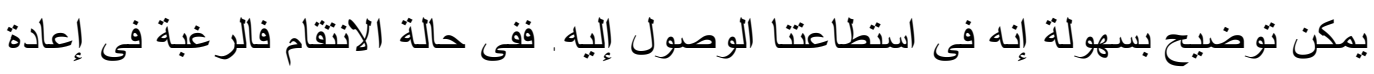

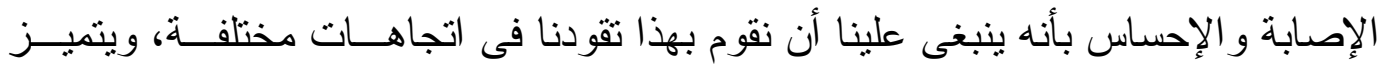

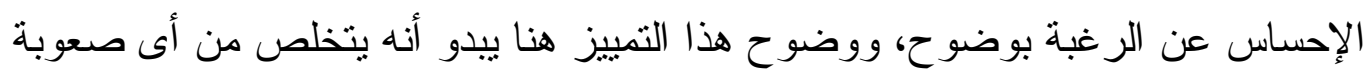

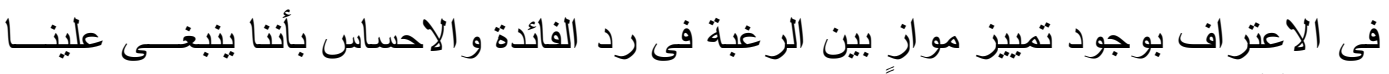
ردها. (1)

بالإضافة إلى أن وجهة النظر تلاك التى تثثير إلى أن الإلز ام لاشئ أكثر من أنه يقوم

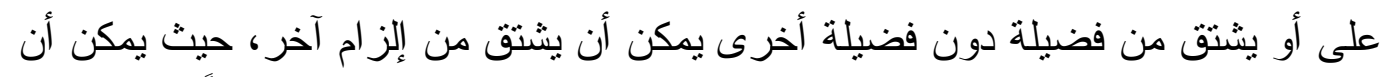

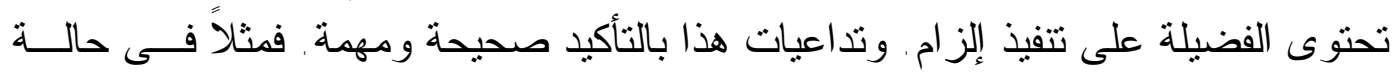

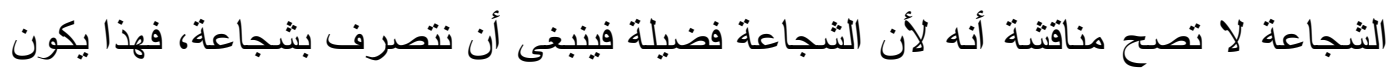

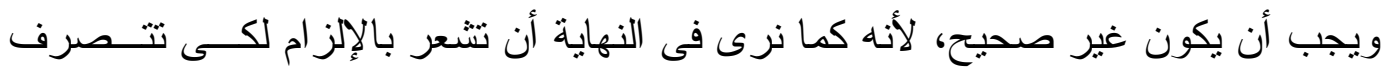

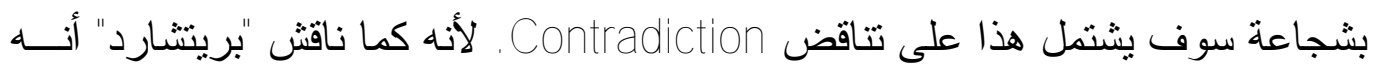

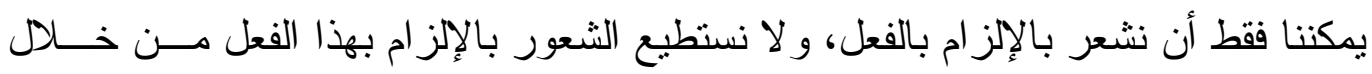

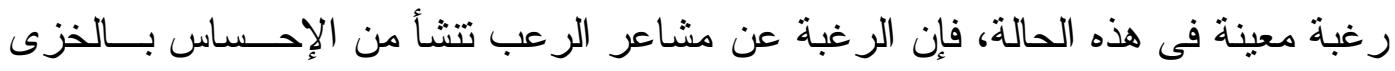

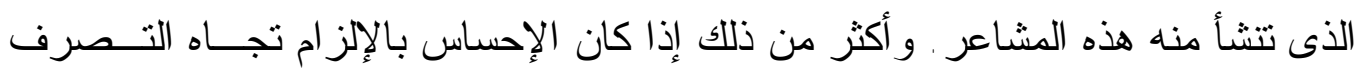




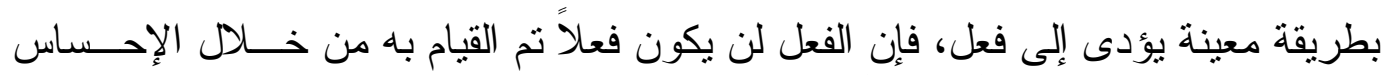

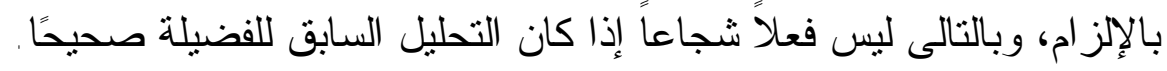

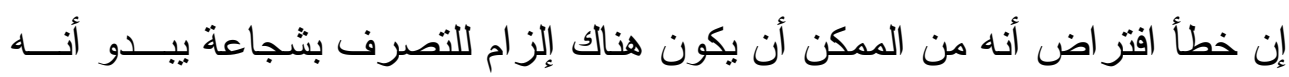
ينشأ نتيجة لسبيين:

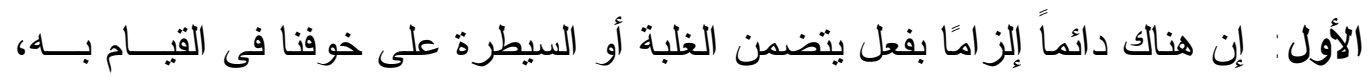

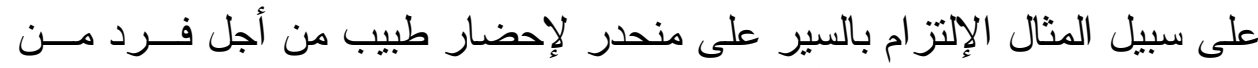

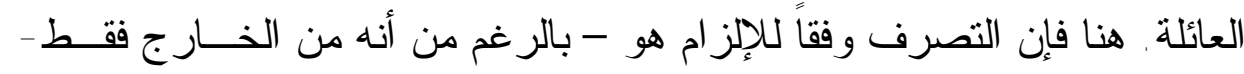
يثبه فعل الثجاعة.

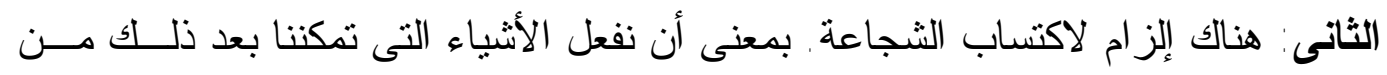

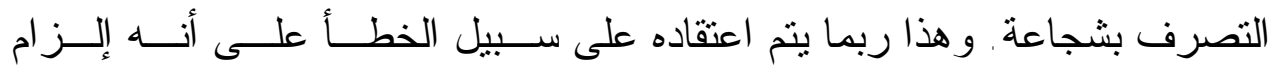


"بريتشارد" - على باقى الفضائل.



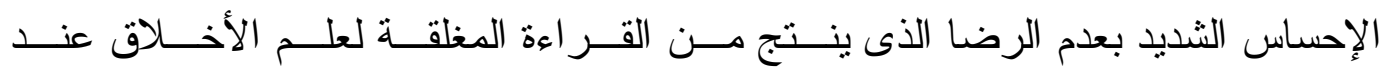

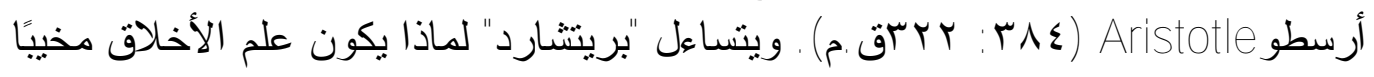

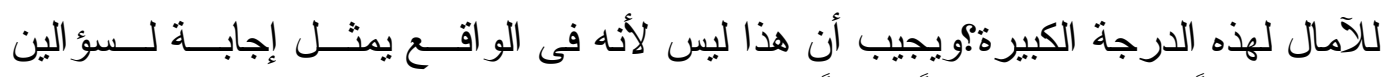

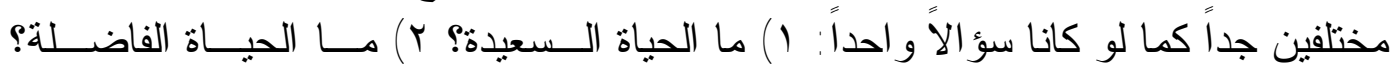

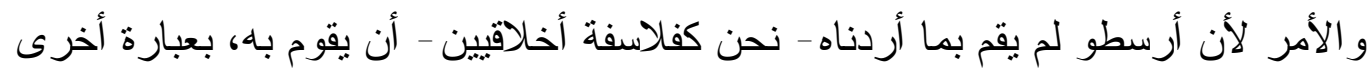

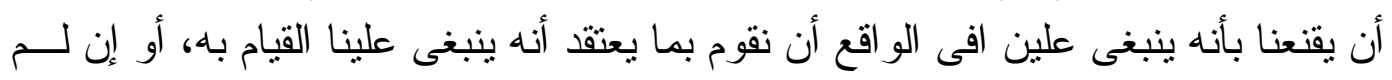

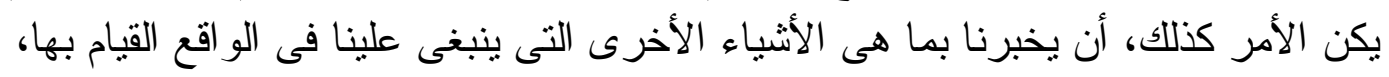

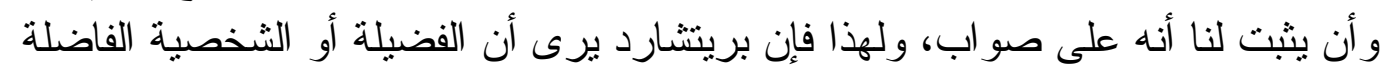

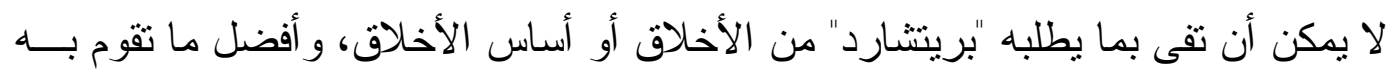

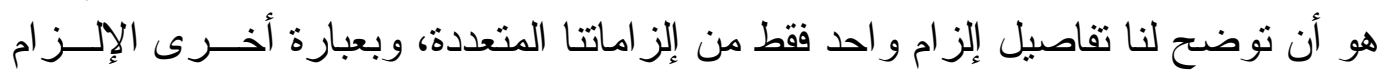

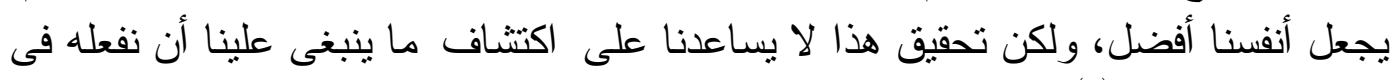
الحياة ككل ولماذا. (9) أنون

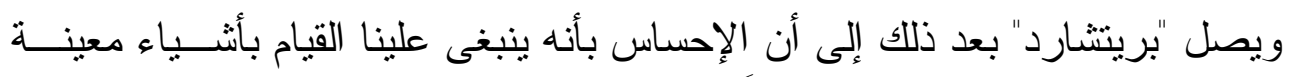

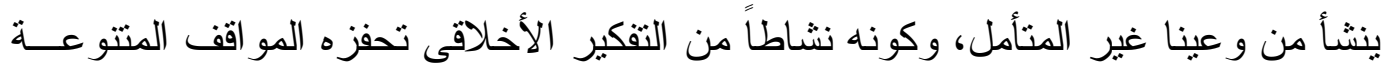

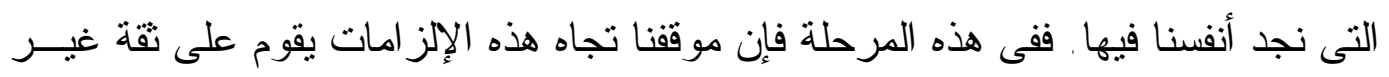


مشكوك فيها و ولكن تقدير مدى نأثير هذه الإلز امات في مصالحنا (أى أنها تسير فى اتجــاه

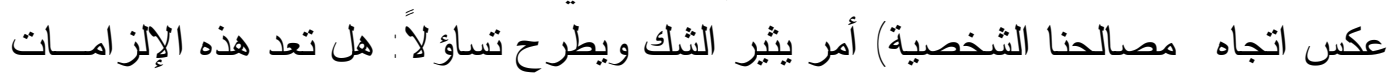

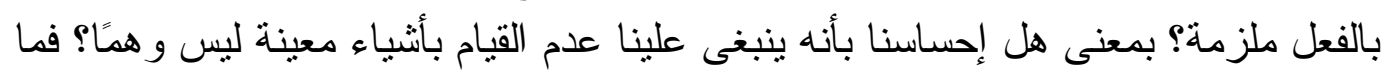

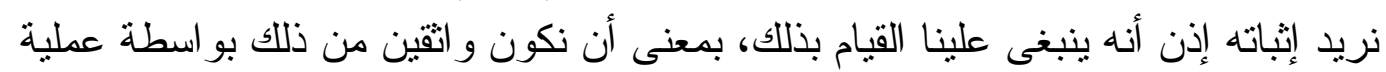

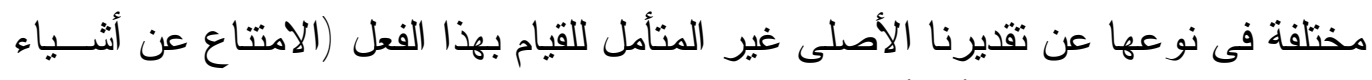
معينة) ولكن "بريتشارد" ر أى أن هذا المطلب غير الأبر مشروع.

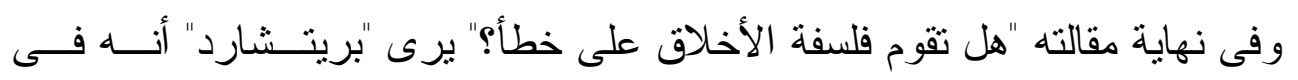

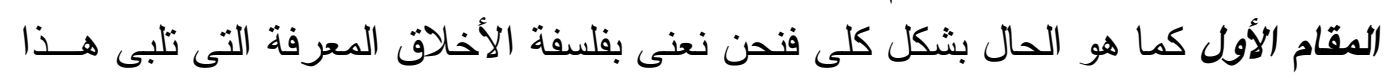

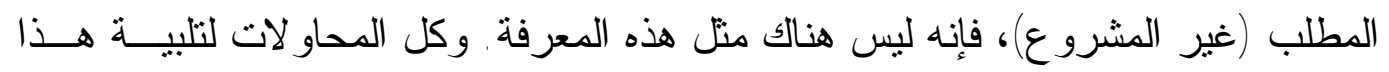

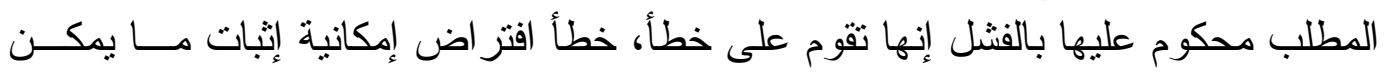

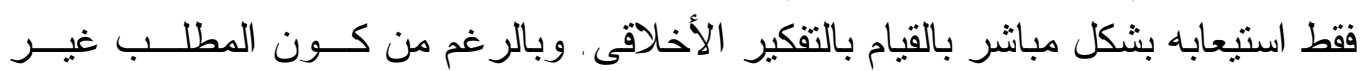

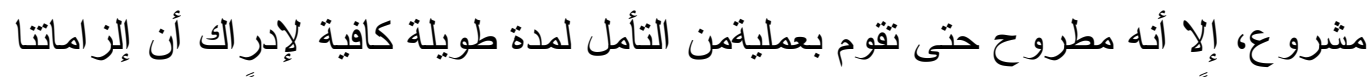

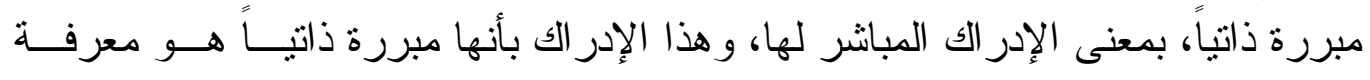

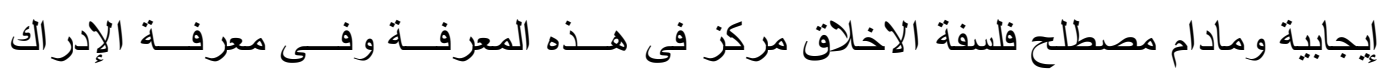

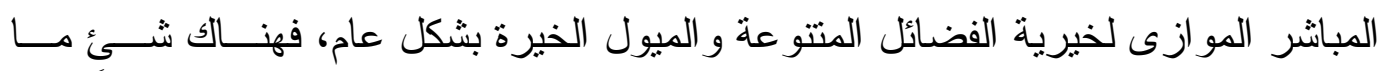

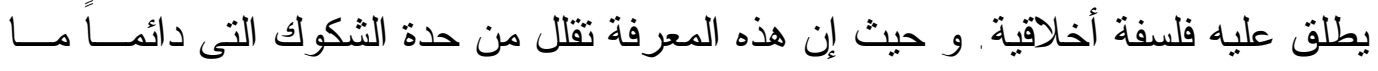

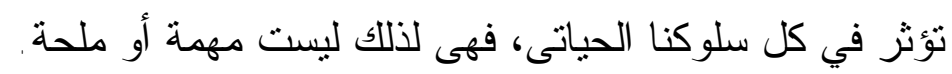

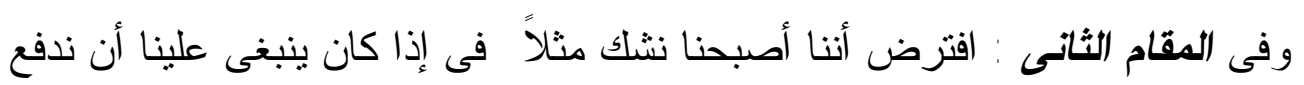

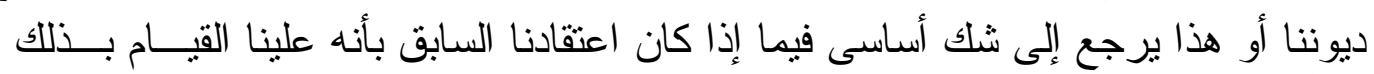

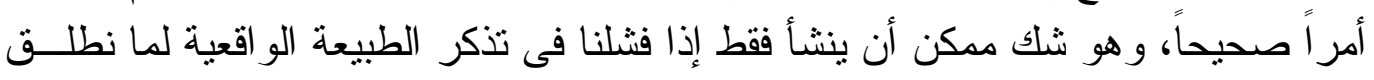

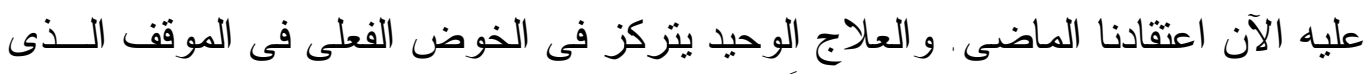

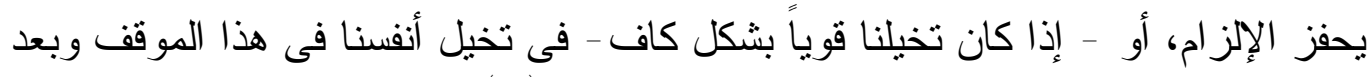

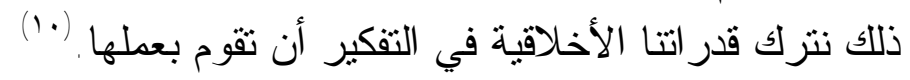

\section{معنى السعادة فى رأى "بريتشارد":}

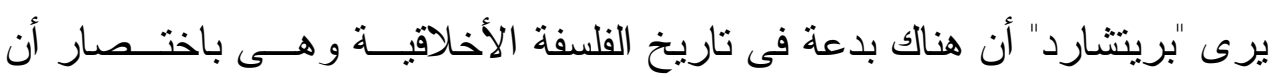

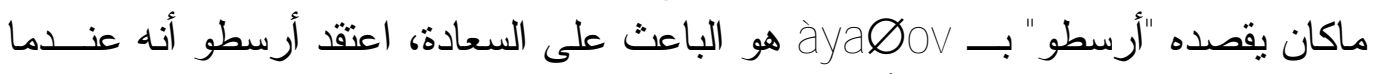

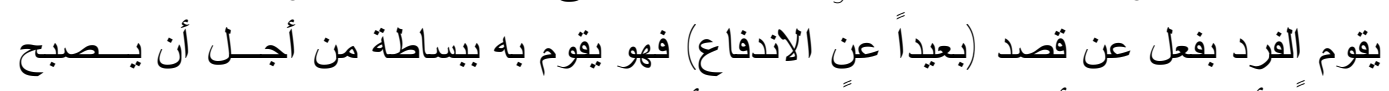

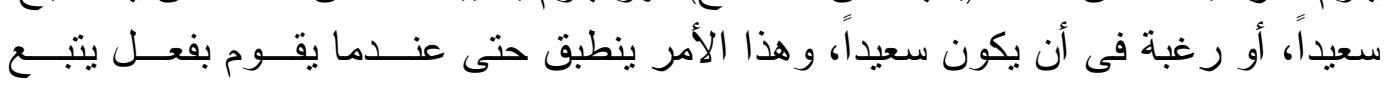

$$
r \cdot \varepsilon r
$$


الفضيلة ،ققد قام أرسطو بإقتاع الفرد بأن يكون فاضلاً ويفعل ما يتفق مــع الفـضيلة عـنـ

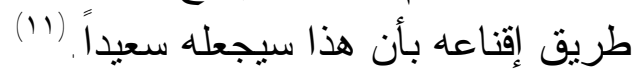

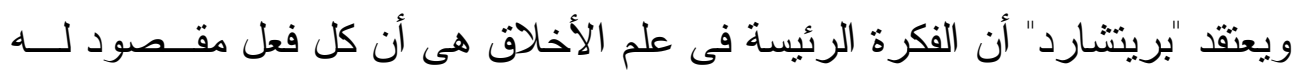

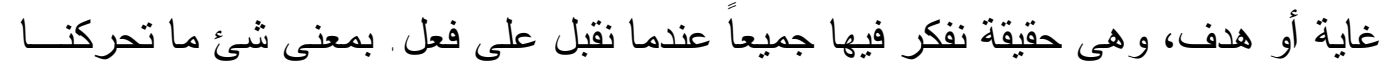

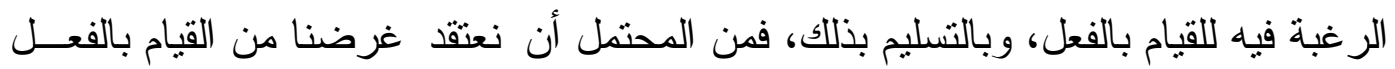

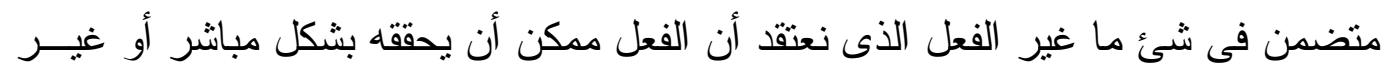

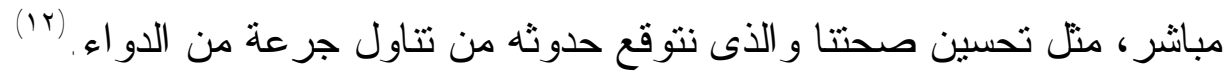

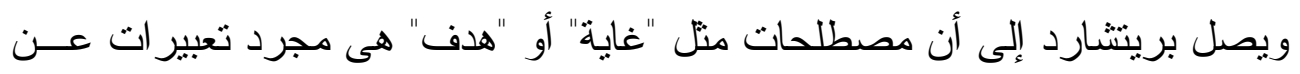

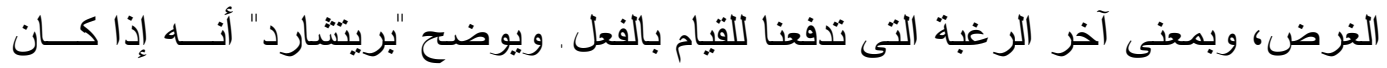

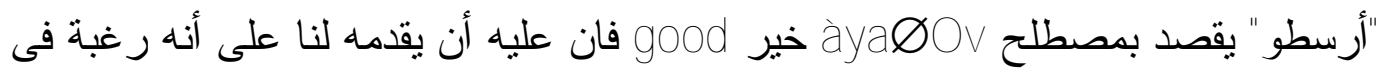

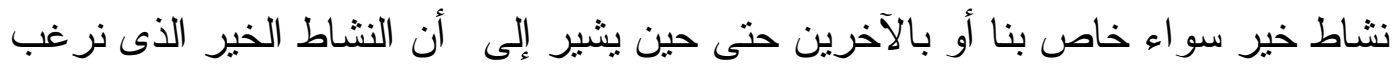

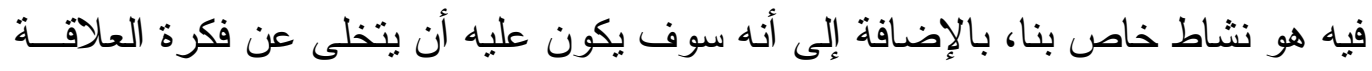

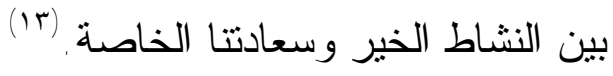

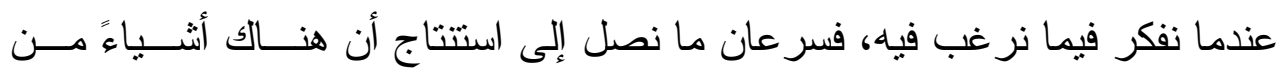

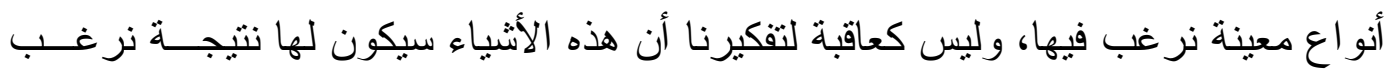

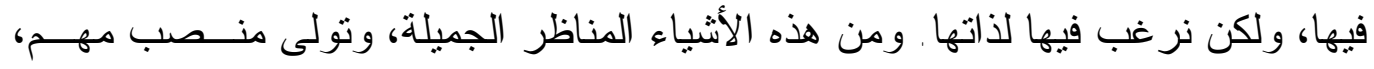

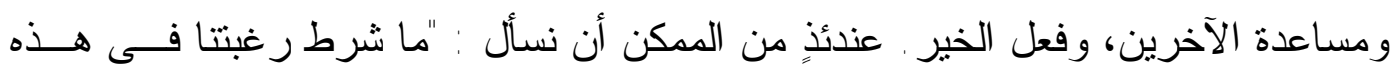

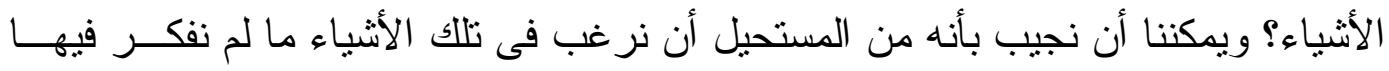

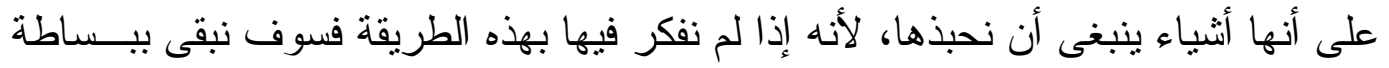

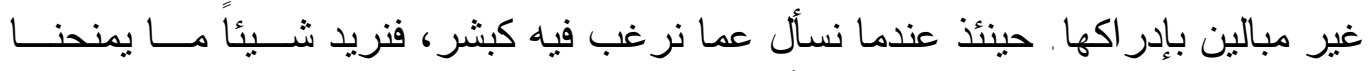

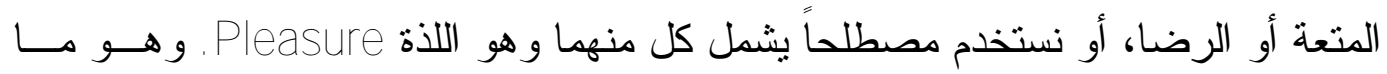

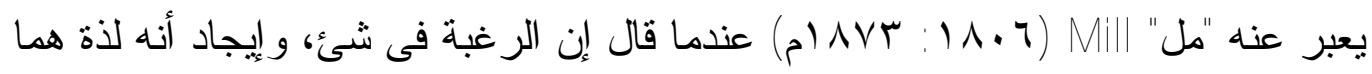

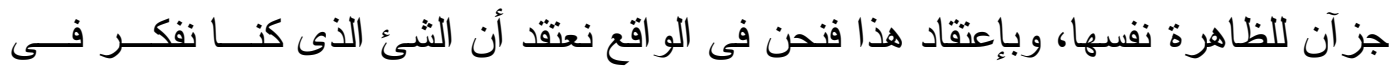

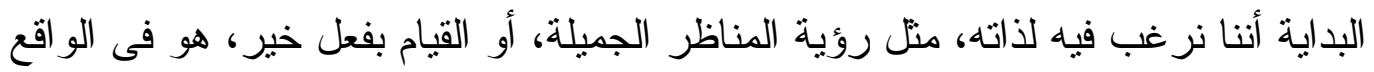

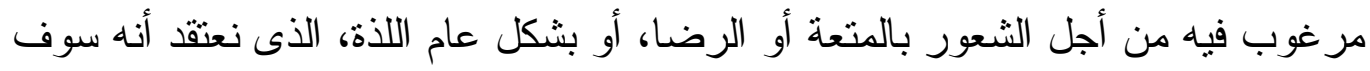

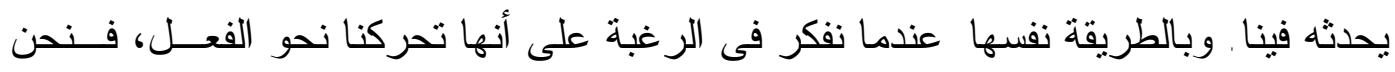

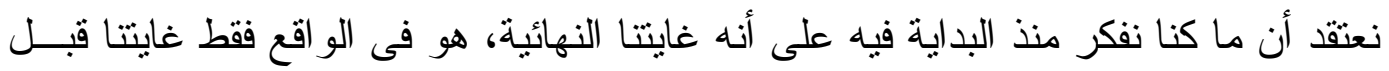

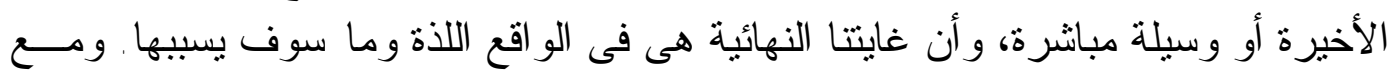


ذلك فمن المكن أن نفكر فى أثنياء تمنحنا المتعة أو الرضا على أنها صفة للشئ كما نفكر

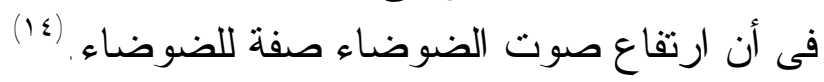

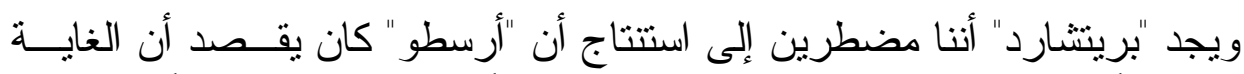

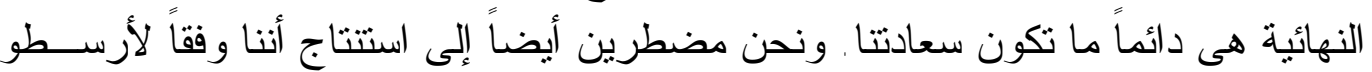

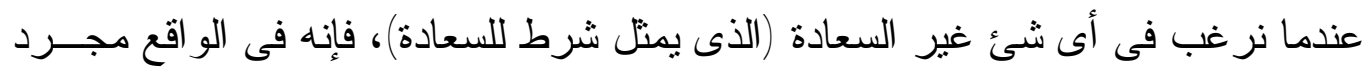

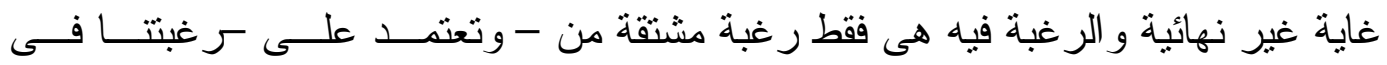

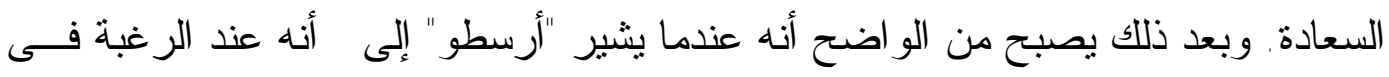

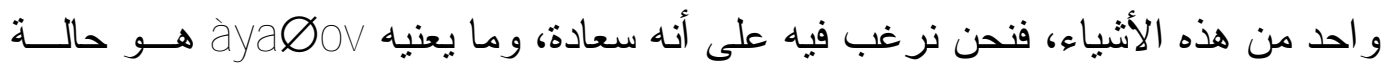

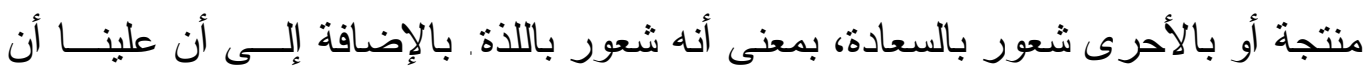

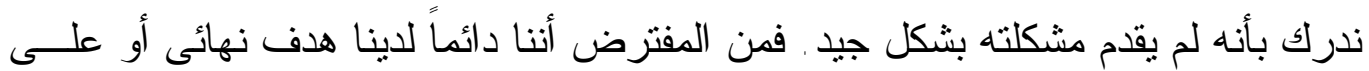

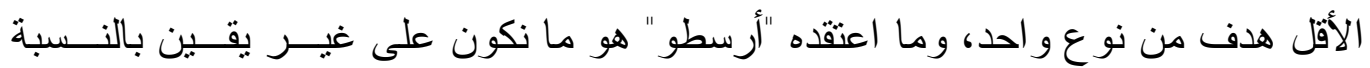

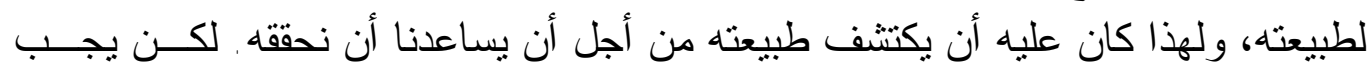

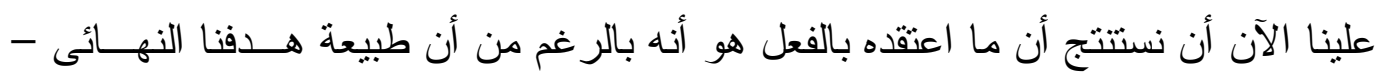

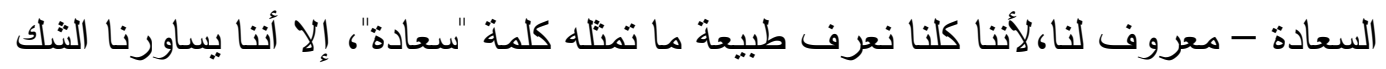

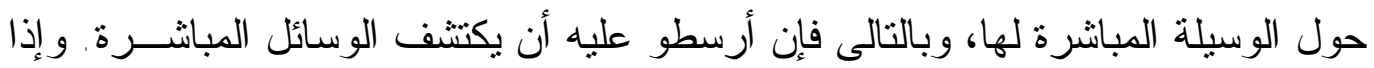

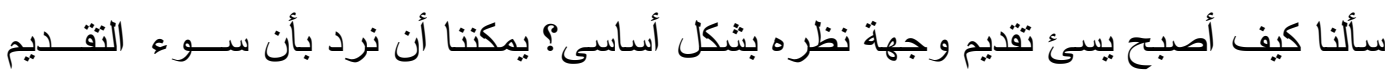

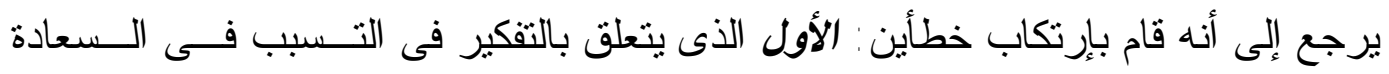

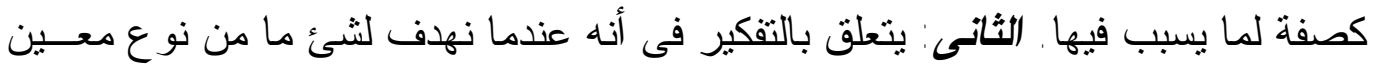

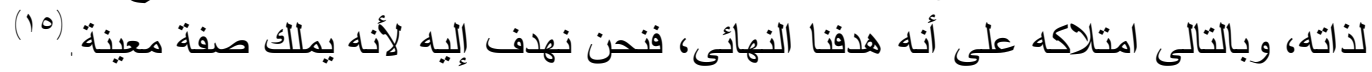

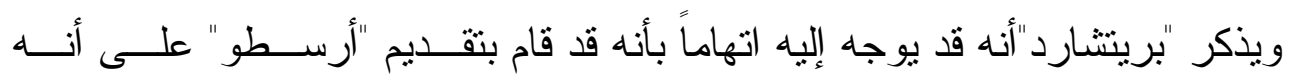

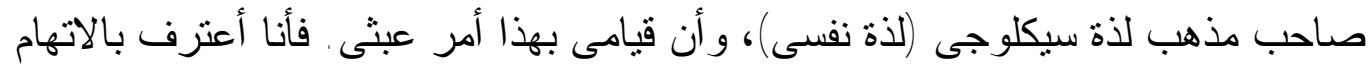

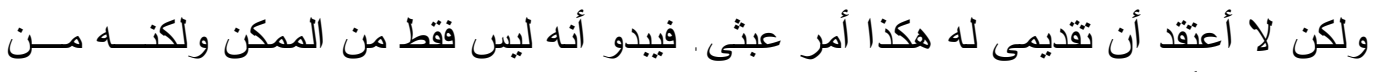

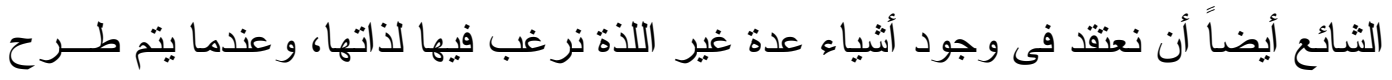

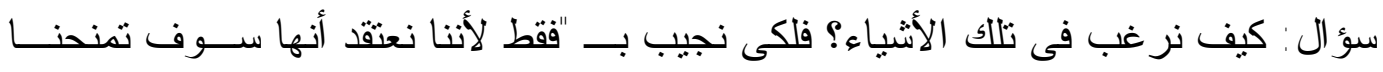

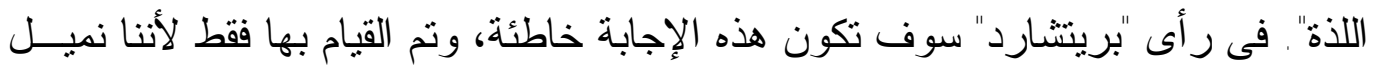

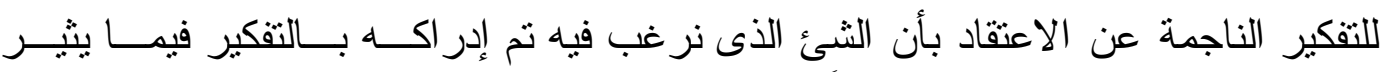

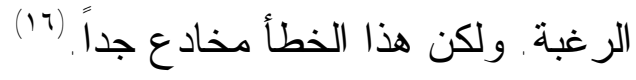




\section{مقالة ريتشارد بين التأييا والنقد:}

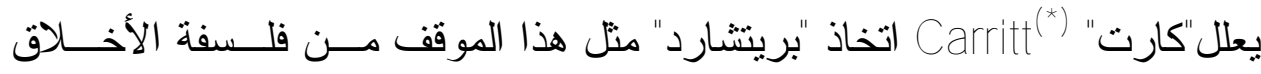

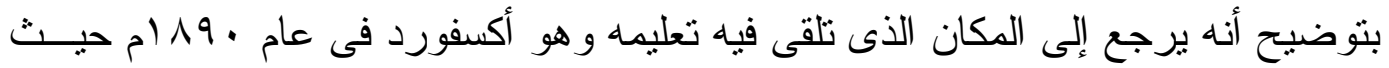

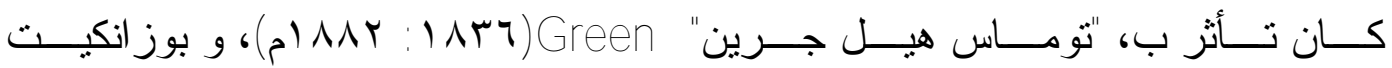

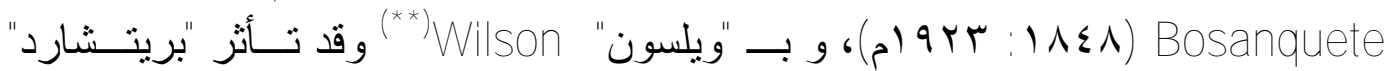

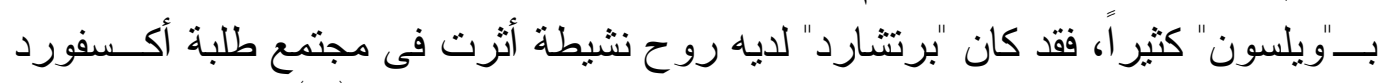

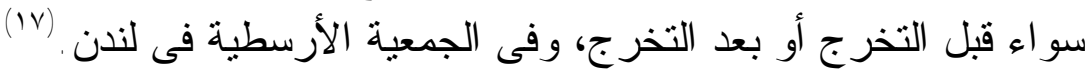

برى "هاوكينز"Hawkins

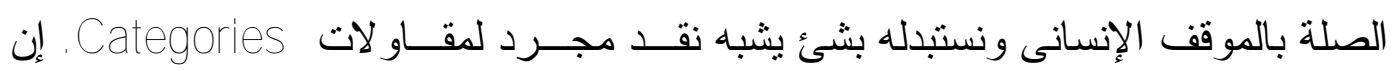

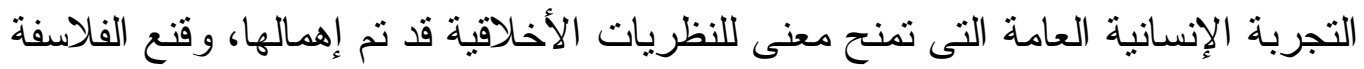

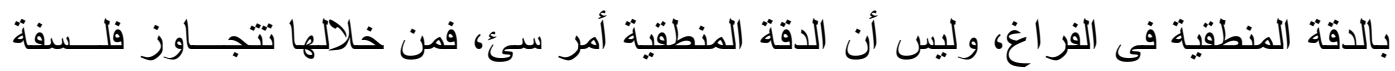

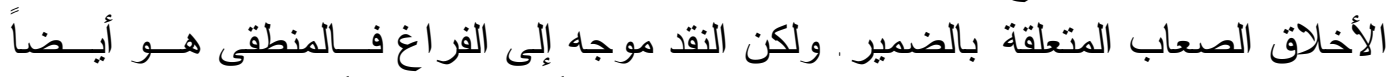

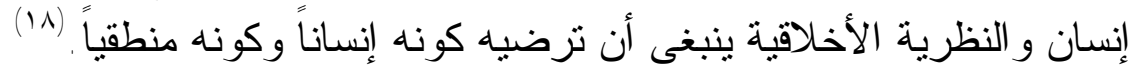

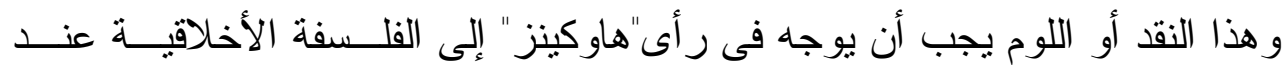

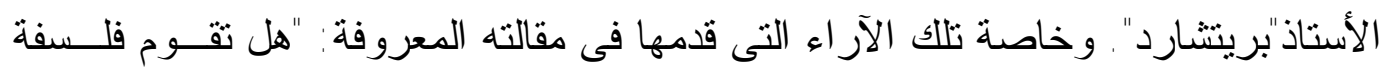

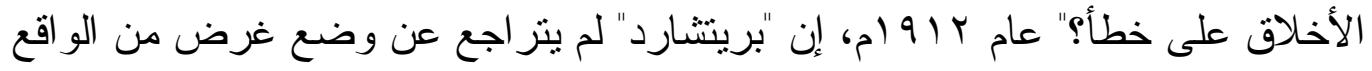

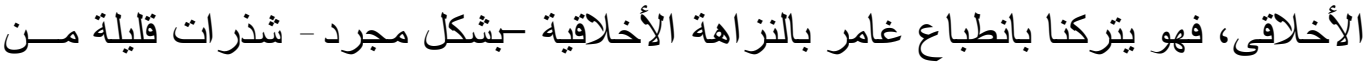

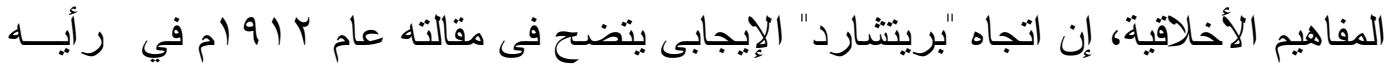

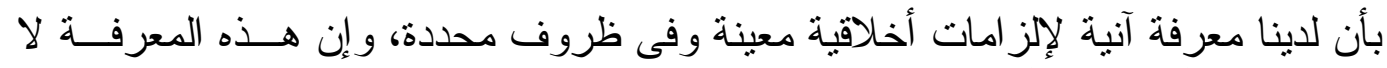

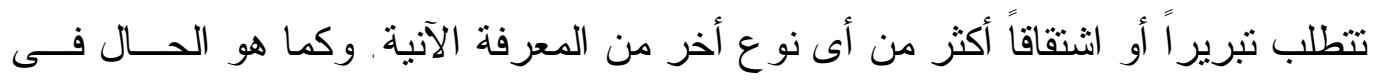

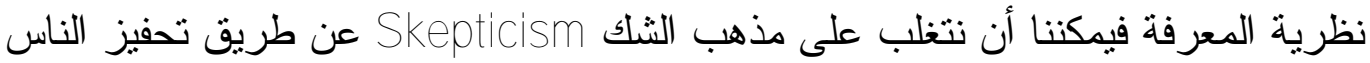

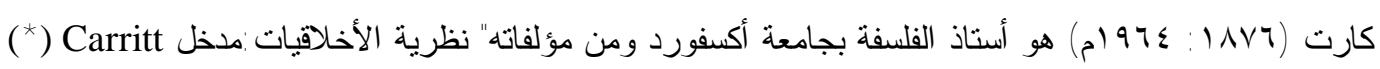
The Theory of Morals:An Introduction to Ethical Philosophy http://www.uvm.edu/ lderosse/courses/intro/Carritt.pdf(6/8/2016)

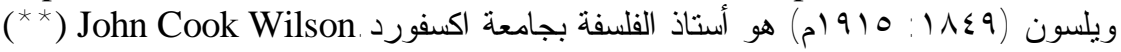
plato.stanford.edu/entries/Wilson(5/8/2016)

"Criticism of Experience $\left._{p}\right) 9 \leq 0$

http://archive.thetablet.co.uk/article/25th-january-1964/25/canon-d-j-b-hawkins-acritical-metaphysician-it-wa http://www.goodreads.com/author/show/1217648.D J B Hawkins

$$
r \cdot \leqslant 0
$$


لكى يلاحظو ا حالات من المعرفة الأصلية، بحيث تكون المهية المبدئي للفلسفة الأخلاقيـــة

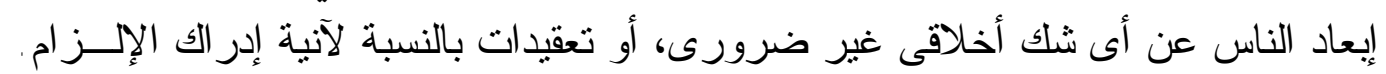

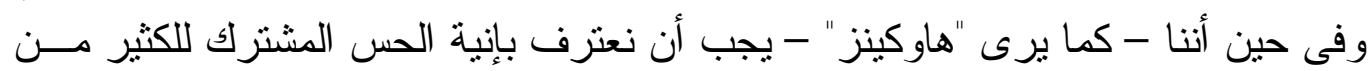

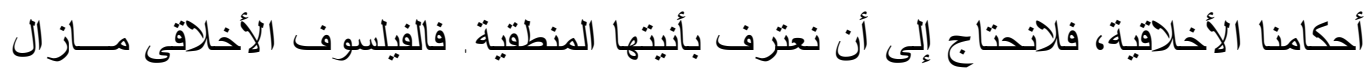

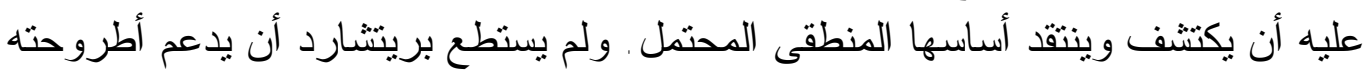

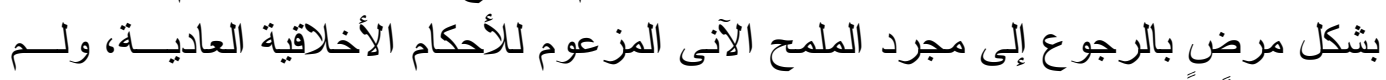

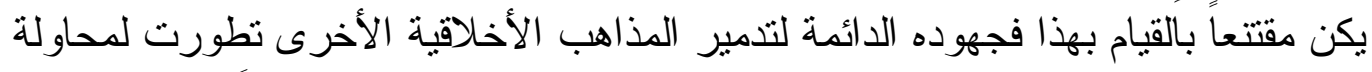

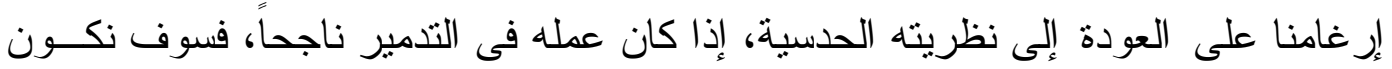
مقتتعين بأن نسكن المبنى الذى ير غب في بنائه.

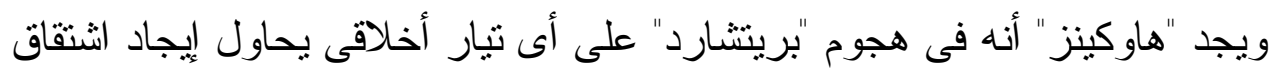

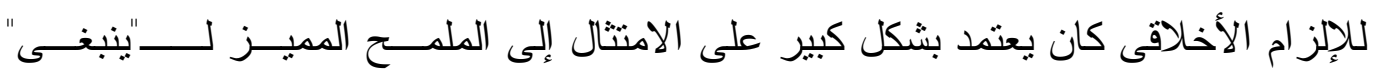

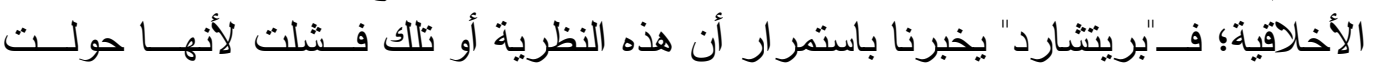

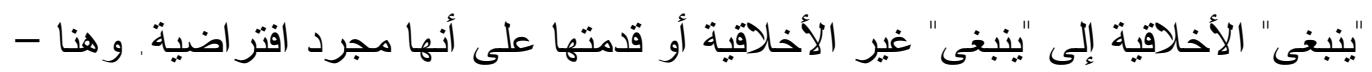

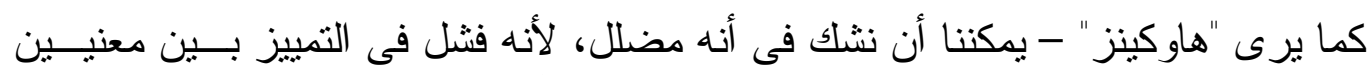

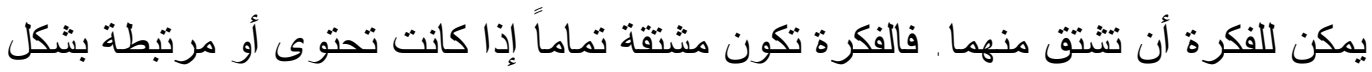

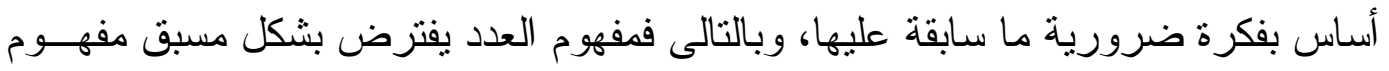

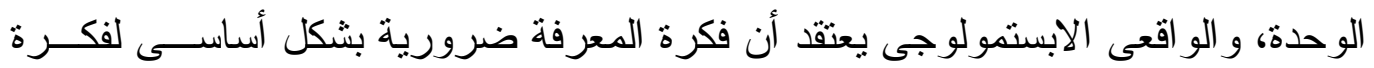

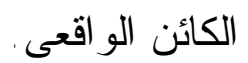

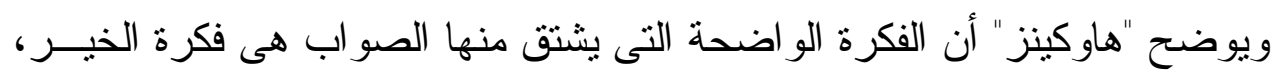

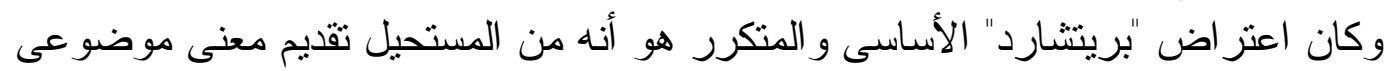

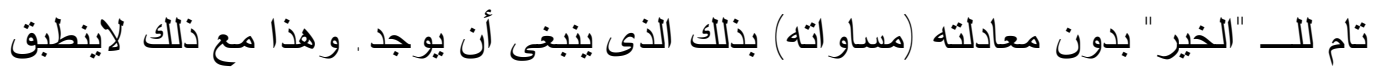

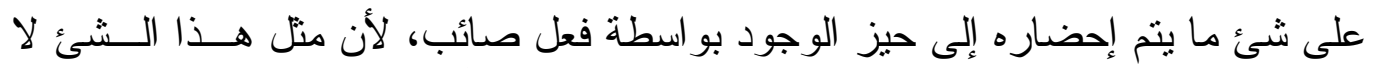

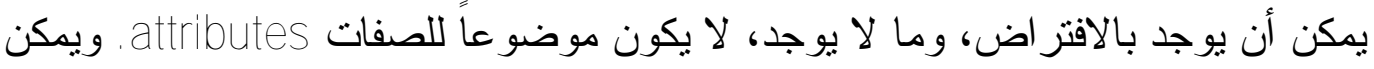

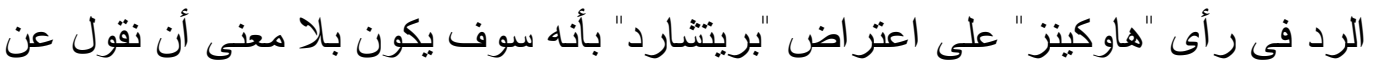

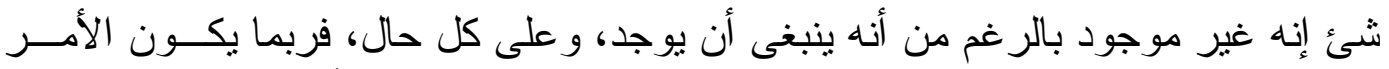

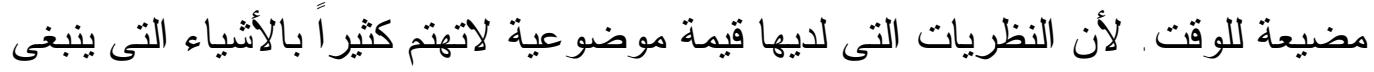

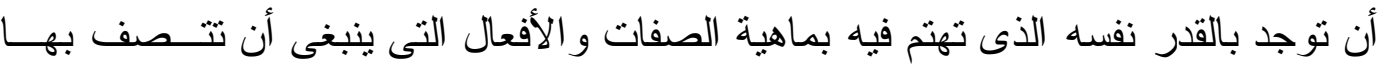

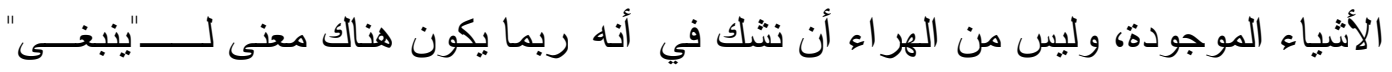


بحيث يكون من الواضح أن نقول إن هذا الثنئ ينبغى أن يكون فى هذه الحالة أو يتجـسد فى هذا الفعل.

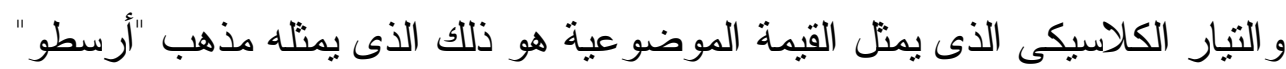

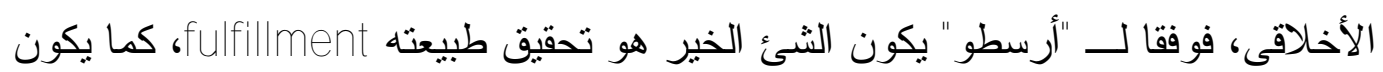

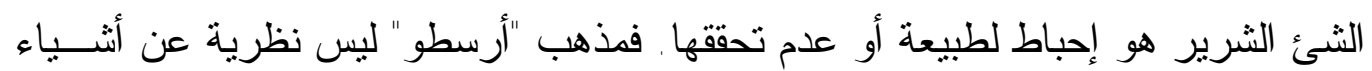

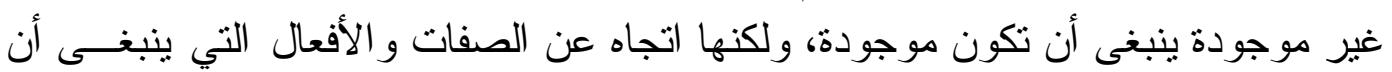

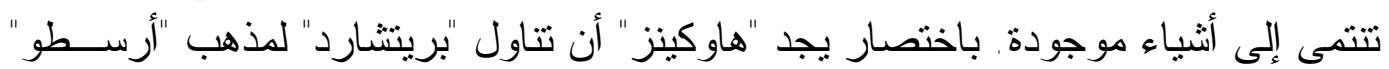

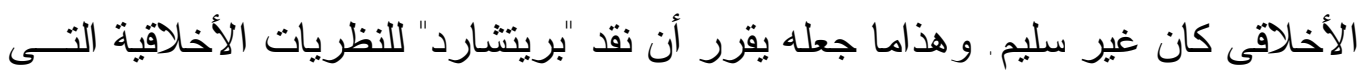

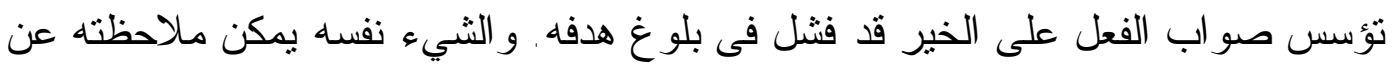

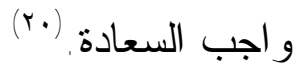

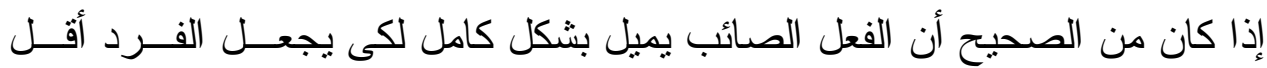

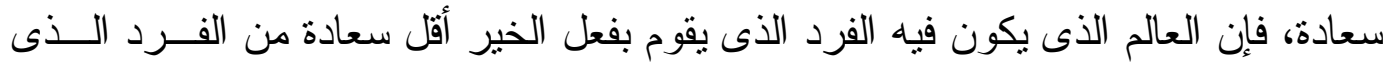

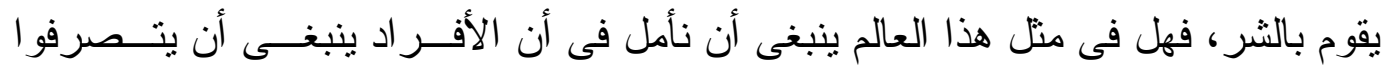

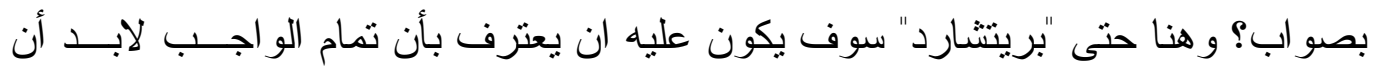

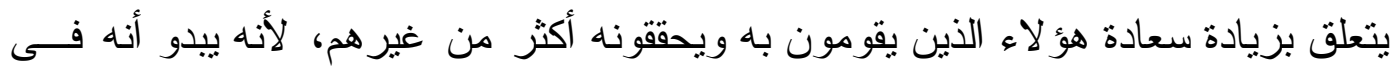

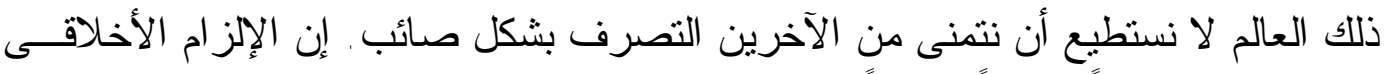

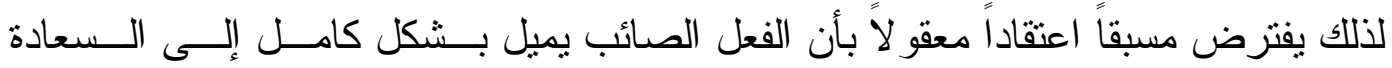
العامة، بالإضافة إلى سعادة الفرد نفسه.

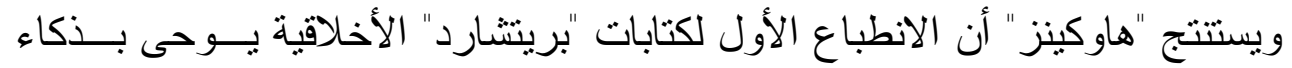

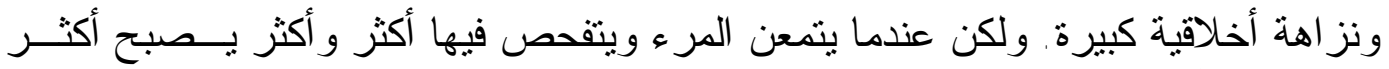

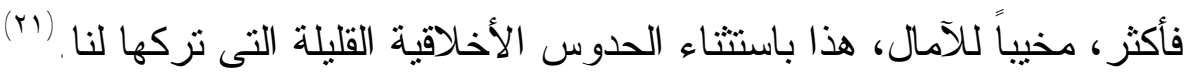

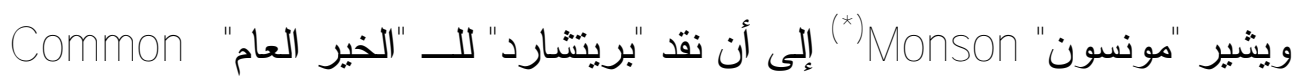

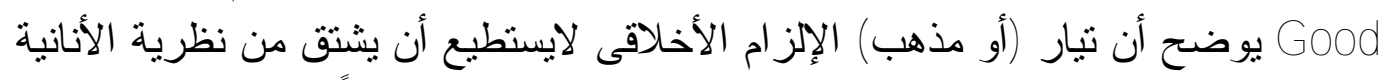

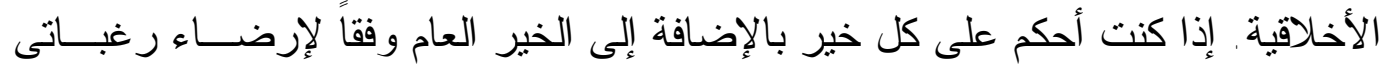

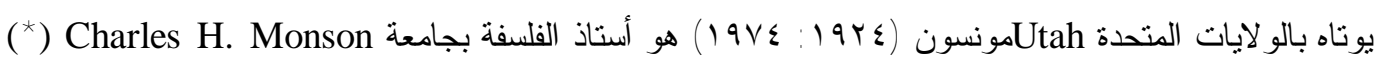
Rocks and men: the problem of freedom

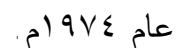

http://philosophy.utah.edu/department history.php(8/8/201) 
الخاصة، فإن إلز امى الخاص سوف يكون لإرضاء إضافى لرغباتى، وو اجبى الوحيد تجاه

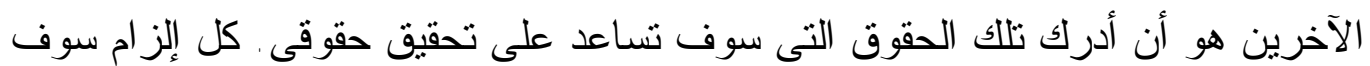

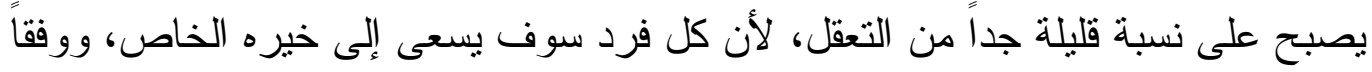

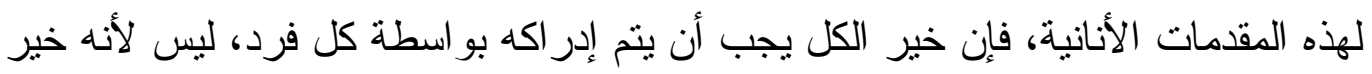

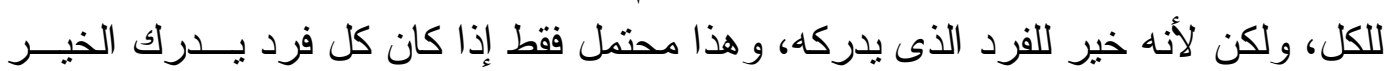

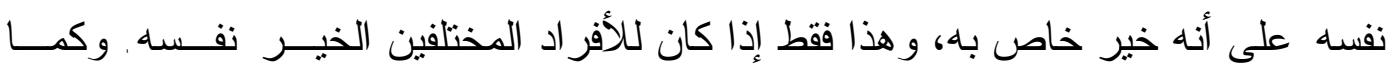

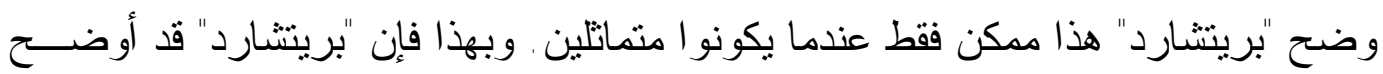

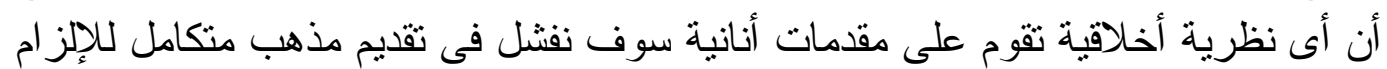

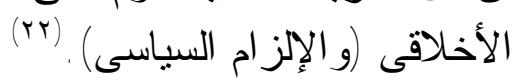

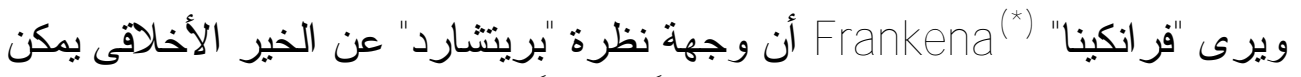

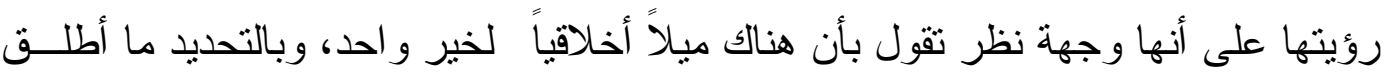

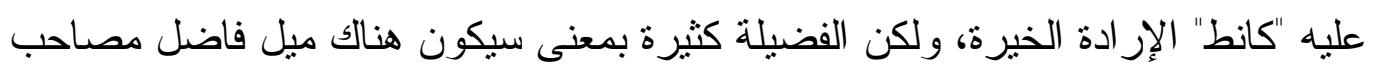

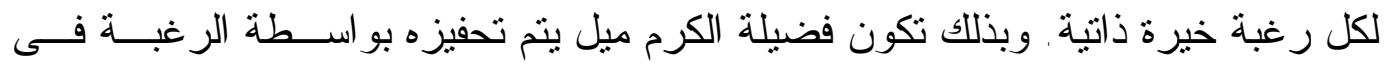

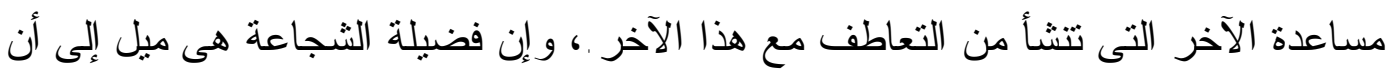

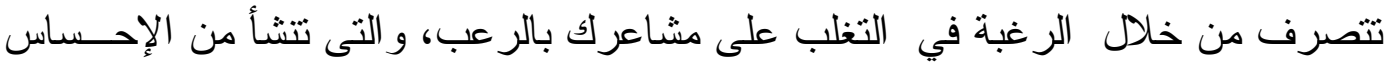

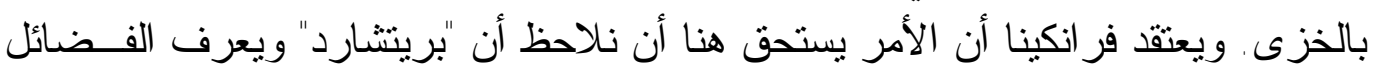

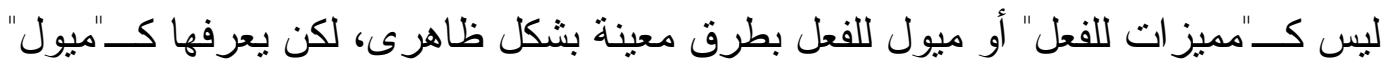

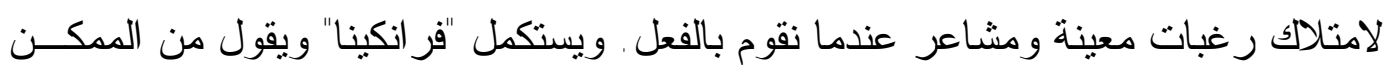

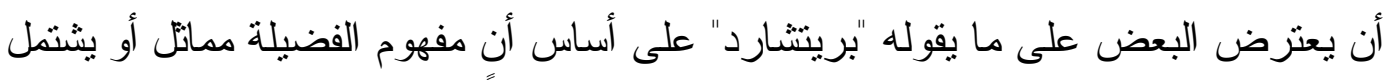

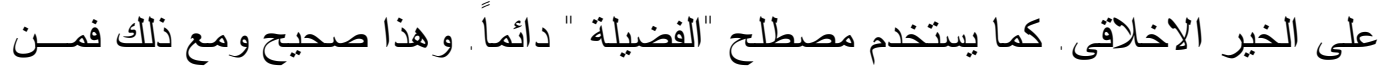

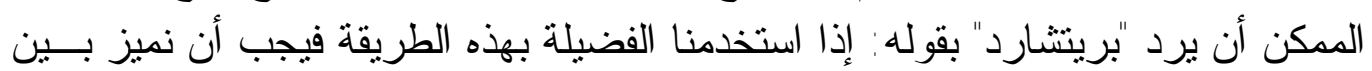

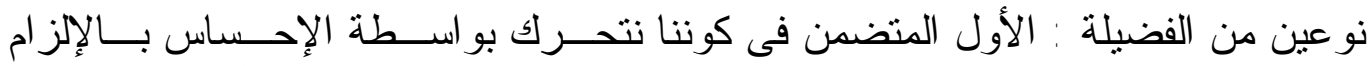

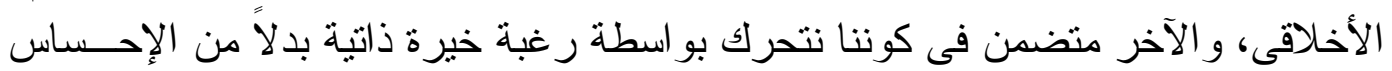

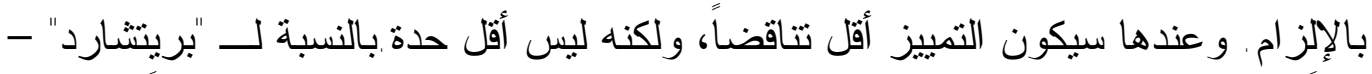

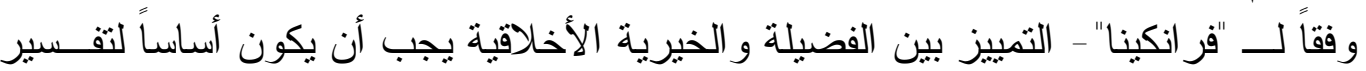

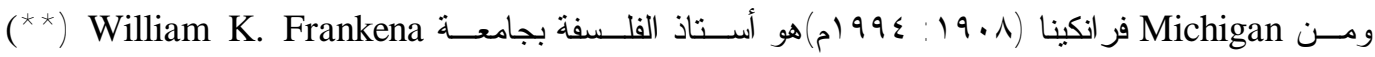

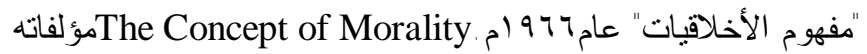
https://lsa.umich.edu/philosophy/undergraduates/prizes/frankena/william-k-frankena.html(8/8/2008) 
و اقعة أن الكثير من الناس محل الإعجاب يعيشون حياتهم بواسطة شئ آخر غير الإحساس

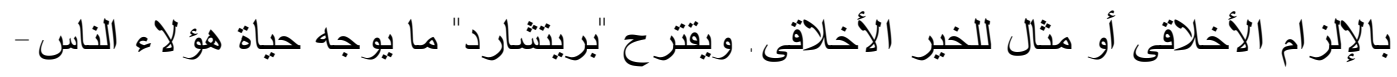

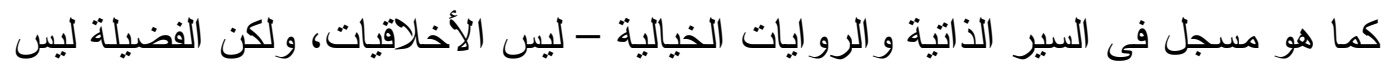

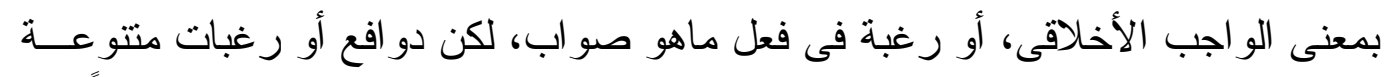

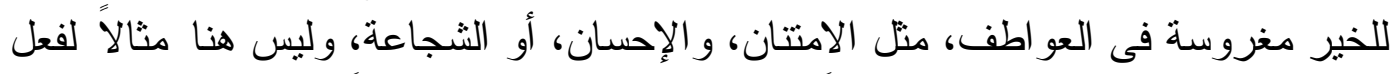

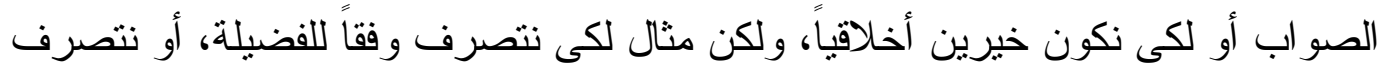

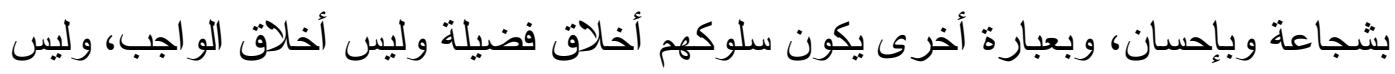

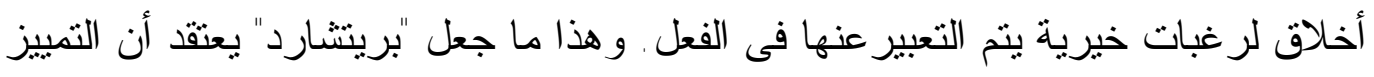

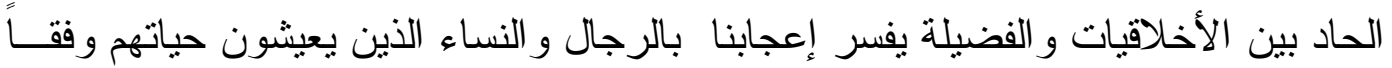

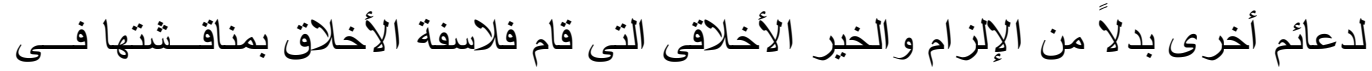

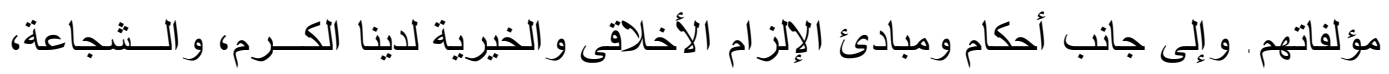

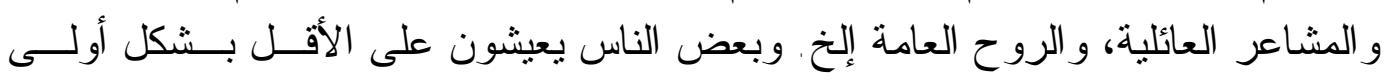

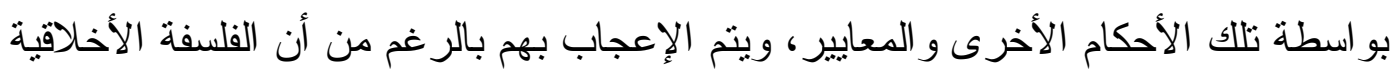

استخفت بهم أو أهملتهم. (rr)

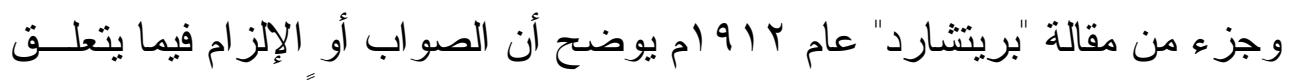

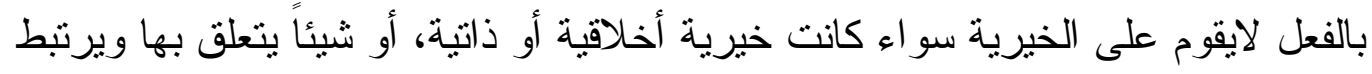

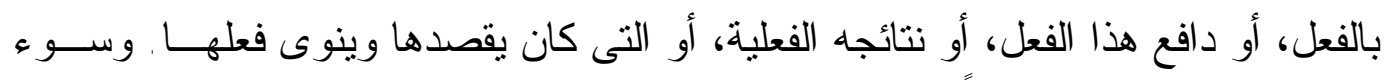

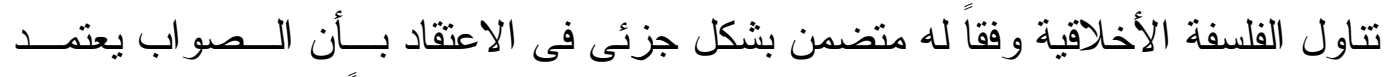

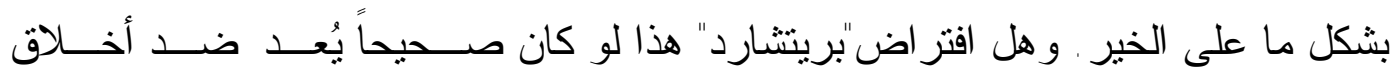

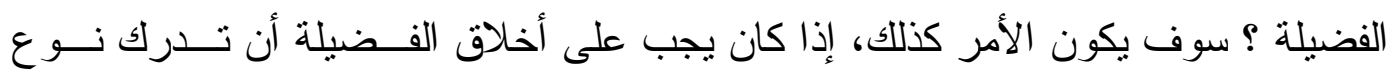

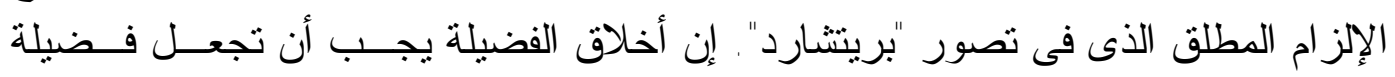

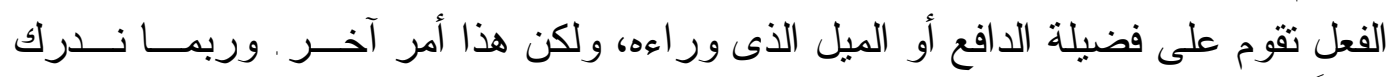

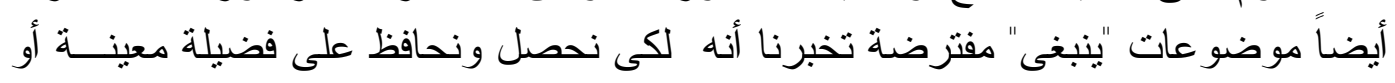

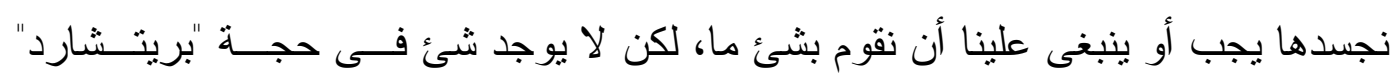

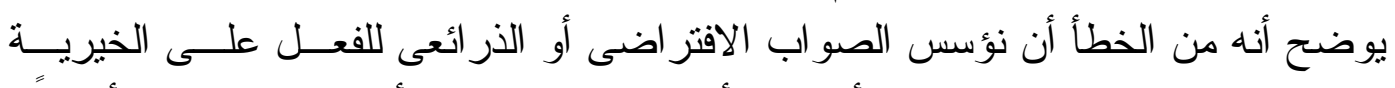

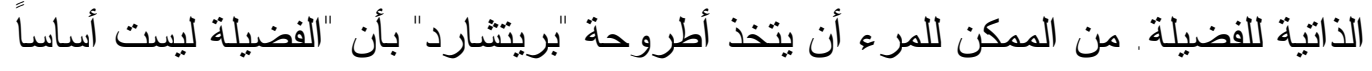

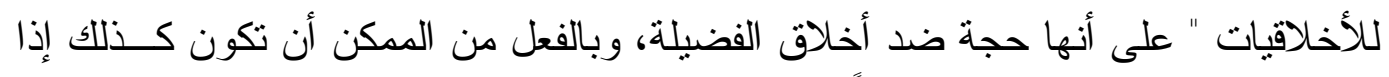

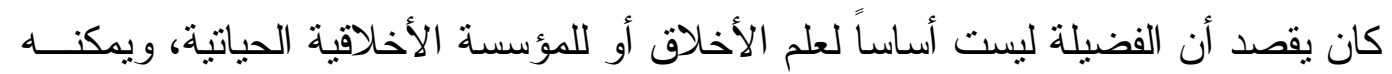




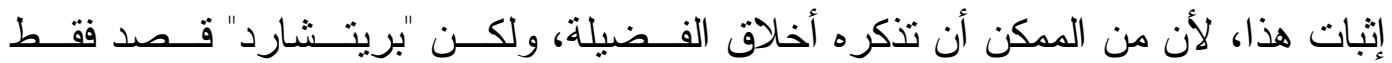

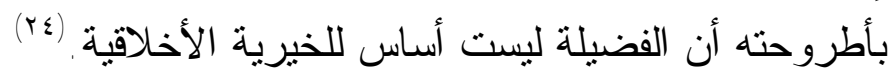

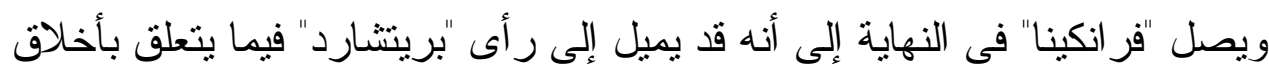

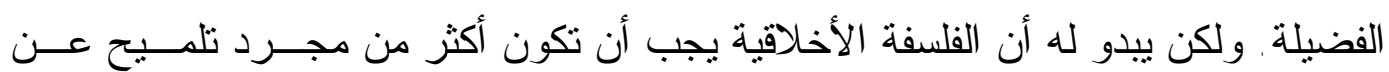

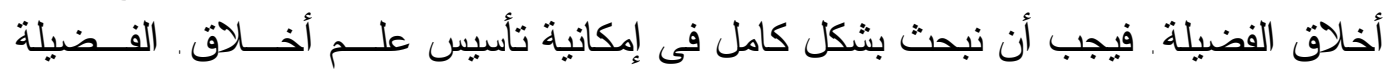

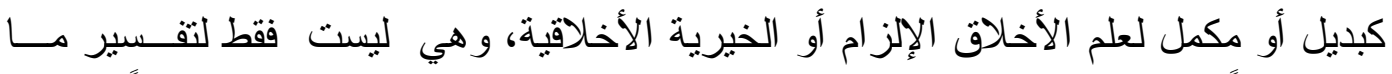

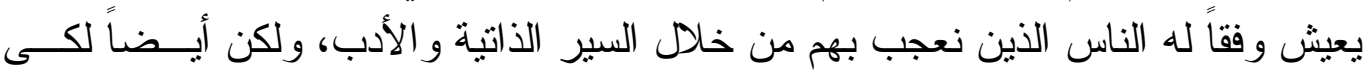

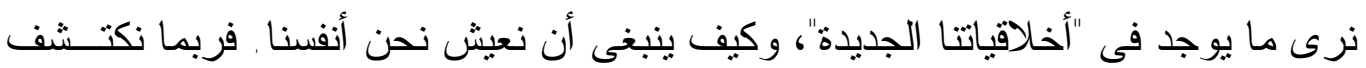

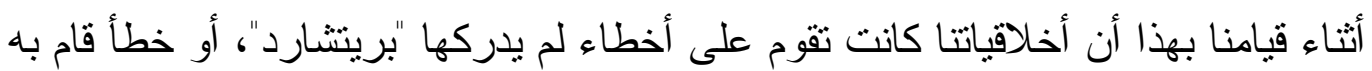

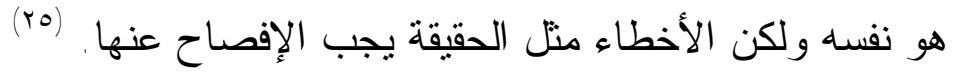

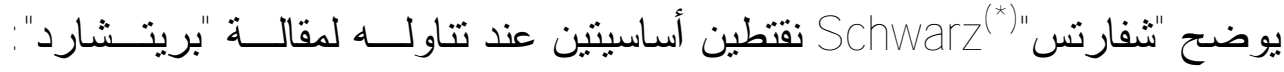

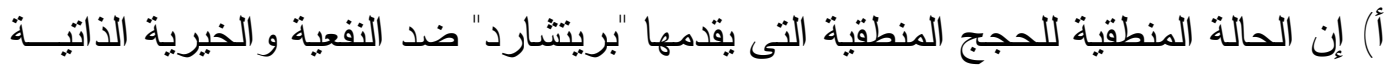

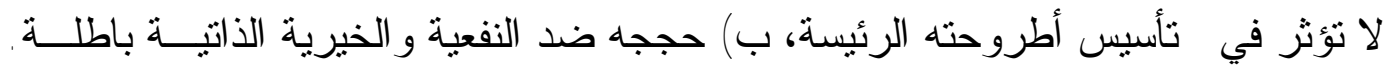

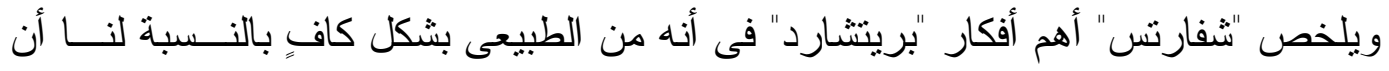

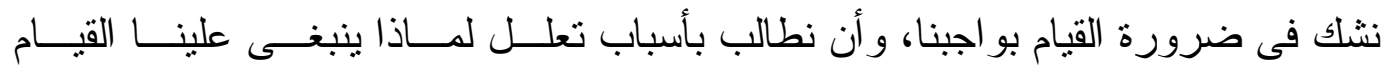

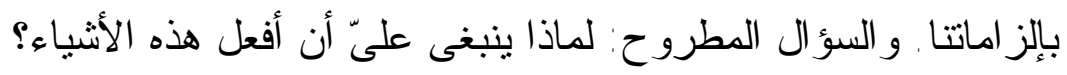

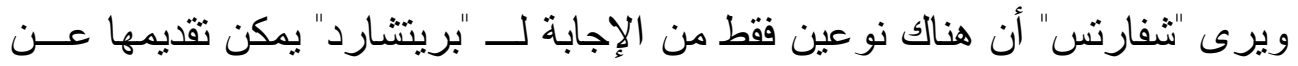

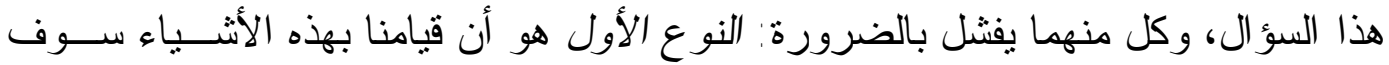

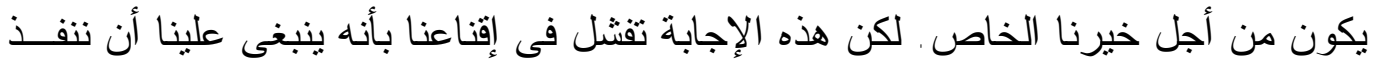

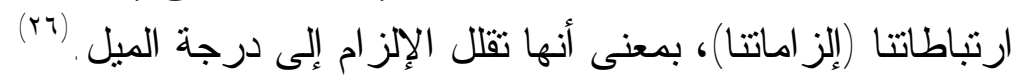

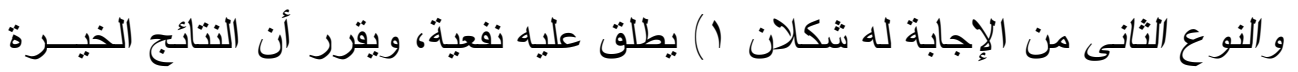

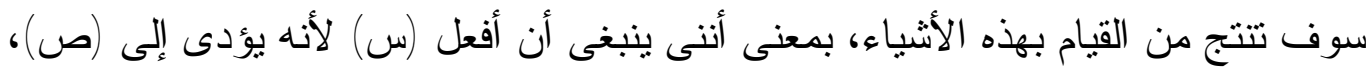

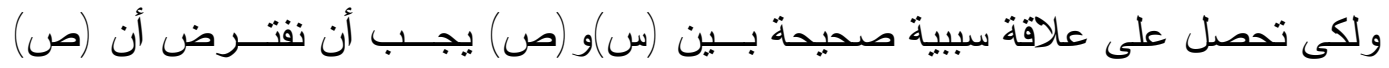

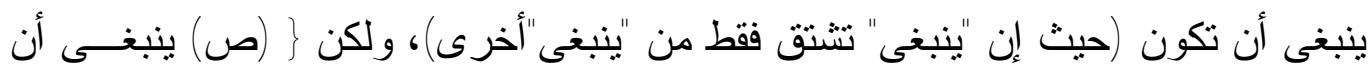

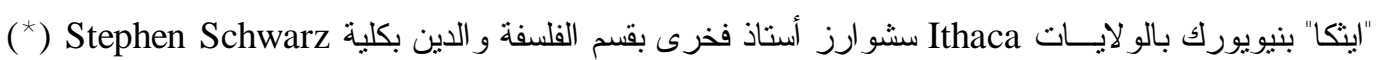
A Brief History of Analytic Philosophy: From Russell to

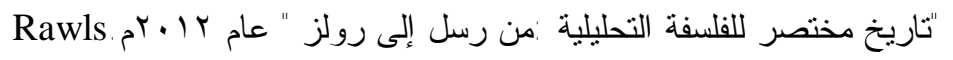
http://faculty.ithaca.edu/sschwart/(8/8/2016)

$$
\text { r.o. }
$$




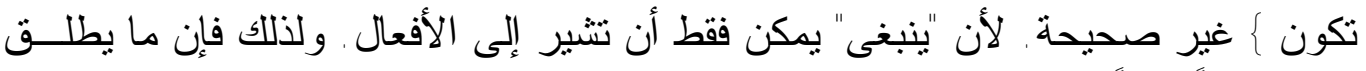

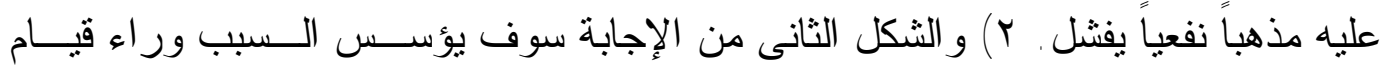

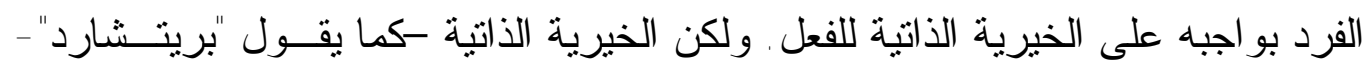

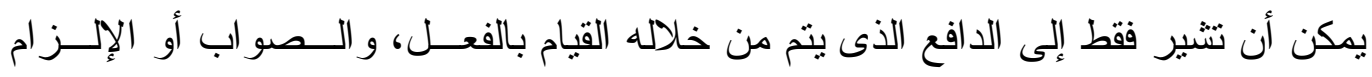

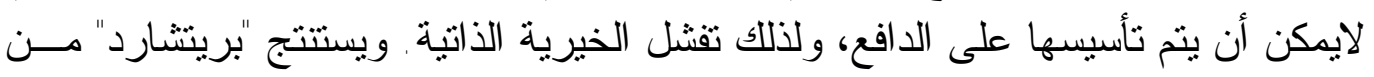

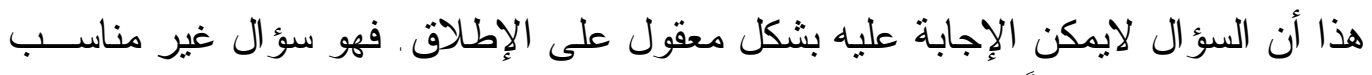

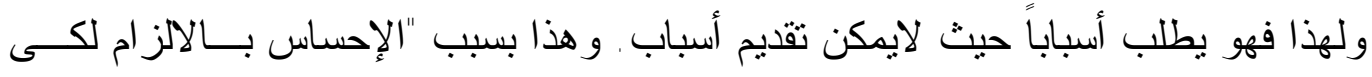

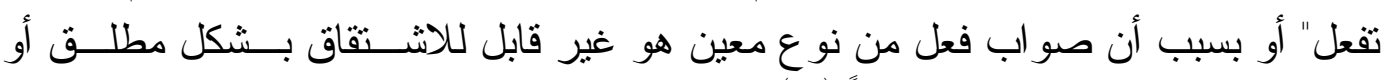
فوري، وتلك الإلز امات مبررة ذاتياً.

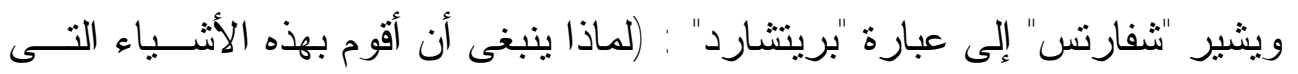

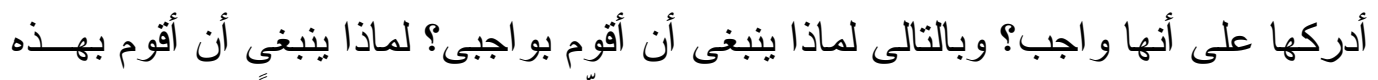

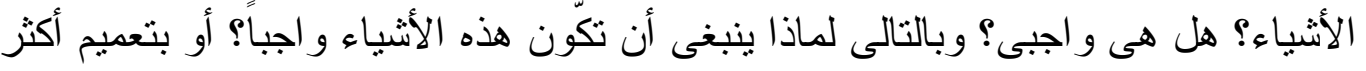

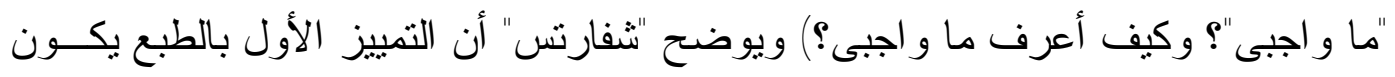

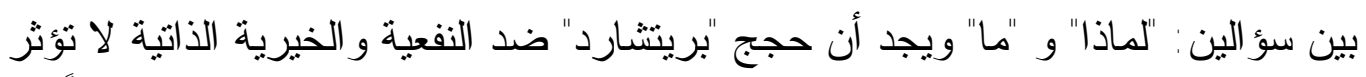

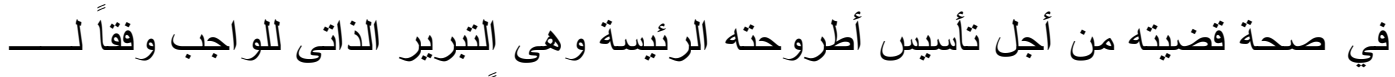

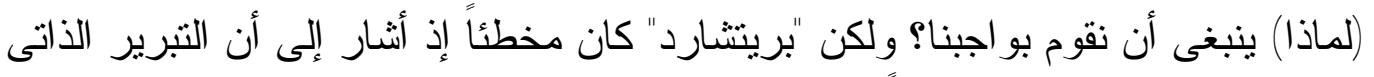

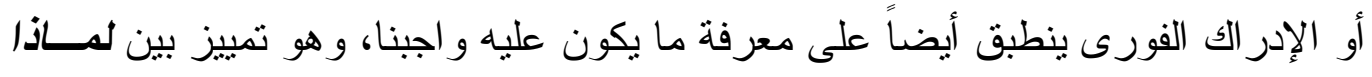

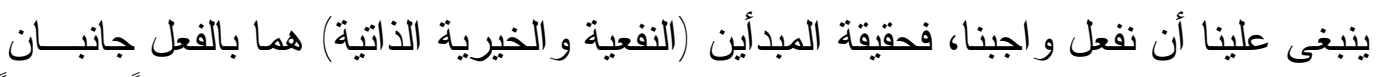
لعملة واحدة، فالمبدأن بالضرورة محددان لأن معرفة ( ما ) يحدد و اجبنا ليس أمر اً مبـــرراً ذاتياً. (rی)

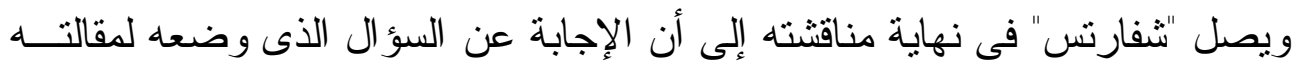

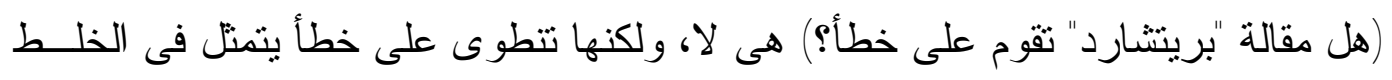

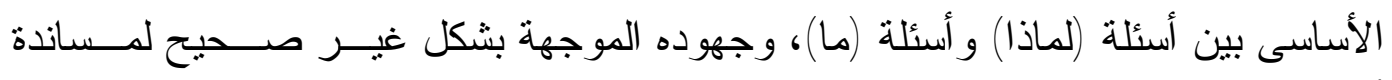

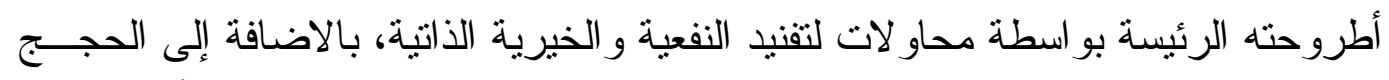

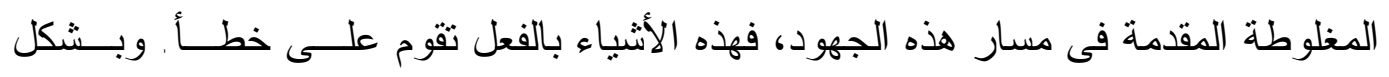

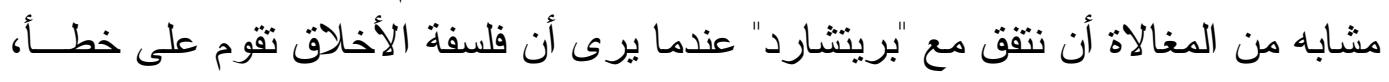

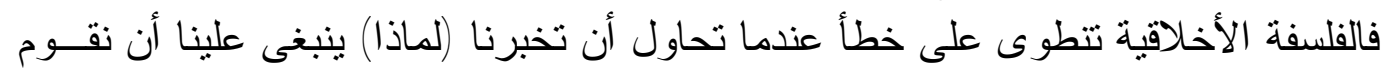

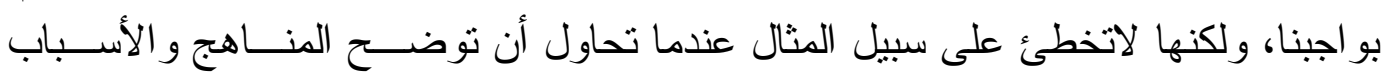


المتعلقة بـــ (ما) يكون عليه و اجبنا، و لاتخطئ أيضـاً عندما تشبر إلى أن محاولة الإجابــة

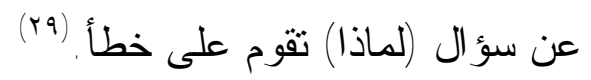

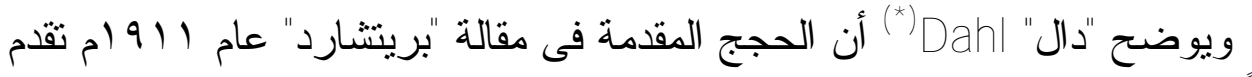

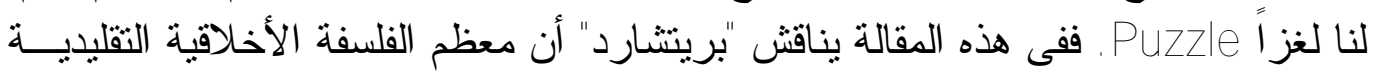

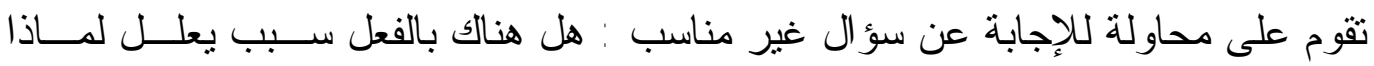

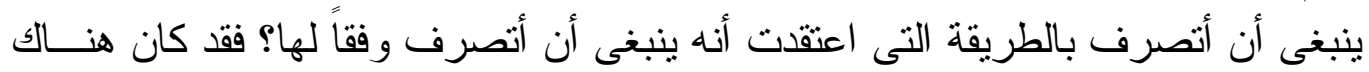

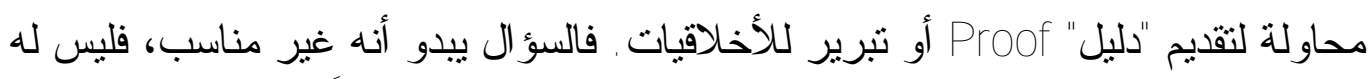

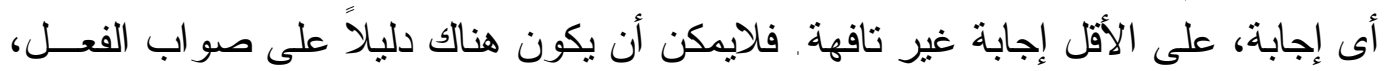

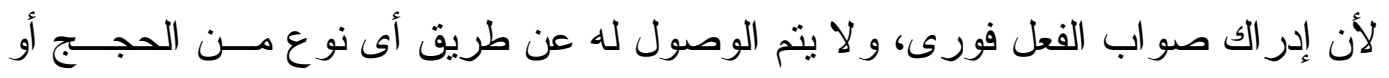

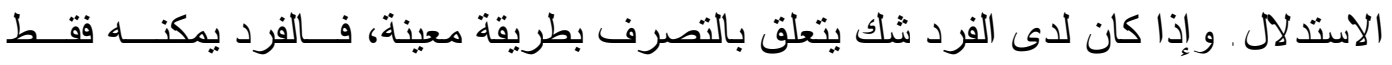

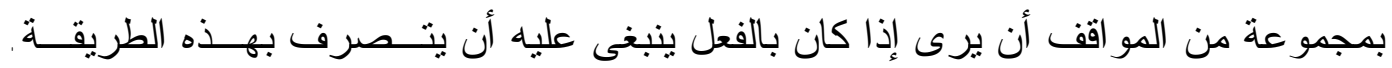

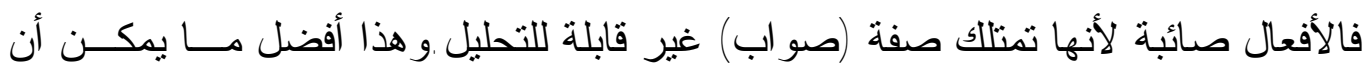

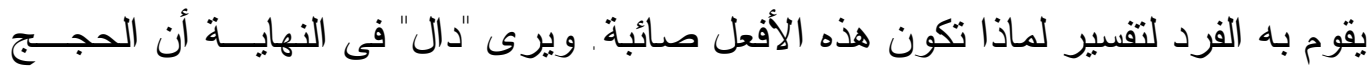

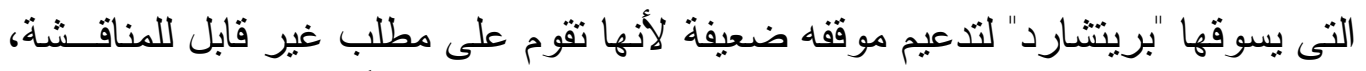

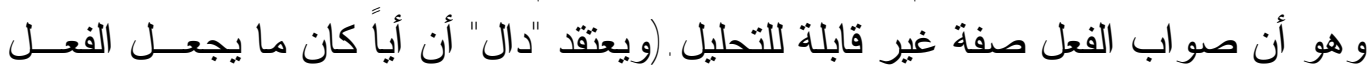

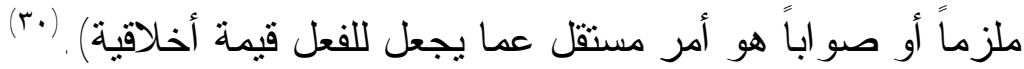

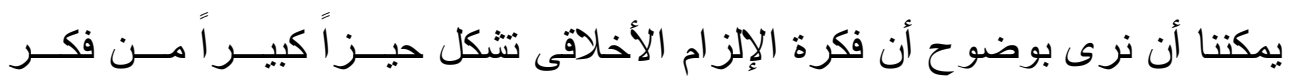

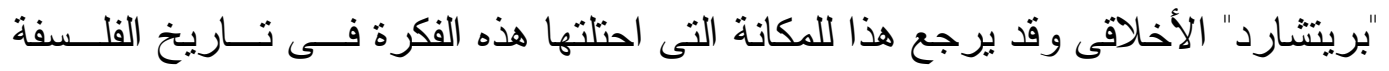

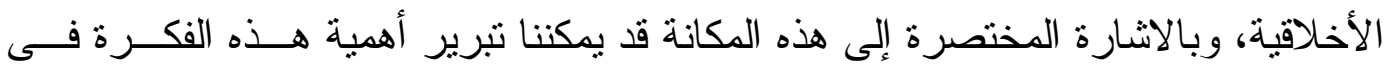

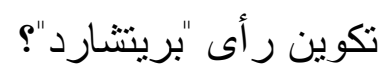

الإلزام الأخلاقى

يرى "بيرتوسى" (Bertocci

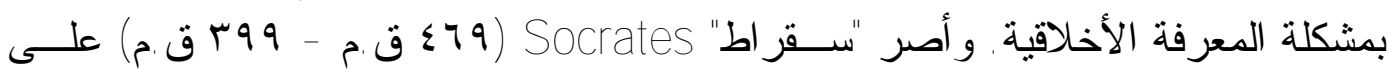

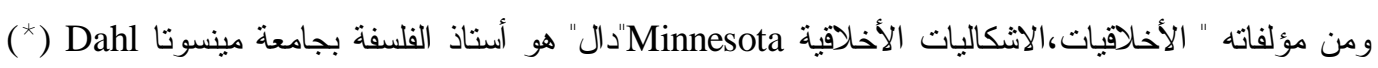

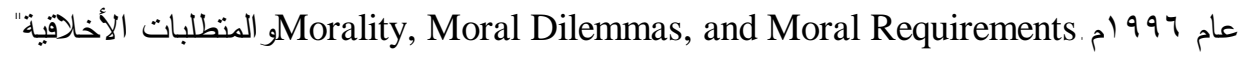
https://cla.umn.edu/about/directory/profile/dahlx005(8/8/2016)

"بيرتوسى"(919 19: • 191م) هو استاذ الفلسفة بجامعة بوسطن ومن مؤلفاته (8) Peter Anthony Bertocci)

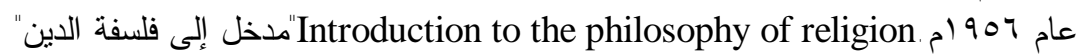
http://www.anthonyflood.com/bertocci.htm(8/8/2016) 


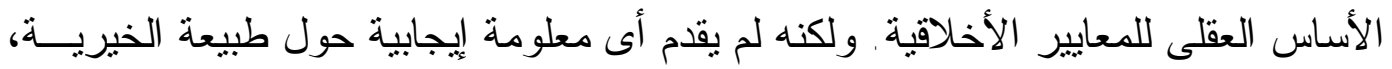

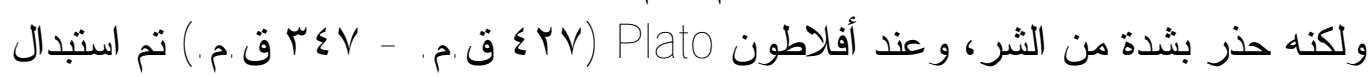

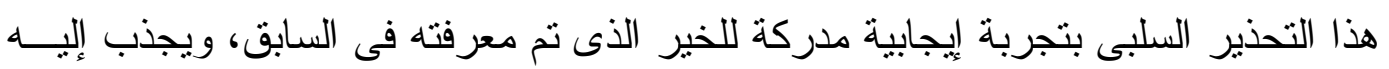

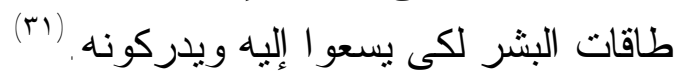

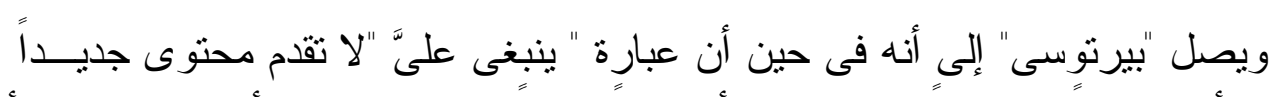

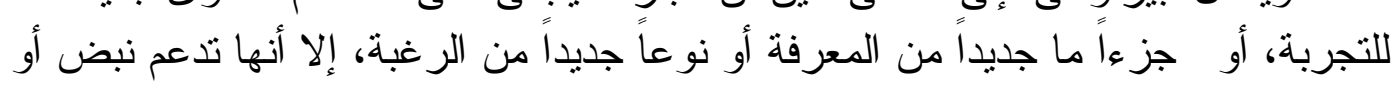

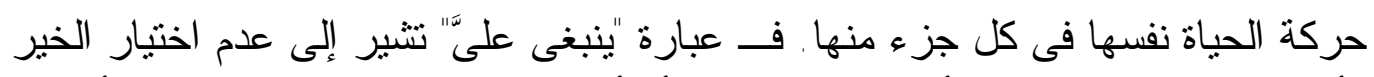

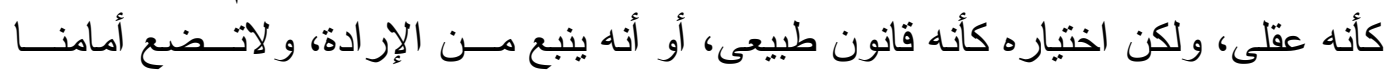

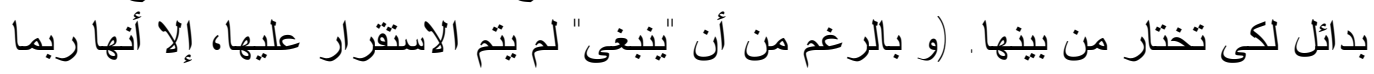

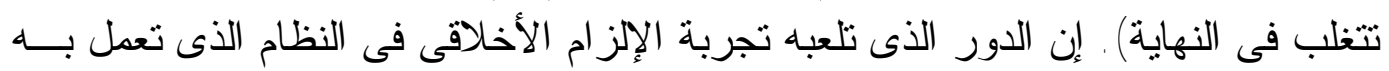

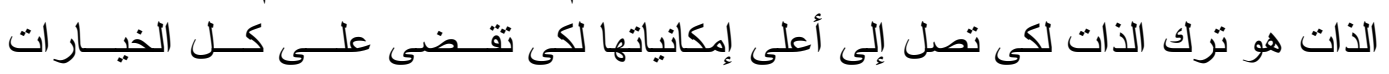

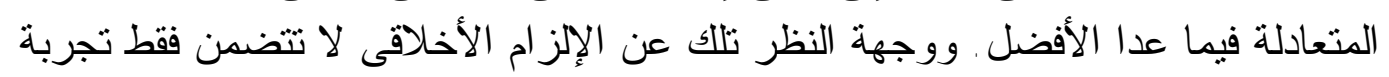

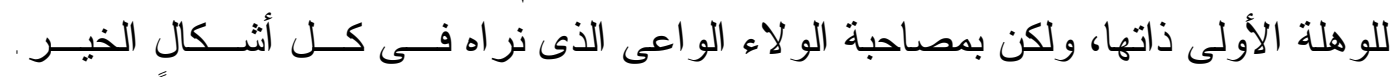

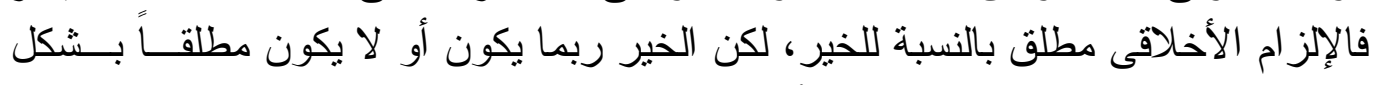

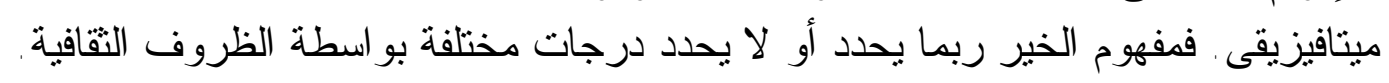

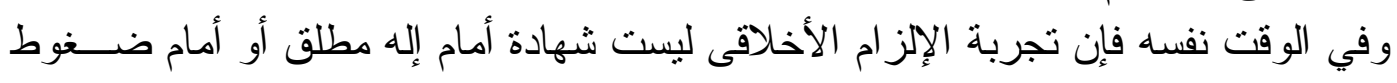

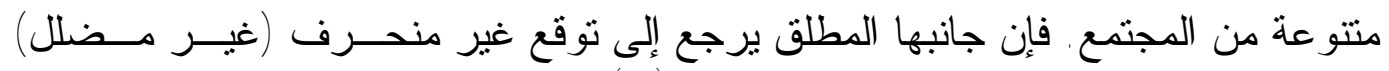

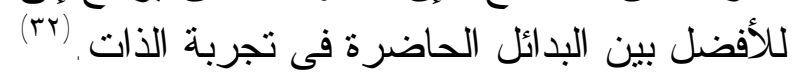

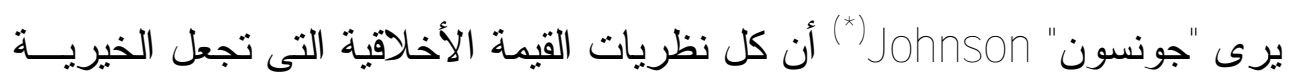

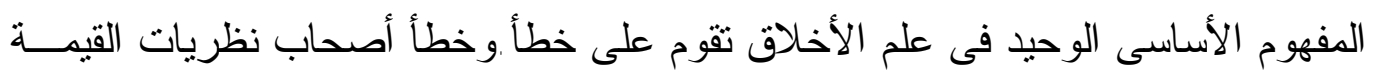

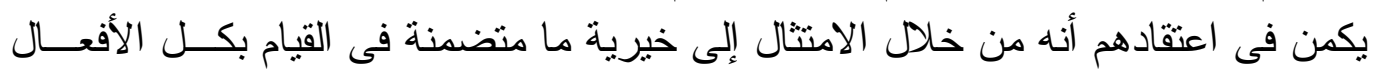

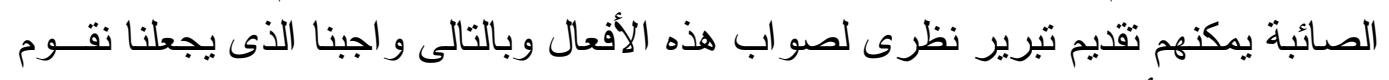

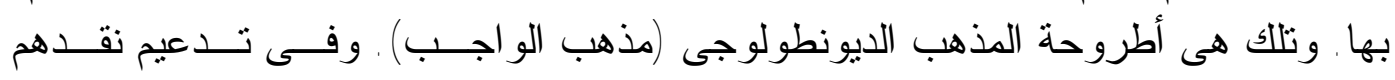

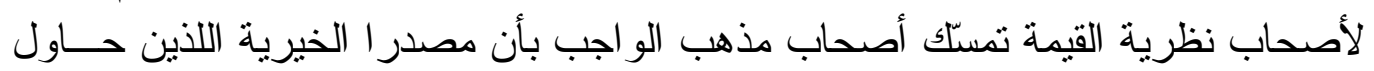

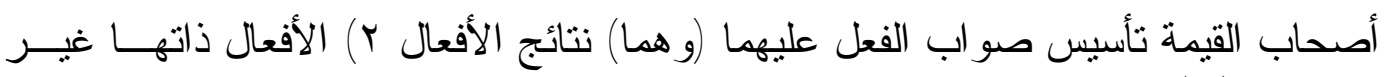
مرضيين. (rr)

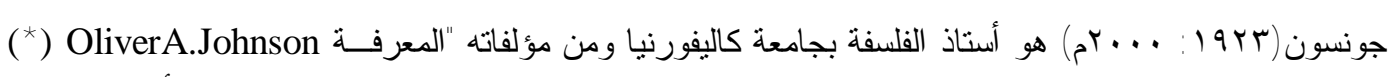
عام Moral Knowledge. الأخلاقية" 1974 http://senate.universityofcalifornia.edu/inmemoriam/OliverA.Johnson.htm(10/8/2016) 


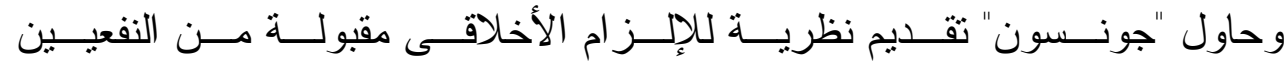

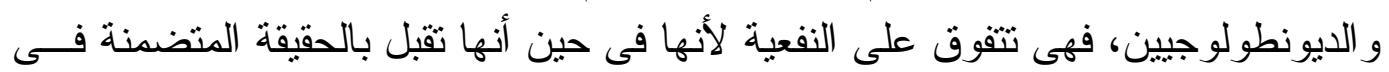

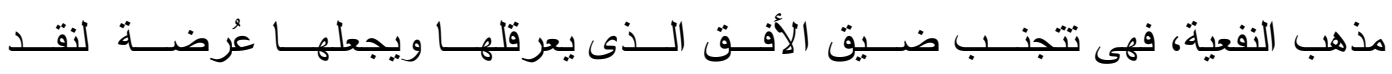

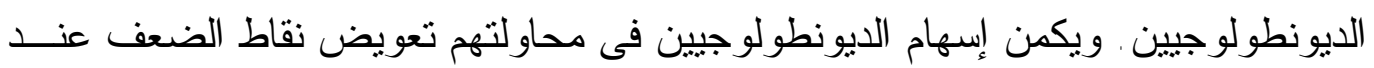

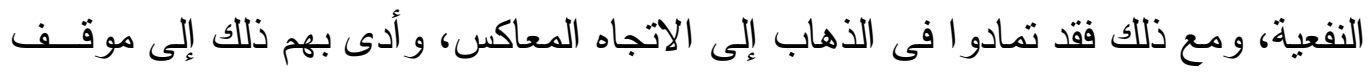

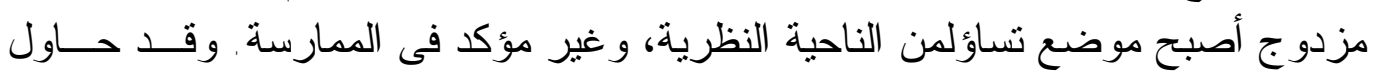

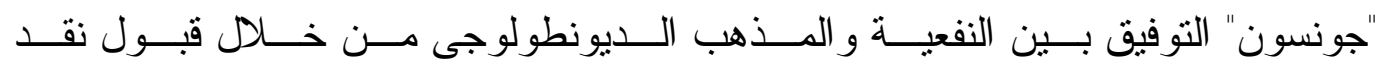

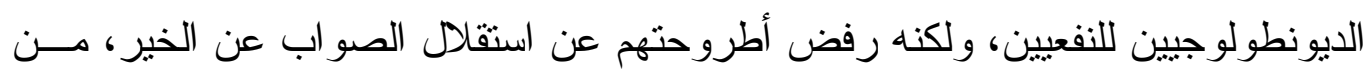

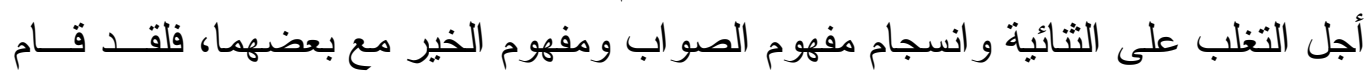

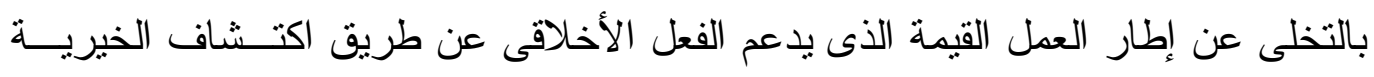

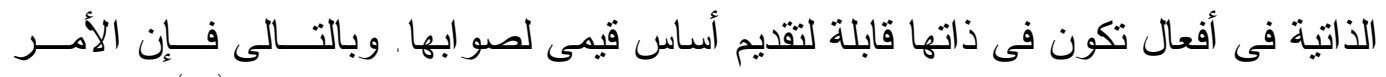

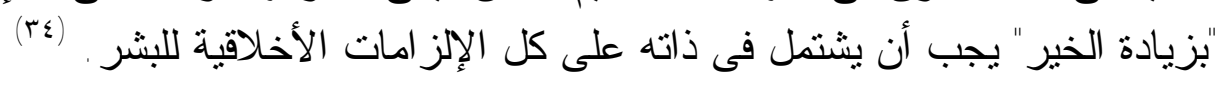

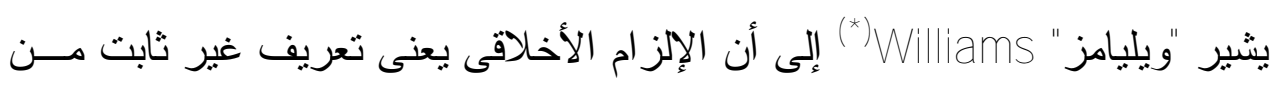

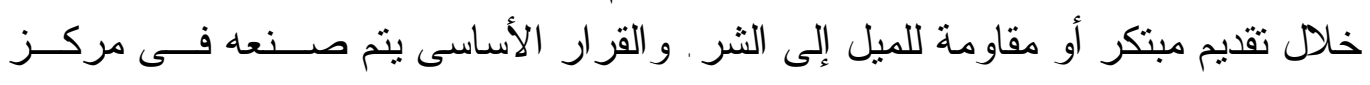

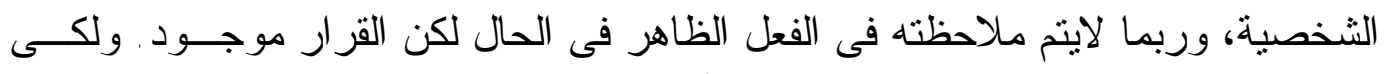

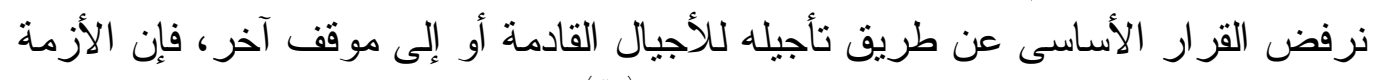

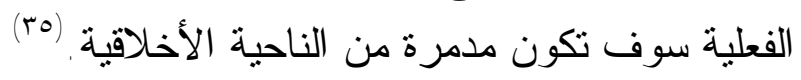

وتقدم الفلسفة العملية نظرية للقيمة تجمع بين كون الإلز ام الأخلاقى مطلقاً إلى جانب

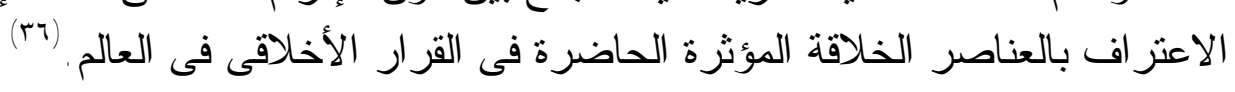

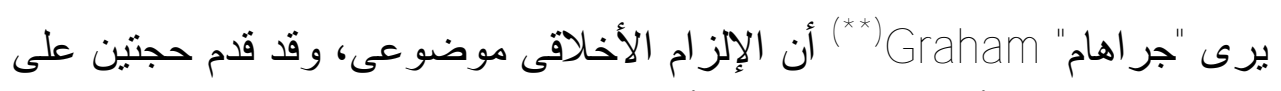

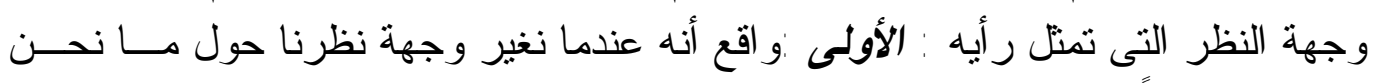

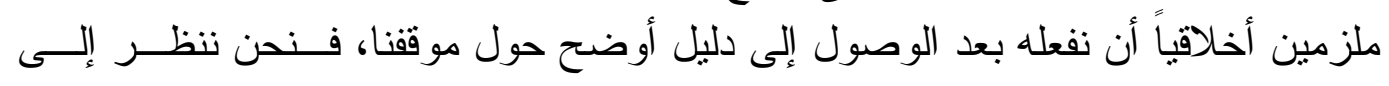

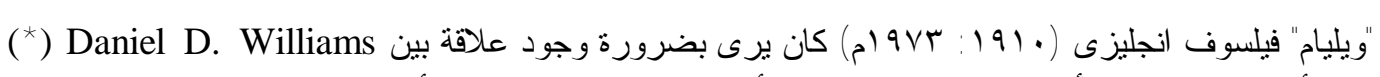

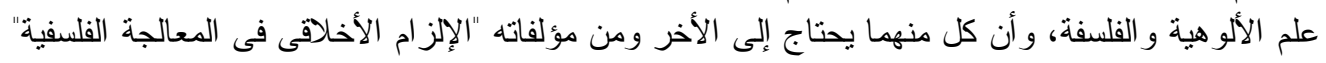

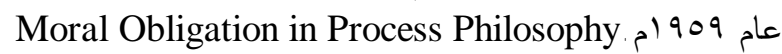

Schwarz,Hans, Theology in Global Context, The Last Two Hundred Years, W.M.B.Eedmans PublisingCo,2005,P.338

http://philpapers.cdp.uwo.ca/s/Daniel\%20D.\%20Williams (10/8/2016)

"جر اهام أستاذ الفلسفة بجامعة نيو يورك ومن مؤلفاته "ينبغى و القدرث" Peter A. Graham (*)

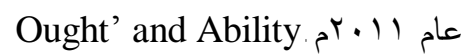

https://www.umass.edu/philosophy/faculty/faculty-pages/graham.htm(10/812016)

$$
\text { r.os }
$$




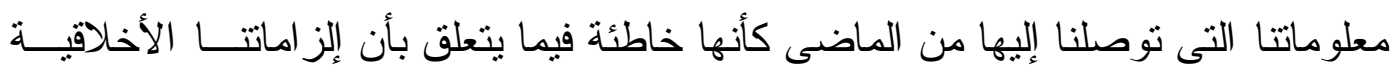

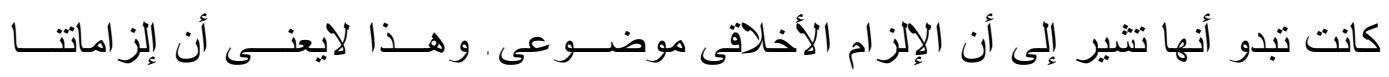
الأخلاقية تغيرت، ولكن هذا يجعلنا فقط نتحقق منها.

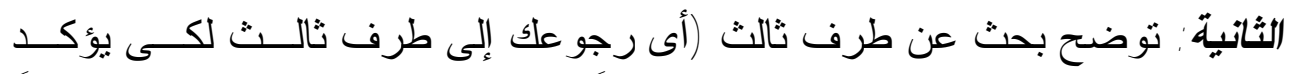

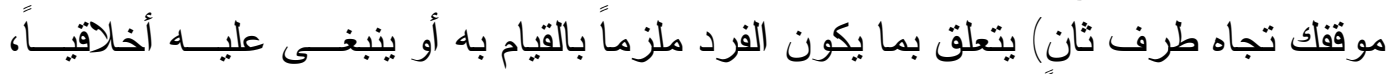

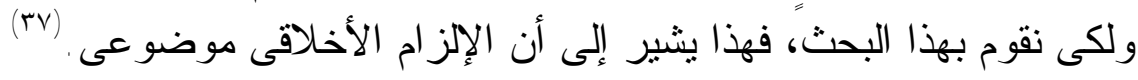

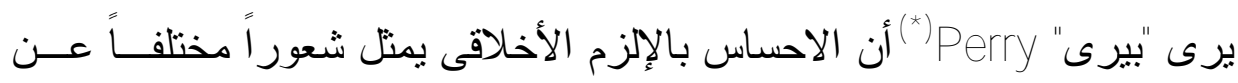

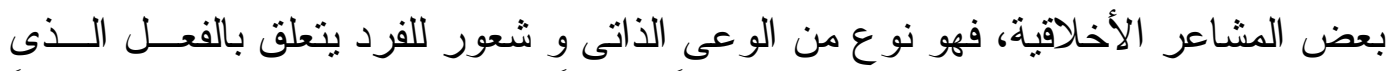

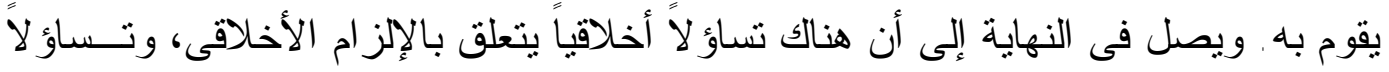

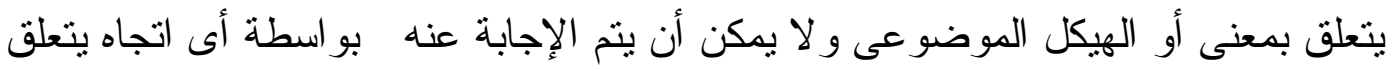

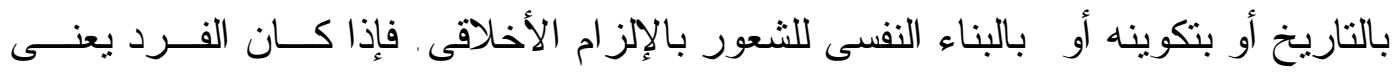

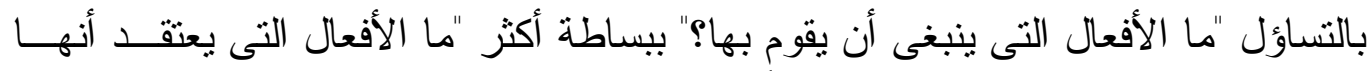

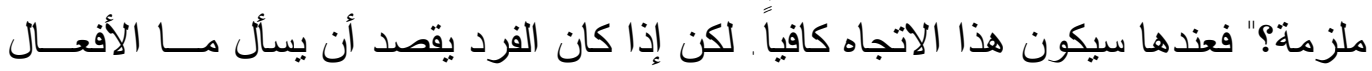

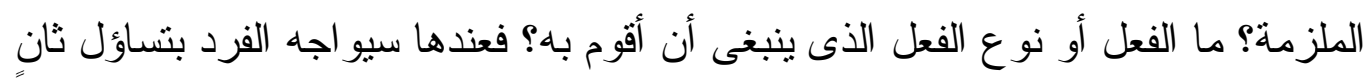

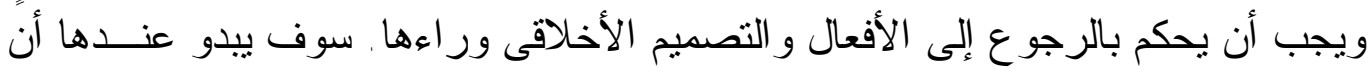

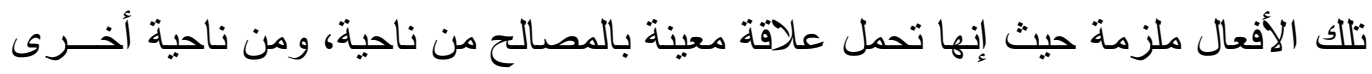

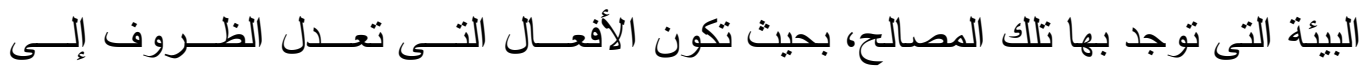

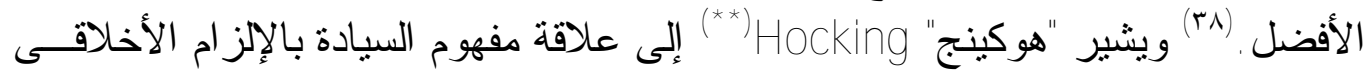

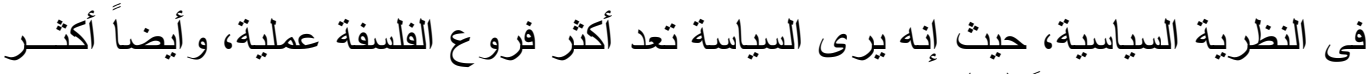
فروع الممارسة تقلسفاً. (ra)

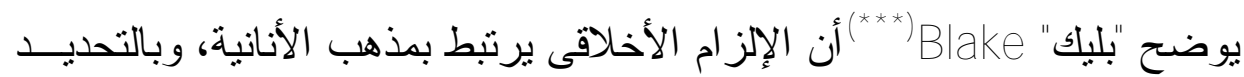

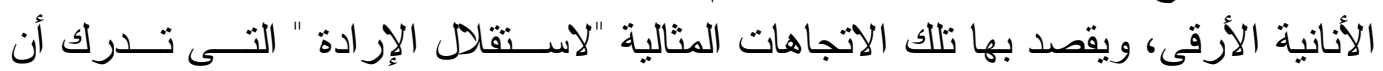

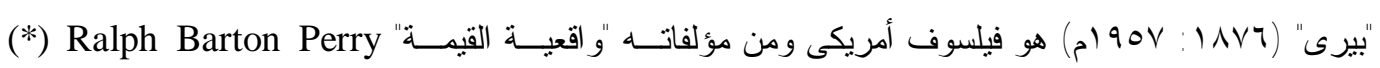
Realms of Value 190 عام https://www.britannica.com/biography/Ralph-Barton-Perry(10/8/2018)

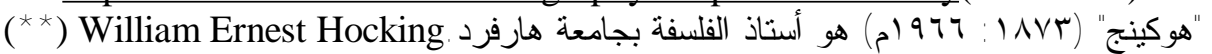
https://macsphere.mcmaster.ca/bitstream/11375/15818/1/Stidsen\%20Catherine.pdf(10 /8/2018)

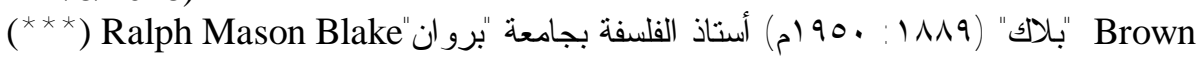
http://www.brown.edu/Administration/News Bureau/Databases/Encyclopedia/search. php?serial=B0260(10/8/2018) 
الذات المتعالية مستمرة فى كل منا، و التى دائماً تتشعر أن من مــصلحتها أن تسـعى إلـى

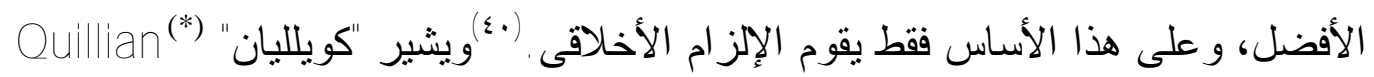

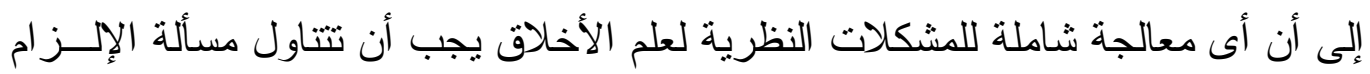

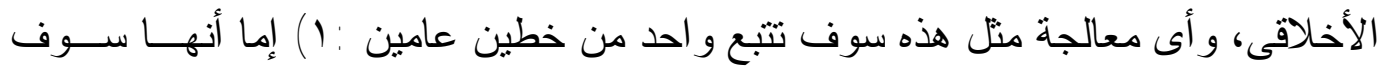

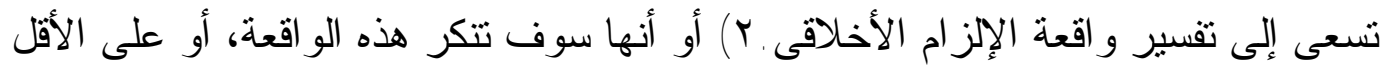

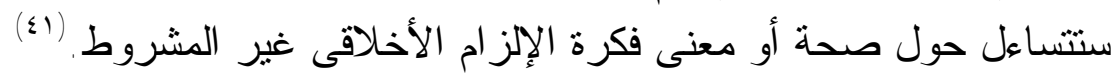
وييحث "ريشير" Rescher

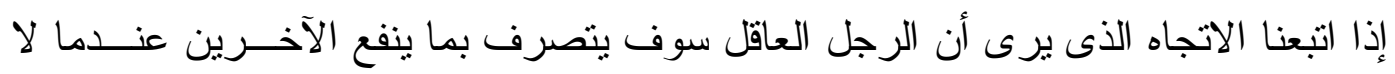

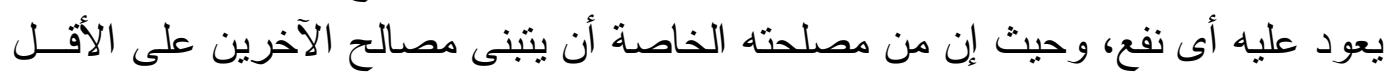

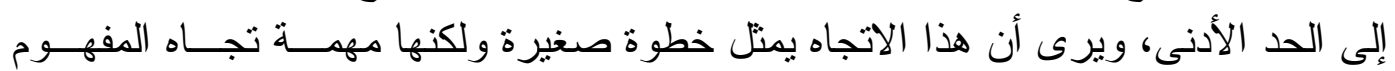
الأكبر للمصلحة الذاتية كما يوضحها إحر اج السجناء

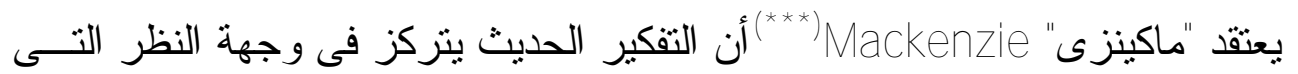

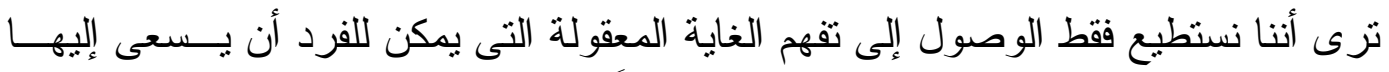

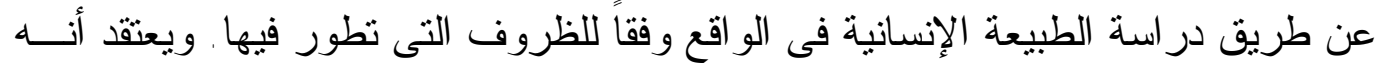

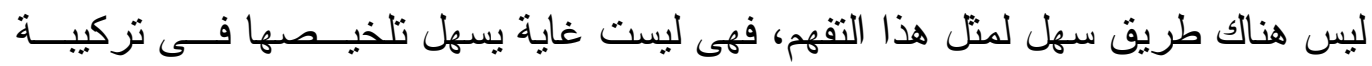

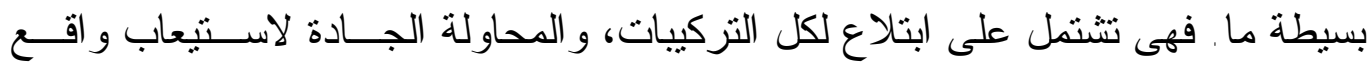

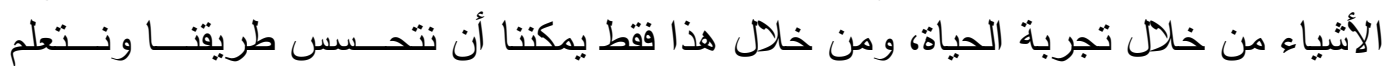

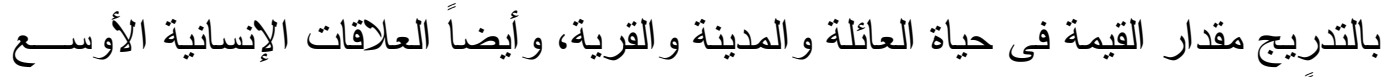

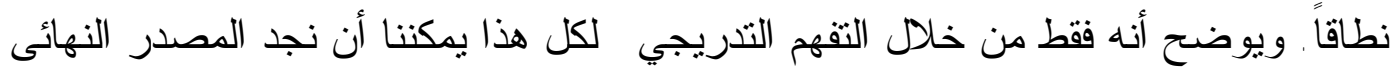

"و Ohio Wesleyan

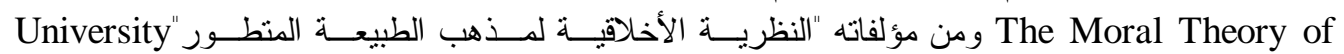

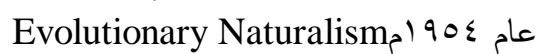
http://tharpfuneralhome.com/dr-william-f-quillian-jr/(10/8/2016)

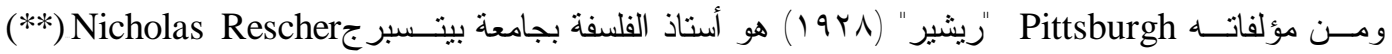

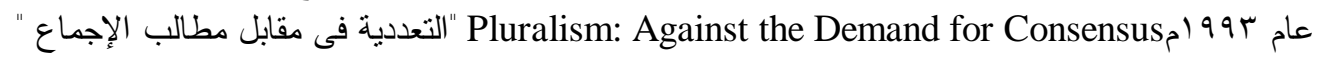
http://www.pitt.edu/ rescher/(10/8/2016)

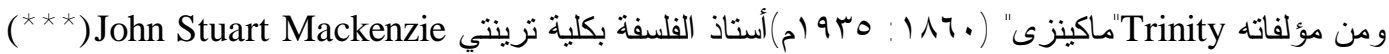

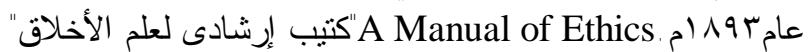
https://www.psa.ac.uk/sites/default/files/JS\%20Mackenzie.pdf(1/8/2016) 
للإلز ام الأخلافى. و الدرس الأكبر الذى تعلمناه من التفكير الحديث هو أن حياتتا هى تطور

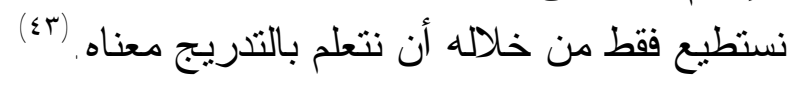

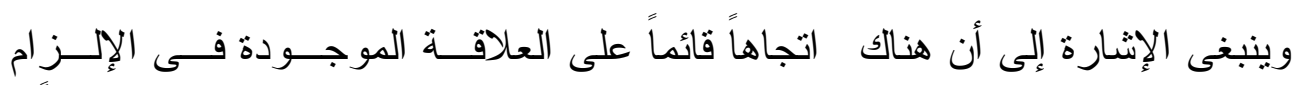

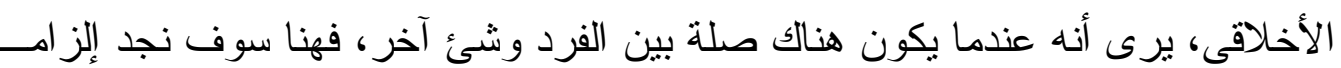

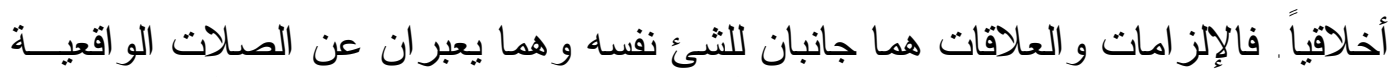

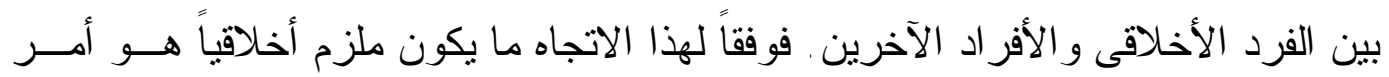

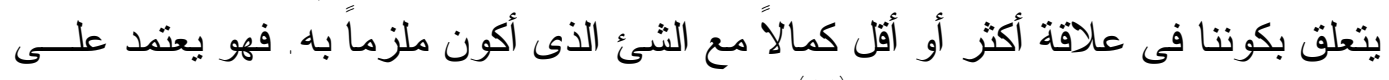

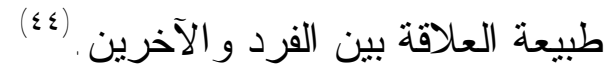

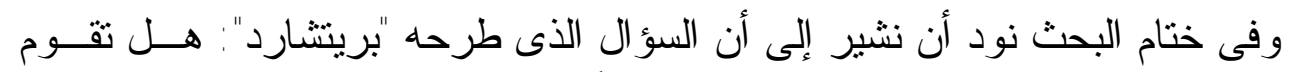

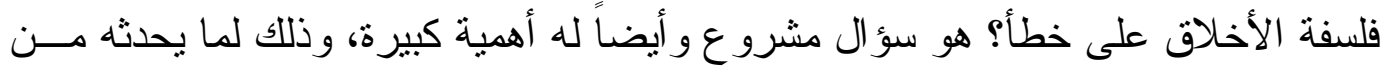

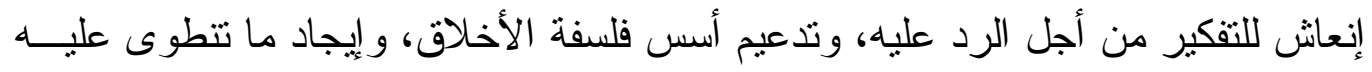

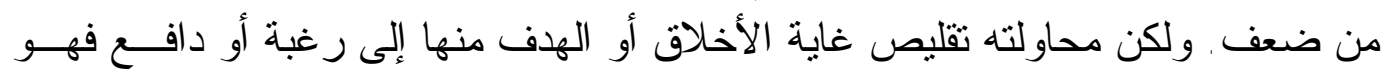

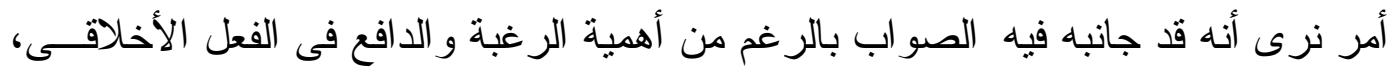

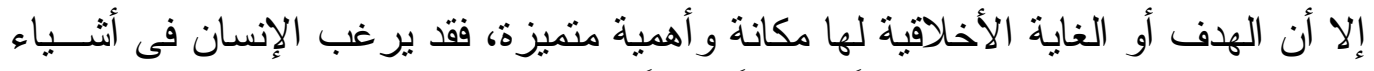

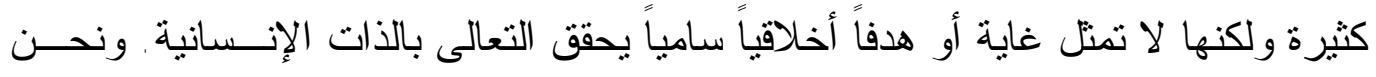

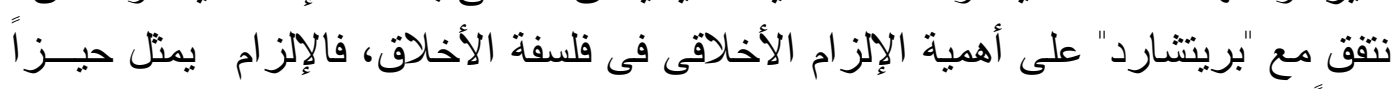

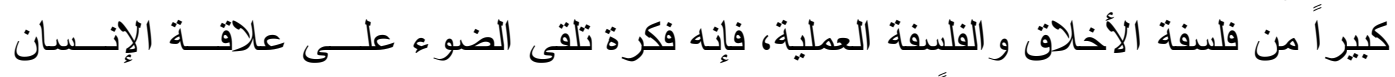

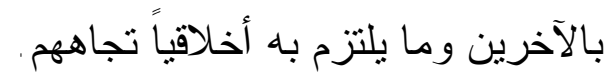


$r .01$

PDF created with pdfFactory Pro trial version www.pdffactory.com 
(1) Prichard, H. A, Does Moral Philosophy Rest on A Mistake?, Mind,Vol.21 ,No.81, Jan, Oxford University Press on Behalf of The Mind Association, 1912, p.21.

(2) Ibid, p.22.

(3) Opt. cit, p.23.

(4) Prichard, H. A, Does Moral Philosophy Rest on A Mistake?, p.24.

(5) Ibid, p.27.

(6) Opt. cit, p.28.

(7) Prichard, H. A, Does Moral Philosophy Rest on A Mistake?, p.30.

(8) Ibid, p.31.

(9) Opt. cit, p. $33: 34$

(10) Prichard,H.A,Does Moral Philosophy Rest on A Mistake?,p.36:37.

(11) Prichard, H. A, The Meaning of yaøóvà in the "Ethics" of Aristotle, philosophy, Vol.10, No.37 (Jan., 1935) Cambridge university press,p.27.

(12) Ibid, p.28:29

(13) Opt.cit,p. 34.

(14) Prichard,H.A,The Meaning of yaøóvà in the "Ethics" of Aristotle,p.35.

(15) Ibid,p.38

(16) Opt.cit,p. 39.

(17) Carritt, E. F, Professor H. A. Prichard. Personal Recollections, Mind, Vol.57, No.226, Apr., Oxford University Press, 1948, p. 147.

(18) Hawkins,D.J.B,The Ethics of H.A.Prichard,The Philosophical Quarterly ,Vol.1,No.3(Apr.,)Oxford University Press,1951,p.243.

(19) Ibid,p.244

(20) Opt.cit,p. 245.

(21) Hawkins,D.J.B,The Ethics of H.A.Prichard,p.247.

(22) Monson, Charles H., Jr, Prichrd, Green, and Moral Obligation, the philosophical review, Vol.63, No.1(Jan), Duke university press, 1954, p.87.

(23) Frankena, William, Prichard and The Ethics of Virtue, Notes on A footnote, the Monist, Vol.54, No.1,Virtue and Moral Goodness, (January) Oxford University press, 1970, p.2:4 
(24) Ibid,p.11:12.

(25) Opt.cit,p.17.

(26) Schwarz, Stephen D., Does Prichard's Essay rest on A Mistake?, Ethics,Vol.81, No.2 (Jan), University of Chicago Press, 1971, p.169

(27) Ibid,p.170.

(28) Opt.cit,p.171:172.

(29) Schwarz, Stephen D., Does Prichard's Essay rest on A Mistake?, p. 179:180

(30) Dahl, Norman O. Obligation and Moral Worth: Reflections on Prichard and Kant, Philosophical Studies: An International Journal for Philosophy in the Analytic Tradition,Vol.50,No.3,Symposium on Rationalityand Moral Values(Nov.),Springer, 1986,p.372.

(31) Bertocci, Peter A.,A Reinterpretation of Moral Obligation, Philosophy and Phenomenological Research,Vol.6,No.2 (Dec), International Phenomenological Society,1945,p.270

(32) Ibid,p.282.

(33) Johnson, Oliver A, Rightness, Moral Oligation, and Goodness, The Journal of philosophy, Vol.50, No.20 (Sep.24), Journal of philosophy, Inc, 1953,p.597.

(34) Ibid, p.607:608.

(35) Williams, Daniel D., Moral Obligation in Process Philosophy, The Journal of philosophy, Vol.56, No.6 (Mar.12), Journal of philosophy, Inc, 1959 ,P.369

(36) Ibid,p.270.

(37) Graham, Peter A., In defense of Objectivism about Moral Obligation, Ethics,Vol.121,No.1(October), The University of Chicago Press, 2010, p.115

(38) Perry, Ralph Barton, The Question of Moral Obligation, International Journal of Ethics,Vol.21, No.3(Apr,),The University of Chicago press,1911, p.293.

(39) Hocking ,W. E, Sovereignty and Moral obligation, International Journal of ethics, Vol.28, No.3(Apr.) the university of Chicago press, 1918, p.315.

(40) Blake, Ralph M., The Ground of Moral Obligation, International Journal of Ethics, Vol.39, No.2 (Jan) the University of Chicago Press,1928, p.140.

(41) Quillian,William F, Jr, the Problem of Moral Obligation, Ethics, Vol.60, No.1 (Oct), The university of Chicago Press,1949,p.40. 
(42) Rescher, Nicholas, Rationality and Moral Obligation, Vol.72, No.1, Kurt Baier Festchrift, Part.1 (Jul,) Springer,1987,p.42.

(43) Mackenzie, J.S, the Source of Moral Obligation, International Journal of Ethics, Vol.10, No.4 (Jul,), the University of Chicago Press, 1900, p.476.

(44) Reader, Soran, Distance, Relationship and Moral Obligation, The Monist, Vol.86, No.3, Moral Distance (July), Oxford University Press, 2003, P.379. 


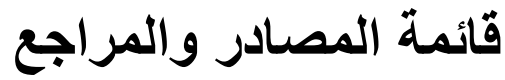

أولاً المراجع والمصادر الأجنبية:

1- Blake,Ralph M., The Ground of Moral Obligation, International Journal of Ethics, Vol.39, No.2 (Jan) the University of Chicago Press, 1928.

2- Bertocci, Peter A., A Reinterpretation of Moral Obligation, Philosophy and Phenomenological Research, Vol.6, No.2 (Dec), International Phenomenological Society, 1945.

3- Carritt, E. F, Professor H. A. Prichard. Personal Recollections, Mind, Vol.57, No.226, Apr., Oxford University Press, 1948

4- Dahl, Norman O., Obligation and Moral Worth: Reflections on Prichard and Kant, Philosophical Studies: An International Journal for Philosophy in the Analytic Tradition, Vol.50, No.3, Symposium on Rationalityand Moral Values (Nov.), Springer, 1986 ,

5- Frankena, William, Prichard and The Ethics of Virtue, Notes on A footnote, the Monist, Vol.54, No.1, Virtue and Moral Goodness, (January) Oxford University press, 1970.

6- Graham, Peter A., In defense of Objectivism about Moral Obligation, Ethics, Vol.121, No.1 (October), The University of Chicago Press, 2010.

7- Hawkins, D.J.B, The Ethics of H. A. Prichard, The Philosophical Quarterly, Vol.1, No.3 (Apr.,) Oxford University Press, 1951.

8- Hocking, W. E, Sovereignty and Moral obligation, International Journal of ethics,Vol.28,No.3(Apr.)the university of Chicago press, 1918

9- Johnson, Oliver A, Rightness, Moral Oligation, and Goodness, The Journal of philosophy, Vol.50, No.20 (Sep.24), Journal of philosophy, Inc,1953.

10- Mackenzie, J.S, the Source of Moral Obligation, International Journal of Ethics,Vol.10, No.4 (Jul,), the University of Chicago Press, 1900.

11- Mautner, Thomas, The Penguin Dictionary of philosophy, Penguin Books, 1997.

12- Monson,Charles H., Jr, Prichrd, Green, and Moral Obligation, the philosophical review, Vol.63,No.1 (Jan), Duke university press, 1954. 
13- Perry, Ralph Barton, The Question of Moral Obligation, International Journal of Ethics, Vol.21, No.3 (Apr,), The University of Chicago press, 1911.

14- Prichard, H. A, Does Moral Philosophy Rest on A Mistake?, Mind, Vol.21, No.81, Jan, Oxford University Press on Behalf of The Mind Association, 1912.

15- Prichard, H. A, The Meaning of yaøóvà in the "Ethics" of Aristotle, philosophy, Vol.10, No.37 (Jan.,) Cambridge university press, 1935 .

16- Quillian, William F, Jr, the Problem of Moral Obligation, Ethics, Vol.60, No.1 (Oct), The university of Chicago Press, 1949.

17- Reader, Soran, Distance, Relationship and Moral Obligation, The Monist, Vol.86, No.3, Moral Distance (July), Oxford University Press, 2003.

18- Rescher, Nicholas, Rationality and Moral Obligation,Vol.72, No.1, KurtBaier Festchrift, Part.1 (Jul,) Springer,1987.

19- Schwarz, StephenD., Does Prichard's Essay rest on A Mistake?, Ethics, Vol.81, No.2 (Jan), University of Chicago Press, 1971.

20- Williams, Daniel D., Moral Obligation in Process Philosophy, The Journal of philosophy, Vol.56, No.6 (Mar.12), Journal of philosophy, Inc, 1959.

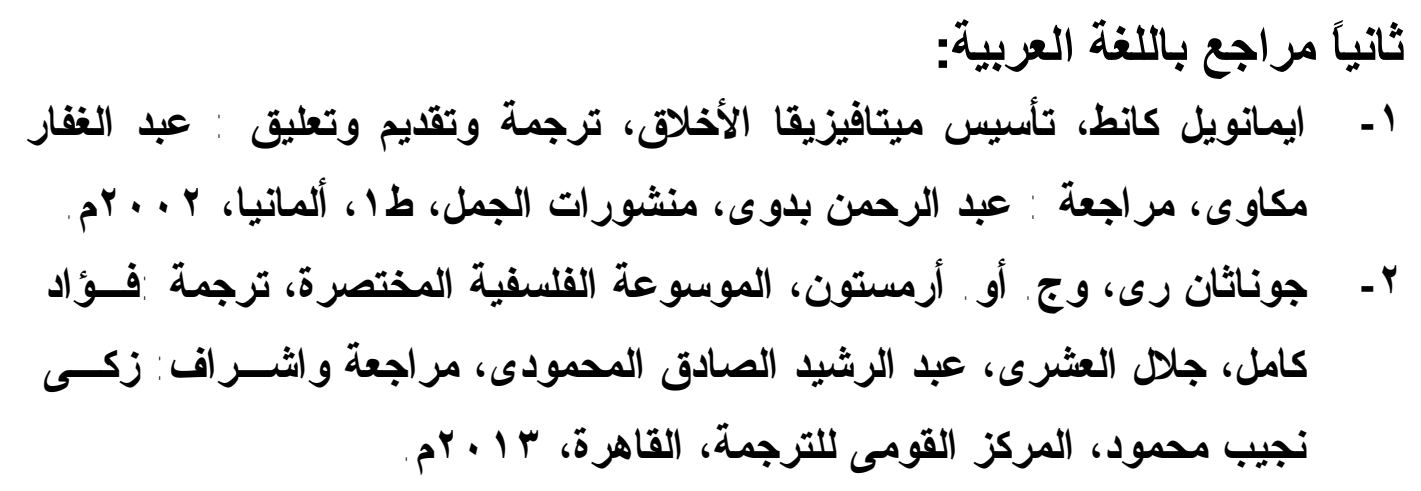


$r \cdot T \leq$

PDF created with pdfFactory Pro trial version www.pdffactory.com 